NASA/TM-2001-211035

ARL-TR-2544
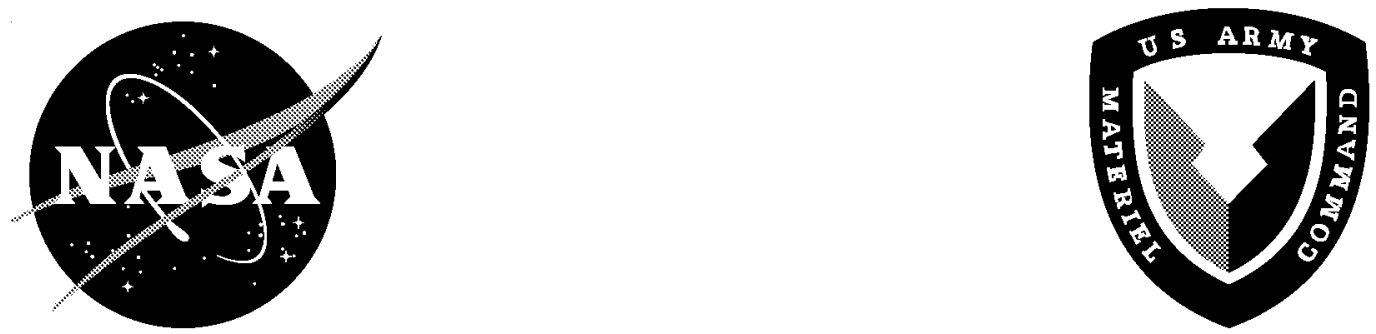

\title{
Transverse Tension Fatigue Life Characterization Through Flexure Testing of Composite Materials
}

T. Kevin O'Brien

U.S. Army Research Laboratory

Vehicle Technology Directorate

Langley Research Center, Hampton, Virginia

Arun D. Chawan

Syracuse University

Syracuse, New York

Ronald Krueger

National Research Council

NASA Langley Research Center

Hampton, Virginia

Isabelle Paris

National Research Council

NASA Langley Research Center

Hampton, Virginia 


\section{The NASA STI Program Office ... in Profile}

Since its founding, NASA has been dedicated to the advancement of aeronautics and space science. The NASA Scientific and Technical Information (STI) Program Office plays a key part in helping NASA maintain this important role.

The NASA STI Program Office is operated by Langley Research Center, the lead center for NASA's scientific and technical information. The NASA STI Program Office provides access to the NASA STI Database, the largest collection of aeronautical and space science STI in the world. The Program Office is also NASA's institutional mechanism for disseminating the results of its research and development activities. These results are published by NASA in the NASA STI Report Series, which includes the following report types:

- TECHNICAL PUBLICATION. Reports of completed research or a major significant phase of research that present the results of NASA programs and include extensive data or theoretical analysis. Includes compilations of significant scientific and technical data and information deemed to be of continuing reference value. NASA counterpart of peer-reviewed formal professional papers, but having less stringent limitations on manuscript length and extent of graphic presentations.

- TECHNICAL MEMORANDUM. Scientific and technical findings that are preliminary or of specialized interest, e.g., quick release reports, working papers, and bibliographies that contain minimal annotation. Does not contain extensive analysis.

- CONTRACTOR REPORT. Scientific and technical findings by NASA-sponsored contractors and grantees.
- CONFERENCE PUBLICATION. Collected papers from scientific and technical conferences, symposia, seminars, or other meetings sponsored or co-sponsored by NASA.

- SPECIAL PUBLICATION. Scientific, technical, or historical information from NASA programs, projects, and missions, often concerned with subjects having substantial public interest.

- TECHNICAL TRANSLATION. Englishlanguage translations of foreign scientific and technical material pertinent to NASA's mission.

Specialized services that complement the STI Program Office"s diverse offerings include creating custom thesauri, building customized databases, organizing and publishing research results ... even providing videos.

For more information about the NASA STI Program Office, see the following:

- Access the NASA STI Program Home Page at $h t t p: / / w w w . s t i . n a s a . g o v$

- E-mail your question via the Internet to help@sti.nasa.gov

- Fax your question to the NASA STI Help Desk at (301) 621-0134

- Phone the NASA STI Help Desk at (301) 621-0390

- Write to: NASA STI Help Desk NASA Center for AeroSpace Information 7121 Standard Drive Hanover, MD 21076-1320 
NASA/TM-2001-211035

ARL-TR-2544
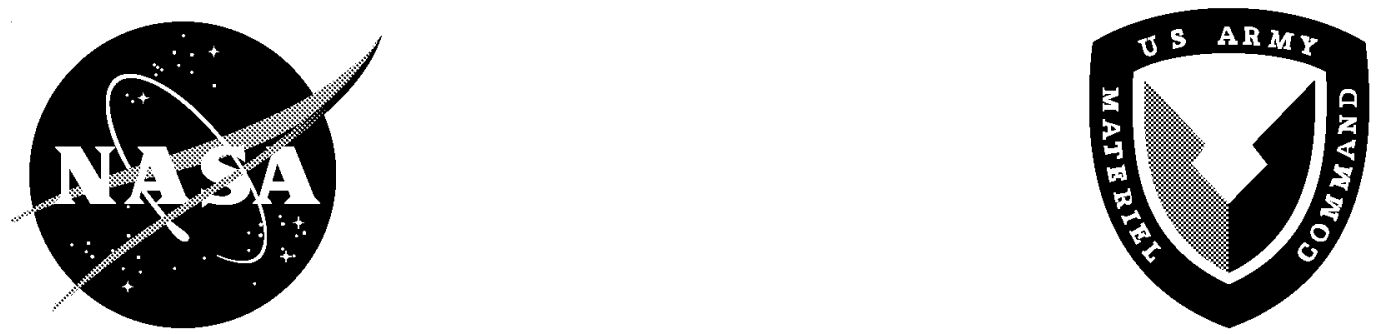

\section{Transverse Tension Fatigue Life Characterization Through Flexure Testing of Composite Materials}

T. Keoin O'Brien

U.S. Army Research Laboratory

Vehicle Technology Directorate

Langley Research Center, Hampton, Virginia

Arun D. Chazwan

Syracuse University

Syracuse, New York

Ronald Krueger

National Research Council

NASA Langley Research Center

Hampton, Virginia

Isabelle Paris

National Research Council

NASA Langley Research Center

Hampton, Virginia

National Aeronautics and

Space Administration

Langley Research Center

Hampton, Virginia 23681-2199

July 2001 
The use of trademarks or names of manufacturers in the report is for accurate reporting and does not constitute an official endorsement, either expressed or implied, of such products or manufacturers by the National Aeronautics and Space Administration or the U.S. Army.

Available from:

NASA Center for AeroSpace Information (CASI) 7121 Standard Drive

Hanover, MD 21076-1320

(301) 621-0390
National Technical Information Service (NTIS) 5285 Port Royal Road

Springfield, VA 22161-2171

(703) 605-6000 


\title{
TRANSVERSE TENSION FATIGUE LIFE CHARACTERIZATION THROUGH FLEXURE TESTING OF COMPOSITE MATERIALS
}

\author{
T. Kevin O’Brien* \\ Arun D. Chawan \\ Ronald Krueger** \\ Isabelle L. Paris** \\ NASA Langley Research Center \\ Hampton, Virginia, U.S.A
}

\begin{abstract}
The transverse tension fatigue life of S2/8552 glass-epoxy and IM7/8552 carbon-epoxy was characterized using flexure tests of 90-degree laminates loaded in 3point and 4-point bending. The influence of specimen polishing and specimen configuration on transverse tension fatigue life was examined using the glass-epoxy laminates. Results showed that 90-degree flexure specimens with polished machined edges and polished tension-side surfaces had lower fatigue lives than unpolished specimens when cyclically loaded at equal stress levels. The influence of specimen thickness and the utility of a Weibull scaling law were examined using the carbon-epoxy laminates. The influence of test frequency on fatigue results was also documented for the 4-point bending configuration. A Weibull scaling law was used to predict the 4-point bending fatigue lives from the 3-point bending curve fit and vice-versa. Scaling was performed based on maximum cyclic stress level as well as fatigue life. The scaling laws based on stress level shifted the curve fit S-N characterizations in the desired direction, however, the magnitude of the shift was not adequate to accurately predict the fatigue lives. Furthermore, the scaling law based on fatigue life shifted the curve fit S-N characterizations in the opposite direction from measured values. Therefore, these scaling laws were not adequate for obtaining accurate predictions of the transverse tension fatigue lives of heterogeneous, fiber reinforced, polymer matrix composites.
\end{abstract}

* U.S. Army Research Laboratory, Vehicle Technology Directorate

** National Research Council 
KEYWORDS: composite materials, carbon-epoxy, glass-epoxy, transverse tension strength, fatigue life, Weibull scaling law

\section{BACKGROUND}

Matrix ply cracking is a common initial damage mechanism in fiber reinforced composites. Ply cracking alone is rarely catastrophic for laminates subjected to in-plane loading. However, for composite structures that experience bending, or other out-of-plane loading conditions, the formation of matrix cracks may lead to catastrophic delamination formation and growth $[1,2]$. Therefore, accurate transverse tensile strength and fatigue characterization of composite materials is needed to predict matrix ply cracking in these structures

The influence of material volume, in the form of a ply thickness dependence on matrix crack formation, is well established. Hence, for a strength-based characterization to be truly generic, volume scaling must be achieved through a Weibull Scaling Law [3]. Early attempts to achieve this characterization were performed using 90-degree laminate tension tests [4]. However, a large percentage of the failures occurred at the grips. An alternate technique would be to create transverse tension failures in 90-degree laminates subjected to bending loads. This type of loading has the added benefits of requiring simple fixtures and relatively small specimen sizes. Hence, a greater number of specimens may be tested for a given specimen size for the same amount of material required to perform uni-axial tension tests. These larger sample sizes facilitate the generation of the large number of replicates required for statistical characterization and generation of the parameters required for the Weibull scaling law.

Previously, the influence of edge flaws due to machining and surface flaws due to manufacture and handling on transverse tensile strength was assessed by testing glassepoxy [5] and carbon-epoxy [6] 90-degree unidirectional specimens with both unpolished and polished edges and bottom-side failure surfaces. As shown in figure 1a, 3-point bending tests were performed using three different spans. In addition, four different 4- 
point bending configurations were tested with different combinations of inner and outer spans. These studies indicated that polishing actually decreased transverse tension strengths. This is in contrast to metallic materials where polishing typically yields a higher, more accurate, strength as a result of removing inherent manufacturing and handling flaws. Little difference was observed in the strengths of 24-ply and 36-ply IM7/8552 carbon epoxy laminates with identical configurations in reference 6. For specimens subjected to uniform tension, the weakest link theory would predict a lower strength for the thicker specimen. However, because failure initiates on the bottom surface in these flexure tests where the tensile stress is a maximum (fig. 1b), the classical thickness effect was not evident. The thicker specimen was weaker for only one of the three 3-point bend configurations (C) and for only one of the three 4-point bend configurations (A1). Hence, the differences in strength observed for identical configurations with different thicknesses was attributed more to variability between panels than to the classical weakest link effect, which assumes a greater probability of a defect causing failure in a thick laminate with a large volume. Transverse tension strength decreased with increasing span length as would be anticipated by the classical weakest link effect. However, a Weibull scaling law over predicted changes in transverse tension strengths in 3-point bending tests and under predicted these changes in 4-point bending tests. Hence, it was unclear if these scaling laws could be used for heterogeneous, fiber reinforced, polymer matrix composites.

\section{INTRODUCTION}

In this study, 90-degree unidirectional laminates made from S2/8552 glass-epoxy and IM7/8552 carbon-epoxy material were tested in 3-point and 4-point cyclic bending to characterize transverse tension fatigue life. The influence of edge flaws due to machining and surface flaws due to manufacturing and handling were assessed by testing the glassepoxy specimens in both the as-manufactured and machined condition as well as testing specimens with polished edges and bottom-side failure surfaces. Only one configuration

was tested for the 3-point bending (configuration B in fig. la) and 4-point bending (configuration Al in fig. 1 a). S-N curves consisting of the maximum cyclic tensile stress 
versus fatigue life were plotted and compared for both the polished and unpolished specimens. After fatigue failure had occurred, selected specimens were potted in epoxy, polished on the edges, and examined in a light microscope to identify the details of the failure location. In addition, histograms were plotted showing the frequency of failure at incremental locations along the beam.

Also in this study, IM7/8552 carbon-epoxy specimens were tested in 3-point and 4-point cyclic bending to characterize transverse tensile fatigue life. All tests were performed on unpolished specimens. Only one configuration was tested for 3-point bending (configuration B in fig. 1a) and 4-point bending (configuration A1 in fig. la). Three point bending tests were performed on $6.35 \mathrm{~mm}$ (0.25 in.) wide 40-ply specimens. Four point bending tests were performed on $12.7 \mathrm{~mm}$ (0.5 in.) wide 24 -ply specimens. The influence of test frequency on fatigue results was documented for the 4-point bending configuration. After fatigue failure had occurred, selected specimens were potted in epoxy, polished on the edges, and examined in a light microscope to identify the details of the failure location. Also, histograms were plotted showing the frequency of failure at incremental locations along the beam. Results from 3-point and 4-point bending were compared using a Weibull scaling law.

\section{MATERIALS}

A single 24-ply $762 \mathrm{~mm}^{2}$ panel of $\mathrm{S} 2 / 8552$ glass-epoxy material was supplied by Bell Helicopter Company, Fort Worth, Texas. This panel was cut into specimens for the previous study on transverse tensile strength [5] and this study on transverse tensile fatigue behavior. The S2 glass fiber density was $2.48 \mathrm{~g} / \mathrm{cm}^{3}$, and the fiber aerial weight was $295 \mathrm{~g} / \mathrm{m}^{2}$. The panel was cured using the manufacturers recommended cure cycle. The panel thickness was $5.56 \mathrm{~mm}$, corresponding to a average ply thickness of $0.231 \mathrm{~mm}$. The average fiber volume fraction was $50 \%$. 
Panels were manufactured from IM7/8552 unidirectional prepreg at the Boeing Company in Philadelphia, Pennsylvania [6]. The IM7 carbon fiber density was $1.75 \mathrm{~g} / \mathrm{cm}^{3}$. The fiber aerial weight was $148 \mathrm{~g} / \mathrm{m}^{2}$. The uncured resin content was $34 \%$ by weight. Panels were cured in an autoclave using the manufacturer's recommended curing cycle. This consisted of a 2-hour hold at $179^{\circ} \mathrm{C}\left(355^{\circ} \mathrm{F}\right)$ under $621 \mathrm{kPa}(90 \mathrm{psi})$ pressure. Panels were placed on a standard aluminum cure plate with a rigid picture frame around the contour to prevent material washout. A $3.18 \mathrm{~mm}(0.125 \mathrm{in})$ aluminum plate was placed on top of the panel. All panels were built from the same batch. One panel consisted of 24 plies of unidirectional prepreg tape, and the other consisted of 40 plies of unidirectional prepreg tape. Both panels measured $610 \mathrm{~mm}$ by $305 \mathrm{~mm}$ ( $24 \mathrm{in}$. by $12 \mathrm{in}$.). For the 24-ply panels, the average panel thickness was $3.31 \mathrm{~mm}$ (0.1305 in.), corresponding to an average ply thickness of $0.138 \mathrm{~mm}$ (0.0054 in.). For the 40-ply panel, the average panel thickness was $4.93 \mathrm{~mm}(0.194 \mathrm{in}$.), corresponding to an average ply thickness of 0.138 $\mathrm{mm}$ (0.0054 in.). No significant flaws were detected in ultrasonic inspection of these panels. Average fiber volume fraction was $62.1 \%$ for both the 24 -ply and 40-ply laminates.

\section{SPECIMEN PREPARATION}

\section{Specimen Cutting}

Transverse test specimens, with their unidirectional fibers oriented perpendicular to the longitudinal axis, were cut using a diamond saw. A $6.35 \mathrm{~mm}$ (0.25 in.) plexi-glass sheet was placed underneath the panel to reduce fiber spalling on the back side of the cut.

The large S2/8552 glass-epoxy panel was first cut into four smaller panels. All specimens were $57.2 \mathrm{~mm}$ (2.25 in.) long by $6.35 \mathrm{~mm}$ (0.25 in.) wide. A total of two hundred specimens were cut [5]. Four sets of 50 specimens were tested, including specimens from random locations on the panel. Two sets of 50 specimens were polished on the edge and bottom surfaces. Specimens were polished by first sanding using 600 grit sandpaper discs, and then polishing using 1200 grit silicon carbide discs. Final polishing was

performed using a nap cloth along with a 0.05 micron alumina suspension solution with a 
lubricant of soapy water. The remaining two sets were left unpolished. For specimens that were polished, thickness and width measurements were taken after polishing.

For the IM7/8552 carbon-epoxy material, the $610 \mathrm{~mm}$ by $305 \mathrm{~mm}$ ( $24 \mathrm{in}$. by $12 \mathrm{in}$.) panels were first cut into two $305 \mathrm{~mm}$ (12 in) square panels, then cut into individual specimens. Specimens measuring $6.35 \mathrm{~mm}$ (0.25 in.) wide and $57.2 \mathrm{~mm}$ (2.25 in.) long were cut from the 40-ply panel for testing in 3-point bending. The 24-ply panels were first cut into five columns $57.15 \mathrm{~mm}$ (2.25 in.) wide, and were then cut into specimens measuring $12.70 \mathrm{~mm}$ (0.5 in.) wide and $57.15 \mathrm{~mm}$ (2.25 in.) long for testing in 4-point bending. The 24-ply specimens were cut wider than the 40-ply specimens to increase the load required for failure and reduce the specimen deflection at failure. All specimens were numbered on the bottom side of the panel relative to the saw cut in sequential order by column.

\section{Thickness and Width Measurement}

For both materials, specimen thickness and width were measured at three points along the specimen length using flat nose digital calipers. The averages of these measurements, along with the percentage variation of thickness and width, were calculated.

\section{EXPERIMENTS}

\section{Testing Equipment and Test Configurations}

Testing was performed using a MTS model 858 tabletop hydraulic load frame with a MTS model 458 controller. The load frame was equipped with a $22.2 \mathrm{kN}(5000 \mathrm{lb})$ load cell. For the purpose of improving the accuracy of measured loads, a $2.22 \mathrm{kN}(500 \mathrm{lb})$ load cell was placed in series with the $22.2 \mathrm{kN}(5000 \mathrm{lb})$ cell. For the glass-epoxy composites, the load frame was equipped with 3-point and 4-point testing fixtures shown in figure 2 that consisted of individual upper and lower supports with load points machined to a radius of $3.18 \mathrm{~mm}$ (0.125 in). For the carbon-epoxy composites, special fixtures consisting of $6.35 \mathrm{~mm}(0.25 \mathrm{in})$ diameter stainless steel pins mounted in ball

bearings (figure 3) were used to achieve a true roller support and avoid problems with 
fixture wear observed with the original set up. This fixture was also outfitted with end restraints to prevent undesired longitudinal movement of the specimens. In addition, washers were placed on the pins to prevent undesired specimen drift in the width direction. All specimens were oriented in the test apparatus with specimen numbers on the top. Hence, failures always occurred on the bottom of the beam corresponding to the top of the panel relative to the saw cut. Three-point bending tests were performed with a bottom span length equal to $50.8 \mathrm{~mm}$ (2.0 in) corresponding to configuration B in fig. la. Four-point bending tests were performed where the bottom span length was $50.8 \mathrm{~mm}(2.0$ in) and the top span length was $25.4 \mathrm{~mm}$ (1.0 in) corresponding to configuration A1 in fig.la.

\section{Test Procedure}

Tests were performed in load control, at ambient laboratory conditions, using a programmed sinusoidal loading cycle. For 3-point bending tests, load values that corresponded to the desired maximum stress levels were determined from the dimensions of each specimen using the beam theory equation

$$
\mathrm{P}=\frac{2 \mathrm{bt}^{2} \sigma}{3 \mathrm{~s}}
$$

where $P$ is the load under the center nose, $b$ is the average specimen width, $t$ is the average specimen thickness, $\sigma$ is the desired cyclic tensile stress on the bottom surface of the beam, and $\mathrm{s}$ is the span between the bottom load points. Similarly for 4-point bending, load levels corresponding to the desired stress levels were calculated using the equation

$$
\mathrm{P}=\frac{2 \mathrm{bt}^{2} \sigma}{3 \ell}
$$


where $\mathbf{P}$ is total load applied to the specimen, and $\ell$ is twice the difference between the outer and inner spans (fig. 1b).

The average transverse tensile strength of $\mathrm{S} 2 / 8552$ glass-epoxy specimens was previously determined to be $140 \mathrm{MPa}$ for the 3-point bend test configuration $\mathrm{B}$ and $131 \mathrm{MPa}$ for the 4-point bend test configuration A1 [5]. The slightly lower strength for configuration A1 was attributed to the larger volume of material that experiences the maximum tensile bending stress under 4-point loading (fig. lb).

Fatigue tests of S2/8552 glass-epoxy specimens were performed at maximum stress levels of $91,84,80.5$, and $77 \mathrm{MPa}$, respectively, corresponding to $65,60,57.5$, and $55 \%$ of the ultimate transverse tensile strength for configuration $B$. The same maximum stress levels were used for configuration A1 so that direct comparisons could be made between fatigue lives for 3-point and 4-point bending test specimens. The load was cycled sinusoidally at a frequency of $10 \mathrm{~Hz}$ and an $\mathrm{R}$ ratio of 0.1 . A digital counter located in the controller recorded the number of cycles at specimen failure.

The average transverse tensile strength of IM7/8552 carbon-epoxy specimens, measured previously [6], was 127.5 MPa for the 36-ply 3-point bending test configuration $\mathrm{B}$ and $115 \mathrm{MPa}$ for the 24-ply 4-point bending test configuration A1. The slightly lower strength for configuration Al was attributed to the larger volume of material that experiences the maximum tensile bending stress under 4-point bending as compared to 3point bending (fig. 1b). Because the 36-ply specimens were close in thickness to the 40 ply specimens tested in 3-point bending fatigue in this study, no static tests were run on the 40-ply specimens. However, because the 24 ply specimens tested in 4-point bending fatigue in this study were wider $(12.7 \mathrm{~mm})$ than the configuration Al specimens tested in reference $6(6.35 \mathrm{~mm})$, a set of 24 static tests were performed. The average strength was $92 \mathrm{Mpa}$ for these tests. This slightly lower strength, compared to the 24-ply specimens of reference 6, was attributed to the larger volume of material that experiences the maximum tensile bending stress in the wider specimens. 
Fatigue tests of IM7/8552 carbon-epoxy specimens were performed at maximum stress levels of $84.9,81.8,78.8,75.8$, and $72.7 \mathrm{MPa}$ for the configuration $\mathrm{B}, 3$-point bending, fatigue tests. This corresponded to stress levels between $57 \%$ and $67 \%$ of the 36 -ply, configuration B, 3-point bending static ultimate strength. Fatigue tests were performed at maximum stress levels of 78.6, 74.0, 69.4, and 64.7 MPa for the configuration A1, 4point bending, fatigue tests. This corresponded to stress levels between $70 \%$ and $85 \%$ of the 24-ply, configuration Al, 4-point bend static ultimate strength. For the 3-point bending configuration B tests, the load was cycled sinusoidally at a frequency of $10 \mathrm{~Hz}$ and an $\mathrm{R}$ ratio of 0.1 . For the 4-point bending configuration $\mathrm{A} 1$ tests, the load was cycled sinusoidally at frequency of 1,5 , or $10 \mathrm{~Hz}$, depending on the load level, with an $\mathrm{R}$ ratio of 0.1 . A digital counter located in the controller recorded the number of cycles at specimen failure.

\section{RESULTS AND DISCUSSION}

\section{S2/8552 glass-epoxy}

Plots of maximum cyclic tension stress versus fatigue life, $N$, are shown in Figures 4-8.

Figure 4 shows transverse tension fatigue life data from 3-point bending tests for both polished and unpolished specimens. Results for five polished and unpolished specimens are plotted at each stress level. In all cases, the scatter in fatigue lives was greater than one order of magnitude. The mean life at each cyclic stress level shifted towards higher lives at lower cyclic stress levels, except for the unpolished specimens tested at lowest maximum stress level. At all four maximum cyclic stress levels, the average (mean) life for the unpolished specimens was greater than the mean life for the polished specimens.

Figure 5 shows transverse tension fatigue life data from 4-point bending tests for both polished and unpolished specimens. Results for five polished and unpolished specimens are plotted at each stress level. Again, the scatter in fatigue lives was greater than one order of magnitude. For the three highest cyclic stress levels, the mean life shifted towards higher lives at lower cyclic stress levels. However, for specimens tested at the 
lowest cyclic stress level, the mean lives were lower than those obtained at the next highest cyclic stress level. This was true for both the unpolished and polished specimens. For three of the four maximum cyclic stress levels, the mean life for the unpolished specimens was greater than the mean life for the polished specimens. For the one stress level where this was not true, mean lives for the polished and unpolished specimens were very close to one another.

A comparison between average fatigue lives for 3-point and 4-point bending is presented in Figure 6. For the unpolished specimens tested at the highest two maximum cyclic stress levels, the average fatigue lives were lowest for the 3-point bend tests. However, for the unpolished specimens tested at the lowest two maximum cyclic stress levels, the average fatigue lives were lowest for the 4-point bend tests. For the polished specimens, the average fatigue lives were lowest for the 3-point bend tests at the highest three maximum cyclic stress levels. However, the opposite was true at the lowest stress level. Hence, a clear trend between the mean fatigue life and configuration could not be established.

In order to investigate these tends further, an additional five specimens, both polished and unpolished, were tested at each of the four maximum stress levels in 4-point bending. Figure 7 shows fatigue life data from these tests for both polished and unpolished specimens with ten replicates tested at each stress level. The greater number of replicates significantly increased the size of the scatter bands to several orders of magnitude. However, the overall scatter band shifted towards higher lives at lower cyclic stress levels. The mean lives for the unpolished specimens increased as the maximum stress level was decreased. The polished specimens exhibited a similar trend at the three highest maximum cyclic stress levels; however, the mean life of polished specimens tested at the lowest maximum stress level was lower than the mean life of specimens tested at the next highest level. For three of the four maximum cyclic stress levels, the mean life for the unpolished specimens was greater than the mean life for the polished specimens. For the one stress level where this was not true, mean lives for the polished and unpolished specimens were very close to one another. 
The average fatigue life from 5 and 10 replicates of the 4-point bending test specimens are compared in figure 8 . For both the polished and unpolished specimens, the mean life decreased slightly with increasing sample size for the highest three maximum cyclic load levels. However, the opposite trend was observed at the lowest maximum cyclic stress level.

Noticeable wear due to abrasion was observed on the loading noses of the support fixtures while performing fatigue tests of the glass-epoxy specimens (Fig.9). The original stainless steel fixtures were replaced with surfaced hardened fixtures. However, some wear was still observed (fig.9). Examination of the fatigue test specimens also showed evidence of wear and indentations at the outer load nose positions. This wear was greatest for the longer life test specimens run at the lowest maximum cyclic stress levels. This is the most probable cause for the unanticipated short fatigue lives obtained at the lowest maximum cyclic stress level (figs.4-8). Hence, while the fixtures used in Reference 5 and in this study were useful for static testing, it is uncertain if they are also suited for fatigue testing. In order to avoid the influence of fixture wear on the carbon-epoxy fatigue test specimens, new supports were manufactured with pins in roller bearings (Fig. 3).

\section{IM7/8552 carbon-epoxy}

Figure 10 shows transverse tension fatigue life data from 3-point bending tests. Results for seven specimens are plotted at each stress level. In all cases, the scatter in fatigue lives was greater than one order of magnitude. This is consistent with findings in a previous investigation where 3-point bend tests were utilized to characterize the transverse tension fatigue life of carbon fiber reinforced epoxy lamina [7]. Figure 10 shows that the mean life at each cyclic stress level (S1-S5 avg) shifted towards higher lives at lower cyclic stress levels. It was difficult to obtain fatigue lives less than $10^{3}$ cycles while running at $10 \mathrm{~Hz}$ because a finite time was needed to make final adjustments to the controller to achieve the desired cyclic load range. Hence, 4-point bending tests were also performed at lower frequencies. 
Figure 11 shows transverse tension fatigue life data from 4-point bending tests for all frequencies tested. Results for 25 specimens are plotted at each stress level. The scatter in fatigue lives was greater than two orders of magnitude, but mean lives shifted towards higher lives at lower cyclic stress levels. Figure 12 shows average fatigue lives, where test results are identified by frequency. Mean lives were lower at lower frequencies at the same maximum stress level. This result implies that lower frequencies, corresponding to greater time at maximum load, are more damaging. As noted earlier, it was necessary to run at frequencies as low as 1 Hertz in order to obtain short fatigue life data. This trend indicates that this is a conservative approach compared to the $10 \mathrm{~Hz}$ characterization desired.

One concern with the carbon epoxy material tested in this study, compared to the glassepoxy material previously tested [5], was the large variability in thickness for each specimen. The influence of specimen thickness variations on 4-point bending fatigue lives is documented in the appendix. Because of these difficulties, fatigue life data for the 24-ply 4-point bend tests were also plotted using data from specimens cut from only column 3 of the original panel (figure 13). Although there is still considerable scatter in the data, it is significantly less than shown in figure 11, which include results from specimens from all five columns. Figure 14 shows average fatigue lives for specimens from column 3 only where test results are identified at different frequencies. As before, mean lives were lower at lower frequencies at the same maximum stress level.

A comparison between average fatigue lives for 3-point and 4-point bending is presented in Figure 15. If the comparison was simply between 40-ply laminates and 24-ply laminates under uniform tension, the classical Weibull weakest link effect would indicate that the thicker beams should have lower fatigue lives than the thinner beams at the same stress level. However, both 3-point and 4-point bending yield a linear variation in tension stress through the bottom half of the beam thickness. Hence, the difference in the stress distributions along the bottom surface in the span direction appears to play the dominant role. At the same maximum cyclic stress level, the 4-point bending tests that have large 
spans under maximum tension on the bottom surface yield lower lives compared to the 3 point bending tests that have only a single point below the center load nose under maximum tension (fig. $1 b$ ).

\section{Histograms of Failure Locations}

\section{S2/8552 glass-epoxy}

For the 3-point bend fatigue tests, histograms are plotted in figures $16 \mathrm{a}$ and $16 \mathrm{~b}$ showing the frequency of occurrence of the failure locations relative to the center load nose for the polished and unpolished specimens, respectively. Failure occurs near, but rarely directly under, the center load nose where beam theory indicates the tension stress is a maximum (fig. 1b), thus illustrating the sensitivity to flaws in the microstructure. There appears to be a slightly greater concentration of failures near the center load nose for the unpolished specimens. Hence, the flaw sensitivity appears to be more severe in the polished specimens.

For the 4-point bend tests of the unpolished specimens, histograms are plotted in figures $17 \mathrm{a}$ and $17 \mathrm{~b}$ showing the frequency of occurrence of the failure locations relative to the inner load noses for the static tests and the fatigue tests, respectively. For the static tests, failures occurred primarily between the inner load noses where the tension stress is a maximum (fig. 1b). However, for the fatigue tests, failures were concentrated closer to the two inner load noses, possibly due to the fretting observed with the original fixtures. A similar pattern was observed for the polished fatigue specimens.

\section{IM7/8552 carbon-epoxy}

For the 3-point bend tests, histograms are plotted in figures $18 \mathrm{a}$ and $18 \mathrm{~b}$ showing the frequency of occurrence of the failure locations relative to the center load nose for the static tests and fatigue tests, respectively. Failure occurs near, but rarely directly under, the center load nose where beam theory indicates the tension stress is a maximum (fig. lb), thus illustrating the sensitivity to flaws in the microstructure. There appears to be 
a greater concentration of failures away from the center load nose for the fatigue tests. Hence, the flaw sensitivity appears to be more severe in fatigue than under monotonic loading.

For the 4-point bend tests, histograms are plotted in figures $19 \mathrm{a}$ and $19 \mathrm{~b}$ showing the frequency of occurrence of the failure locations relative to the inner load noses for the static tests and the fatigue tests, respectively. Failures occurred primarily between the inner load noses where the tension stress is a maximum (fig.1b). However, more failures were concentrated near one load nose than the other. This was attributed to the severe thickness variations in these specimens.

\section{Post mortem examination}

After fatigue failure had occurred, selected specimens were potted in epoxy, polished on the edges and examined in an optical microscope to identify the details of the failure location

\section{S2/8552 glass-epoxy}

Figures 20a-b show the photomicrographs taken at the failure location for two of the 4point bending unpolished specimens (fig.20a) and two of the 4-point bending polished specimens (fig. 20b). The left and right sides at the failure point are shown for each specimen. One of the two specimens examined had a short life, and the other a had long life at the same maximum cyclic stress level. All specimens have variations in volume fraction at the bottom surface. For one specimen, there is a pocket of resin on the bottom surface at the failure location. However, there are no resin pockets at the failure location for the other specimens. Hence, failure is not always influenced by the presence of a resin pocket. There was also no noticeable difference between the specimens exhibiting a short life and those with a long life at the same cyclic stress level. 


\section{IM7/8552 carbon-epoxy}

Figures 2la-d show the photomicrographs taken at the failure location for four of the 40 ply 3-point bending specimens and four of the 24-ply 4-point bending fatigue specimens. The left and right sides at the failure point are shown for each specimen. For each configuration, two of the four specimens examined had short lives and the other two had long lives. All specimens have variations in volume fraction at the bottom surface. For specimens C5-20 (specimen \#20 from col. 5 of the original panel) and C1-29, there is a pocket of resin on the bottom surface at the failure location. However, there are no resin pockets at the failure location for the other specimens. Hence, failure is not always influenced by the presence of a resin pocket. There was also no noticeable difference between the specimens exhibiting a short life and those with a long life at the same cyclic stress level. Furthermore, there was no noticeable difference between the specimens from different panel column positions.

\section{Transverse tension strength Characterization}

The strength of a material is typically characterized assuming either a symmetric (normal) distribution or a skewed (Weibull [3]) distribution. For the normal distribution, the mean strength and coefficient of variation, CV (standard deviation divided by the mean strength), are calculated. The mean strength characterizes the central tendency of the strength distribution, whereas the CV quantifies the scatter in the strength distribution. However, since most strength data is not normally distributed, a Weibull distribution is often assumed as an alternative.

Weibull assumed an extreme value, or "weakest link," distribution for material strength by developing a two parameter function for the probability of failure at a given stress level, $P(\sigma)$, of the form 


$$
\mathrm{P}(\sigma)=1-\exp \left[-\left(\frac{\sigma}{\sigma_{\mathrm{c}}}\right)^{\mathrm{m}}\right]
$$

Where $\sigma_{\mathrm{c}}$ is the location parameter known as the characteristic strength, and $\mathrm{m}$ is the shape parameter known as the Weibull slope [3]. The location parameter, $\sigma_{c}$, provides a measure of the central tendency of the distribution, similar to the mean for a normal distribution. The Weibull slope, $\mathrm{m}$, provides a measure of the scatter in the distribution, with a small value of $m$ corresponding to a large amount of scatter in the data. Therefore, the amount of scatter is inversely proportional to $\mathrm{m}$. Hence, as the magnitude of $\mathrm{m}$ increases, the scatter decreases. Equation 3 may also be recast into an equation of the form

$$
y=m \ln \sigma+b
$$

Where

$$
y=\ln \left[\ln \left(\frac{1}{1-P(\sigma)}\right)\right]
$$

And

$$
\mathrm{b}=-\mathrm{m} \ln \sigma_{\mathrm{c}}
$$

Then by assuming a probability of failure corresponding to a median ranking of the data

$$
P(\sigma)=\frac{(i-1)+0.7}{n+0.4}
$$


where $\mathrm{n}$ is the total number of data points in the sample, and $\mathrm{i}$ is the number of the data points in ascending order from 1 to $\mathrm{n}$. A least squares regression fit of the logarithmic equation 4 was performed to determine $m$ and $\sigma_{c}$.

In addition to characterizing the strength distribution for a given material, Weibull postulated that the characteristic strengths for two different volumes, $V_{1}$ and $V_{2}$, of the same material will obey the following scale law [3]

$$
\frac{\left(\sigma_{c}\right)_{1}}{\left(\sigma_{c}\right)_{2}}=\left(\frac{V_{2}}{V_{1}}\right)^{1 / m}
$$

Because of the inverse relationship between the Weibull slope and the degree of scatter in the data, the inverse of the Weibull slope, $1 / \mathrm{m}$, was tabulated and plotted in reference 6 to allow a more intuitive feeling for the trends observed. Furthermore, it is the inverse Weibull slope that appears as the exponent in the Weibull volume scale law in equation 8.

The scaling law in equation 8 assumes that the two volumes being compared are subjected to a uniform tensile stress throughout the volume. However, the stress distributions in the 3-point and 4-point bend tests are not uniform (fig.1). Hence, the scaling law was modified in reference 8 for 3 -point bending as

$$
\frac{\sigma_{\mathrm{f}}^{3 p t}}{\sigma_{t}}=\left[2(\mathrm{~m}+1)^{2} \frac{\mathrm{V}_{\mathrm{t}}}{\mathrm{V}_{\mathrm{f}}^{3 p t}}\right]^{1 / \mathrm{m}}
$$

Where the subscript " $\mathrm{f}$ " corresponds to the stress and volume in the flexure test and the subscript " $\mathrm{t}$ " corresponds to the stress and volume under uniform tension.

A similar expression was derived in reference 8 for 4-point bending as 


$$
\frac{\sigma_{\mathrm{f}}^{4 \mathrm{pt}}}{\sigma_{\mathrm{t}}}=\left[\frac{4(\mathrm{~m}+1)^{2}}{(\mathrm{~m}+2)} \frac{\mathrm{V}_{\mathrm{t}}}{\mathrm{V}_{\mathrm{f}}^{4 p t}}\right]^{1 / \mathrm{m}}
$$

The relationship between the 4-point and 3-point bending cases may be expressed by combining equations 9 and 10 to yield

$$
\frac{\sigma_{\mathrm{f}}^{4 p t}}{\sigma_{\mathrm{f}}^{3 p t}}=\left[\frac{2}{(\mathrm{~m}+2)} \frac{\mathrm{V}_{\mathrm{f}}^{3 \mathrm{pt}}}{\mathrm{V}_{\mathrm{f}}^{4 \mathrm{pt}}}\right]^{1 / \mathrm{m}}
$$

\section{Transverse tension fatigue life Characterization}

As was the case with transverse tension strength, the transverse tension fatigue life may be characterized assuming a Weibull "extreme value", or "weakest link", distribution. A two parameter function for the probability of failure at a given number of cycles, $P(N)$ may be written as

$$
P(N)=1-\exp \left[-\left(\frac{N}{N_{c}}\right)^{m}\right]
$$

where $\mathrm{N}_{\mathrm{c}}$ is the location parameter known as the characteristic life, and $\mathrm{m}$ is the Weibull slope. The location parameter, $\mathrm{N}_{\mathrm{c}}$, provides a measure of the central tendency of the distribution, similar to the mean for a normal distribution. As before, the Weibull slope, $\mathrm{m}$, provides a measure of the scatter in the distribution, with a small value of $\mathrm{m}$ corresponding to a large amount of scatter in the data. Therefore, the amount of scatter is inversely proportional to $\mathrm{m}$. Hence, as the magnitude of $\mathrm{m}$ increases, the scatter decreases.

Equation 12 may also be recast into an equation of the form 


$$
y=m \ln N+b
$$

Where

$$
y=\ln \left[\ln \left(\frac{1}{1-P(N)}\right)\right]
$$

And

$$
\mathrm{b}=-\mathrm{m} \ln \mathrm{N}_{\mathrm{c}}
$$

Then by assuming a probability of failure corresponding to a median ranking of the data

$$
P(N)=\frac{(i-1)+0.7}{n+0.4}
$$

where $\mathrm{n}$ is the total number of data points in the sample and $\mathrm{i}$ is the number of the data point in ascending order from 1 to $\mathrm{n}$. A least squares regression fit of the logarithmic equation 13 was performed to determine $m$ and $N_{c}$. As before, characteristic fatigue life may be scaled based on volume by substituting $N_{\mathrm{c}}$ for $\sigma_{\mathrm{c}}$ in equations 8-11,

$$
\frac{\mathrm{N}_{\mathrm{f}}^{3 \mathrm{pt}}}{\mathrm{N}_{\mathrm{t}}}=\left[2(\mathrm{~m}+1)^{2} \frac{\mathrm{V}_{\mathrm{t}}}{\mathrm{V}_{\mathrm{f}}^{3 \mathrm{pt}}}\right]^{1 / \mathrm{m}}
$$

Where the subscript " $\mathrm{f}$ " corresponds to the stress and volume in the flexure test and the subscript " $t$ " corresponds to the stress and volume under uniform tension. A similar expression was derived in reference 8 for 4-point bending as 


$$
\frac{\mathrm{N}_{\mathrm{f}}^{4 \mathrm{pt}}}{\mathrm{N}_{\mathrm{t}}}=\left[\frac{4(\mathrm{~m}+1)^{2}}{(\mathrm{~m}+2)} \frac{\mathrm{V}_{\mathrm{t}}}{\mathrm{V}_{\mathrm{f}}^{4 \mathrm{pt}}}\right]^{1 / \mathrm{m}}
$$

The relationship between the 4-point and 3-point bending cases may be expressed by combining equations 17 and 18 to yield

$$
\frac{\mathrm{N}_{\mathrm{f}}^{4 \mathrm{pt}}}{\mathrm{N}_{\mathrm{f}}^{3 \mathrm{pt}}}=\left[\frac{2}{(\mathrm{~m}+2)} \frac{\mathrm{V}_{\mathrm{f}}^{3 \mathrm{pt}}}{\mathrm{V}_{\mathrm{f}}^{4 p t}}\right]^{1 / \mathrm{m}}
$$

\section{Life prediction from Weibull scaling law}

In order to verify that the Weibull Scaling law is applicable for fiber reinforced composites, measured data from one volume should be used with this scaling law to accurately predict the fatigue life of any other volume of the same material with the same failure mode. The following section documents attempts to do this for transverse tension fatigue life using the 3-point and 4-point bending tests on the IM7/8552 carbon-epoxy specimens tested in this study.

Figure 22 shows the curve fit to the mean of the 40-ply 3-point bending fatigue data from figure 10 using a least squares regression analysis. Quasi-static data from the 36-ply 3point bending tests performed in reference 6 were also included in the curve fit. Also shown in figure 22 are curves representing \pm one standard deviation in maximum cyclic stress level from the mean curve. Fatigue lives of the 24-ply 4-point bending specimens were predicted using this curve fit by substituting the 40-ply 3-point bending maximum cyclic stress levels, corresponding to the selected fatigue lives for 4-point bending, in equation 11. The Weibull slope used to scale stress levels in the scaling law was the value $(\mathrm{m}=18.83,1 / \mathrm{m}=0.0531)$ determined for the 36-ply 3-point bending quasi-static tests from reference 6. Fig. 23 shows the original 3-point bending mean curve fit, the stress scaled mean curve fit from equation 11, and the mean 4-point bending data from all the 
columns as well as from column 3 only. The scaling law shifts the 3 -point bending S-N curve toward the measured 4-point bending data. However, the magnitude of the shift is not adequate to accurately predict the 4-point bending fatigue lives.

Curve fits to the mean of the 24-ply 4-point bending quasi-static and fatigue data were also generated using the data from all columns of the original panel (fig.24) and from column 3 only (fig.25). Also shown in figure 25 are curves representing \pm one standard deviation in stress level from the mean curve. For the curve fit performed using data from all columns, the scatter was too large to obtain the minus one standard deviation curve (fig.24). Fatigue lives of the 40-ply 3-point bending specimens were predicted using this curve fit by substituting the 24-ply 4-point bending maximum cyclic stress levels, corresponding to the selected fatigue lives for 3-point bending, in equation 11. The Weibull slope used to scale stress levels in the scaling law was the value $(\mathrm{m}=11.59,1 / \mathrm{m}$ $=0.086$ ) determined for the 24-ply 4-point bending quasi-static tests. Figures 26 and 27 compare the 3-point bending data to the 3-point bending stress scaled curved fit from equation 11 using 4-point bending fatigue data from all the columns (fig.26) as well as from column 3 only (fig.27). The scaling law shifts the 4-point bending S-N curve toward the measured 3-point bending data. However, the magnitude of the shift is not adequate to accurately predict the 3 -point bending fatigue lives.

Fatigue lives of the 24-ply 4-point bending specimens were also predicted by substituting the fatigue lives for 40-ply 3-point bending specimens, corresponding to the selected maximum cyclic stress levels for 3-point bending, into equation 19. Figure 28 compares the 4-point bending life data (from all the columns as well as from column 3 only) to the 4-point bending life-scaled curve fit from equation 19. This prediction was performed using the average of the Weibull shape parameters calculated for fatigue life distributions at all five cyclic stress levels $(\mathrm{m}=0.573,1 / \mathrm{m}=1.75)$. As shown in fig. 28 , the scaling law based on life actually shifts the 3-point bend S-N curve away from the measured 4-point bend data. This result was relatively insensitive to the choice of Weibull scaling parameter, as shown in figure 29 where the scaled mean curves were predicted using the average, the largest, and the smallest Weibull shape parameters calculated for fatigue life 
distributions at all five cyclic stress levels. Therefore, these scaling laws were not adequate for obtaining accurate predictions of the transverse tension fatigue lives of heterogeneous, fiber reinforced, polymer matrix composites.

\section{CONCLUSIONS}

The S2/8552 glass-epoxy specimens polished on the edges and tension side failure surfaces exhibited shorter average fatigue lives than unpolished specimens for all 3-point bending tests, and for all but one stress level for 4-point bending tests. Therefore, polishing specimens seems to artificially decrease transverse tensile fatigue life rather than producing longer and more accurate fatigue lives as a result of removing inherent manufacturing and handing flaws in the material.

The mean life of the IM7/8552 carbon-epoxy specimens tested at each cyclic stress level in 3-point and 4-point bending shifted towards higher lives at lower cyclic stress levels. However, there was significant scatter in the data. For the 4-point bending fatigue tests, mean lives were lower for specimens run at lower frequencies at the same maximum stress level. Hence, lower frequencies, corresponding to greater time at maximum load, were more damaging. Therefore, tests performed at lower frequencies $(1 \& 5 \mathrm{~Hz})$ yielded conservative results compared to the $10 \mathrm{~Hz}$ characterization desired.

Significant variability in specimen thickness was measured for the IM7/8552 specimens tested in 3-point and 4-pont bending in this study. For the 4-point bending tests, specimens cut from the columns closest to the panel edge were the thinnest and had the largest variability in specimen thickness $(>4 \%)$. Specimens cut from the center of the panel were the thickest and had very small thickness variations (average less than $1 \%$ ). The large thickness variability observed in these specimens is probably a result of resin bleeding in the transverse (90-degree) panel direction that occurred during manufacture. At most cyclic stress levels, average fatigue lives for specimens taken from the five columns cut from the original panel increased continuously from the left edge, to the middle, and then to right edge. Hence, mean fatigue life did not seem to correlate directly 
with thickness variability. However, the scatter in the life data at each cyclic stress level, as measured by the Coefficient of Variation (CV), correlated directly with the thickness variability observed, with the specimens cut near the panel edges exhibiting the greatest scatter.

The 4-point bending fatigue tests of the IM7/8552 carbon-epoxy were performed on thinner (24-ply) laminates than the 3-point bending tests (40-ply). However, the mean fatigue lives for the 4-point bending tests were significantly lower than the mean fatigue lives for the 3-point bending tests at the same maximum cyclic stress levels. Hence, the difference in the stress distributions in the span direction was more significant than the simple volume difference in influencing relative transverse tension fatigue life in bending.

For the 3-point bending fatigue tests of the IM7/8552 carbon-epoxy, failures occurred near, but rarely directly under, the center load nose where beam theory indicates the tension stress is a maximum, thus illustrating the sensitivity to flaws in the microstructure. For the 4-point bending tests, failures occurred primarily between the inner load noses where the tension stress is a maximum. However, more failures were concentrated near one load nose than the other due to the severe thickness variations within these specimens.

A least squares regression analysis was performed on the 3-point and 4-point bending fatigue test results to characterize the transverse tension fatigue life of the IM7/8552 carbon epoxy material tested. A Weibull scaling law was used to predict the 4-point bending fatigue lives from the 3-point bending curve fit and vice-versa. Scaling was performed based on maximum cyclic stress level as well as fatigue life. The scaling laws based on stress level shifted the curve fit S-N characterizations in the desired direction, however, the magnitude of the shift was not adequate to accurately predict the fatigue lives. Furthermore, the scaling law based on fatigue life shifted the curve fit S-N characterizations in the opposite direction from measured values. Therefore, these scaling 
laws were not adequate for obtaining accurate predictions of the transverse tension fatigue lives of heterogeneous, fiber reinforced, polymer matrix composites.

\section{ACKNOWLEDGEMENTS}

This study was performed as part of Cooperative Research and Development Agreements (CRDA) between the U.S. Army Research Laboratory, Vehicle Technology Directorate, located at NASA Langley Research Center and Bell Helicopter, Fort Worth, Texas and the Boeing Company, Philadelphia, Pennsylvania. 


\section{REFERENCES}

1) Minguet, P.J, and O'Brien, T.K., "Analysis of Test Methods for Characterizing Skin/Stringer Debonding Failures in Reinforced Composite Panels" Composite Materials: Testing and Design, Twelfth Volume, ASTM STP 1274, August, 1996, p.105-124.

2) O'Brien, T.K., and Sen, J.K., "Tension-Torsion Behavior of Glass Epoxy Flexbeam Laminates" ASTM Journal of Composites Technology and Research, JCTRER, Vol. 20, No.4, October, 1998, pp. 221-226.

3) Weibull, W., "A Statistical Theory of the Strength of Materials", Ing. Vetenskaps Akad. Handl. (Royal Swedish Institute Engineering Research Proceedings) NR151, 1939.

4) O'Brien, T. K. and Salpekar, S. A., "Scale Effects on the Transverse Tensile Strength of Carbon-epoxy Composites", Composite Materials: Testing and Design, Eleventh Volume, ASTM STP 1206, 1993, pp.23-52.

5) O’Brien, T.K., Chawan, A.D., DeMarco, K., “Influence of Specimen Preparation and Specimen Size on the Transverse Tensile Strength and Scatter of Glass Epoxy Laminates" Proceedings of the Twelfth International Conference on Composite Materials, Paris, France, July 5-9, 1999, paper 976, ISBN 2-9514526-2-4,.

6) O'Brien, T. K., Chawan, A.D., DeMarco, K. and Paris, I.L.,: Influence of Specimen Preparation and Specimen Size on Composite Transverse Tensile Strength and Scatter, NASA TM-2001-211030, ARL TR-2540, July, 2001.

7) Peck, A.W., "An Experimental Investigation of Transverse Tension Fatigue Characterization of IM6/3501-6 Composite Materials using a Three-Point Bend 
Test" Composite Materials:Fatigue and Fracture, Seventh Volume, ASTM STP 1330, September 1998, p.145-164.

8) Bullock, R.E., "Strength Ratios of Composite Materials in Flexure and in Tension“, Journal of Composite Materials, Vol.8, April. 1974, p.200. 


\section{APPENDIX}

Figure A1 shows the percentage thickness variation within each of the 40-ply specimens. Typical variations were between 1 and $4 \%$. Figure A2 shows the percentage thickness variation in each specimen cut from columns 1-5, respectively, of the 24-ply panel. The average thickness and percentage thickness variation in each specimen is plotted in figures A3 and A4, respectively, as a function of panel column position. Specimens cut from the columns closest to the panel edge $(1 \& 5)$ were the thinnest and had the largest variations in specimen thickness $(>4 \%)$, whereas specimens cut from the center of the panel (column 3) were the thickest and had very small thickness variations (average less than $1 \%$ ). To visualize this thickness variability, specimen thickness data were also plotted as a function of the specimen position from the five columns cut from the original 24-ply panel (figure A5). The large thickness variability observed in these specimens is probably a result of resin bleeding in the transverse (90 degree) panel direction that occurred during manufacture.

Figure A6 shows the average fatigue life of the 24-ply specimens as a function of column position at the four maximum cyclic stress levels tested, where $n$ is the number of specimens tested from each column. Fig. A7 also isolates the average fatigue life at one stress level as a function of column position and test frequency. In most cases, average lives increased continuously from columns 1 to column 5. Hence, mean fatigue life did not seem to correlate directly with thickness variability. Figures A8 shows the percentage coefficient of variation (CV) in the fatigue life of the 24-ply specimens at the four maximum cyclic stress levels tested as a function of column position. Fig. A9 also isolates the percentage $\mathrm{CV}$ at one stress level as a function of column position and test frequency. Unlike the mean fatigue lives, the scatter in the life data, as measured by the $\mathrm{CV}$, correlated directly with the thickness variability for most cases, with the specimens cut near the panel edges (columns 1 \& 5) exhibiting the greatest scatter. 


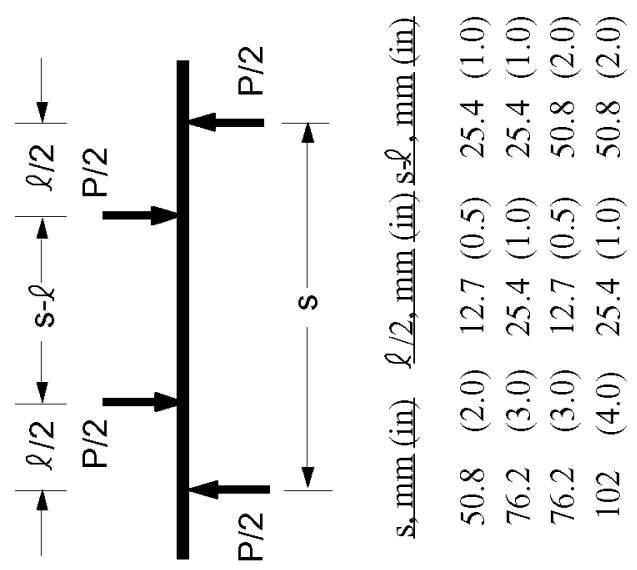

或 $\bar{x} x \cong$
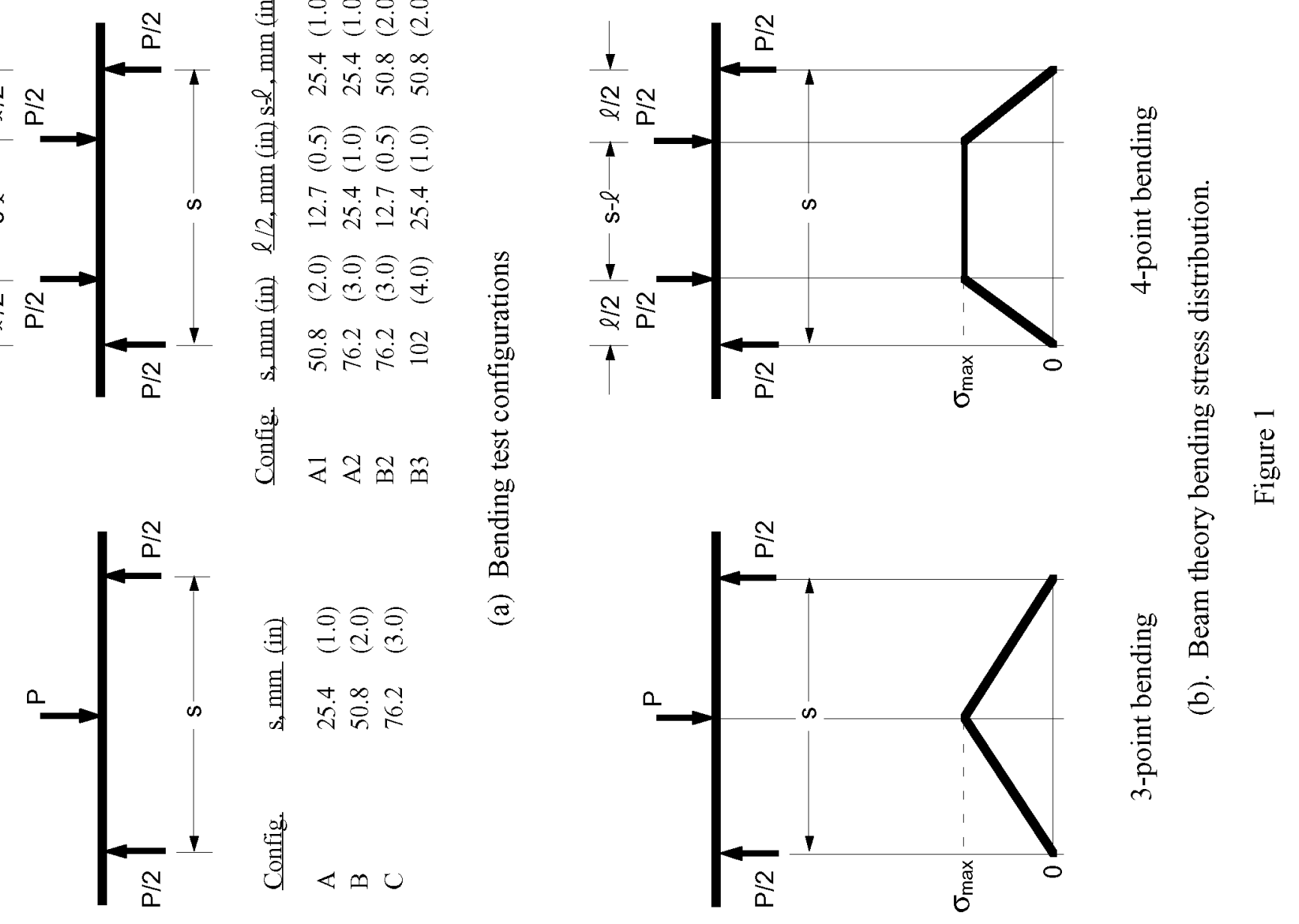


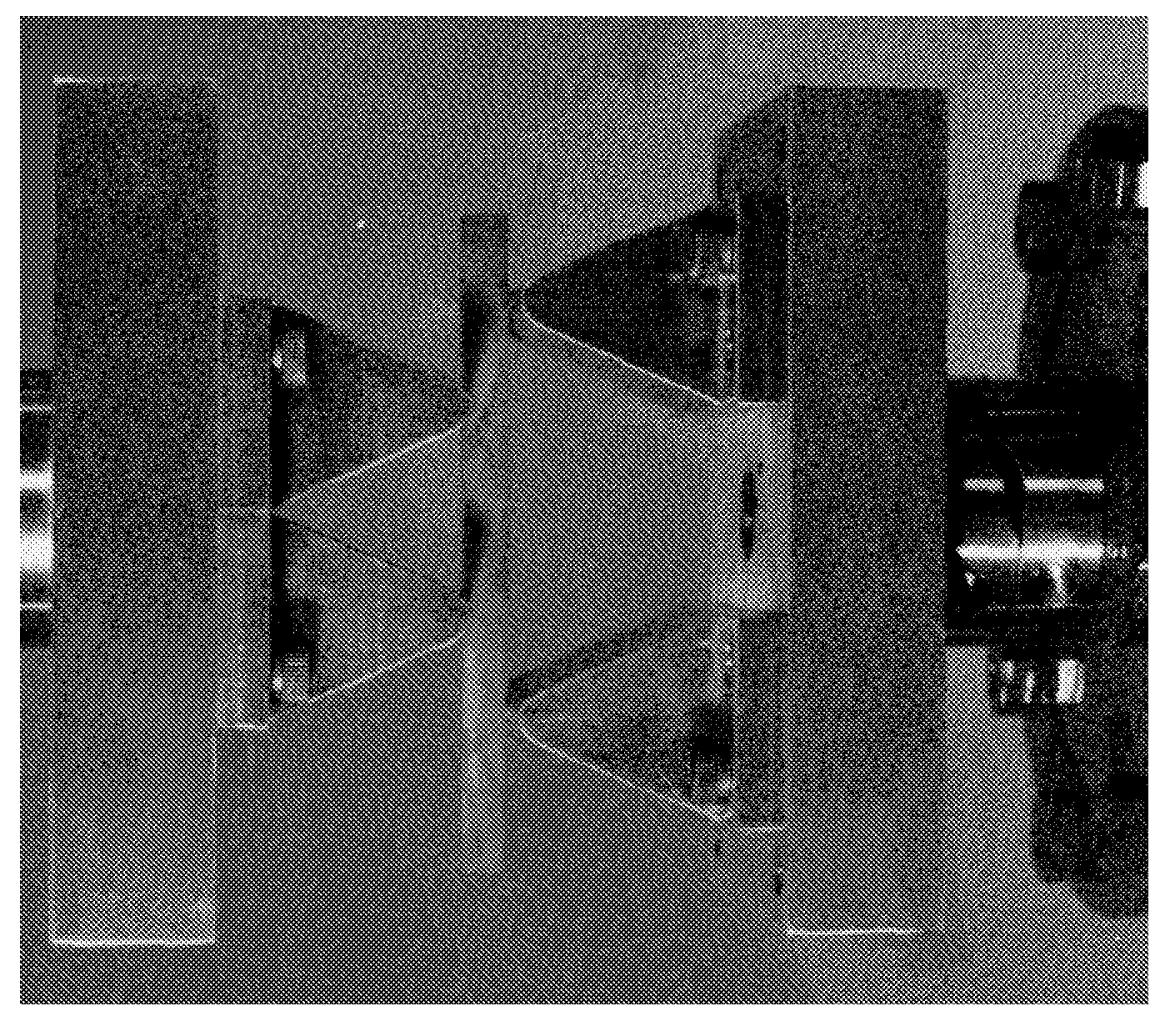

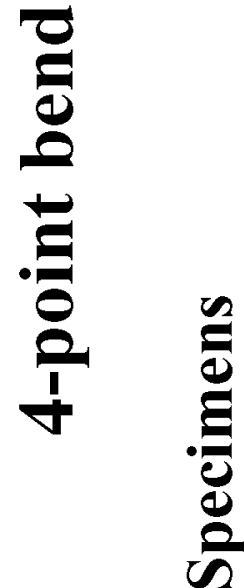
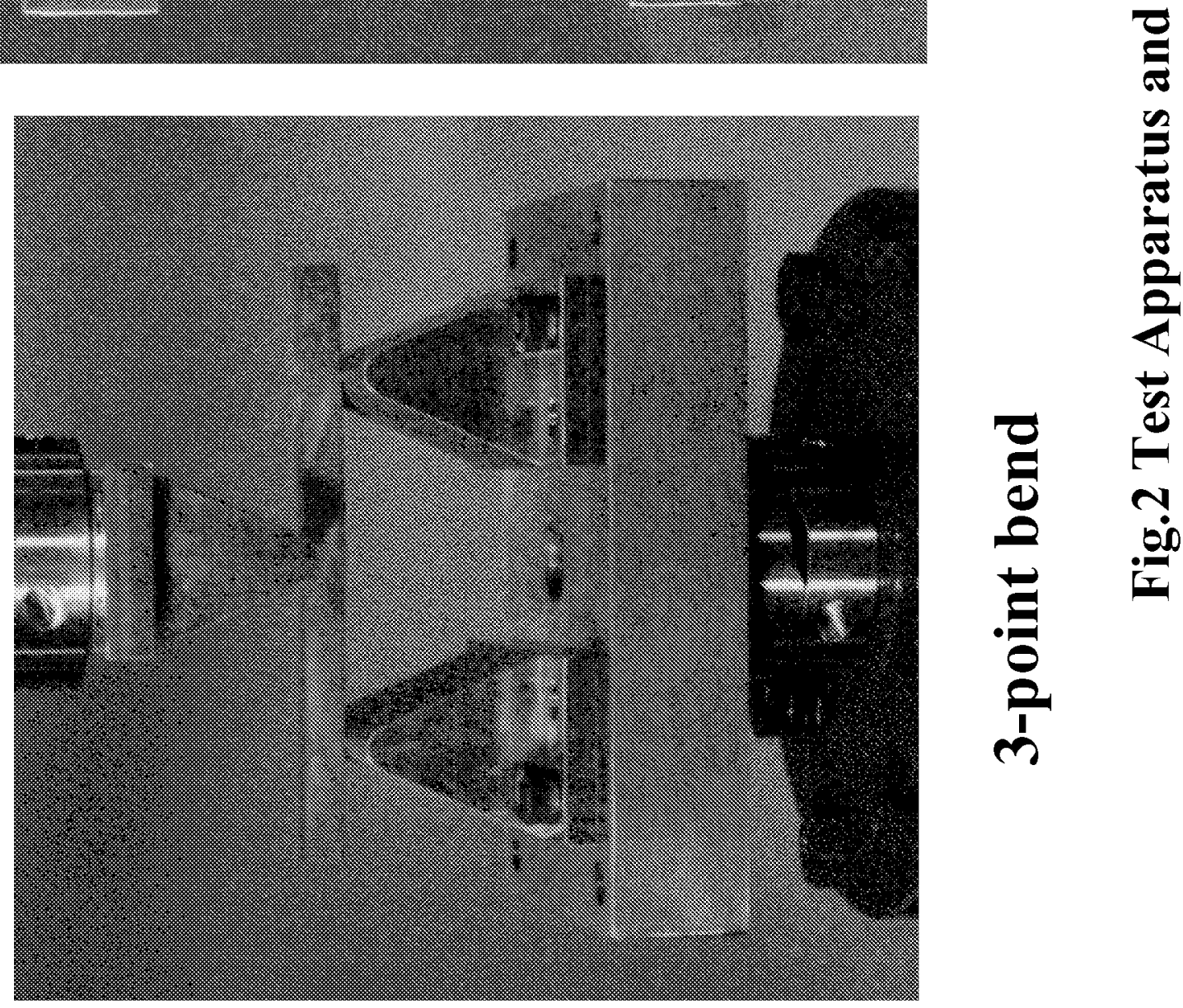

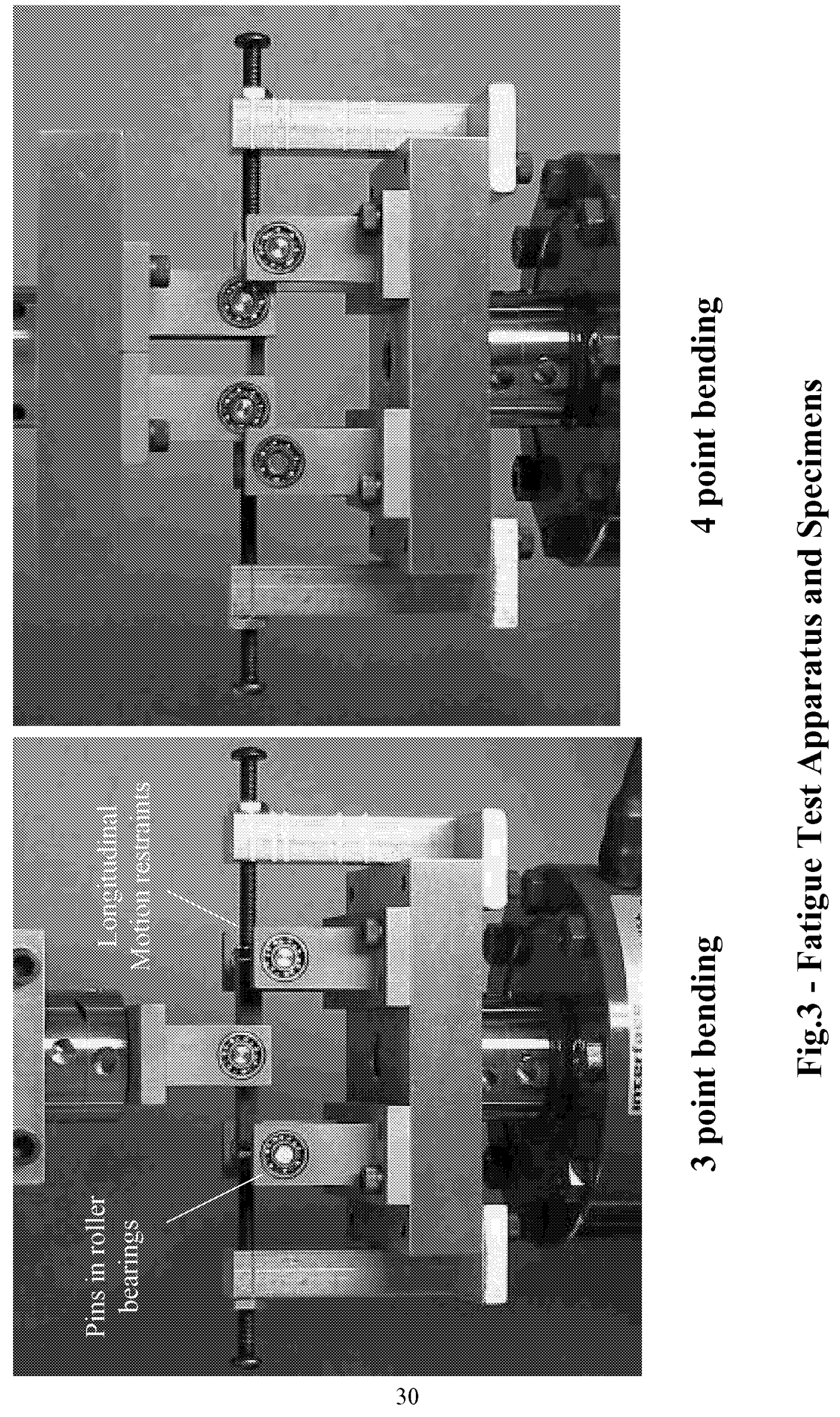


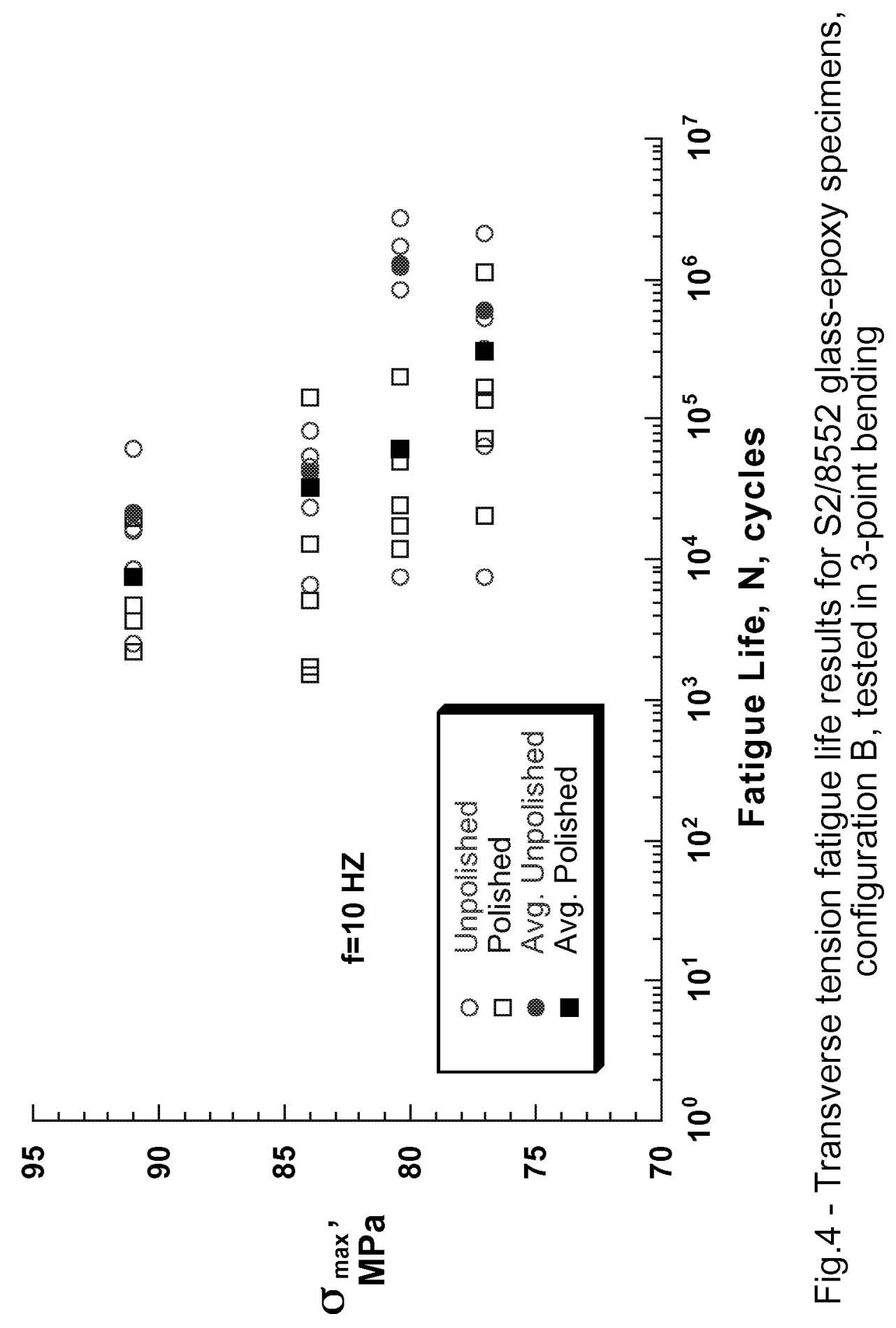




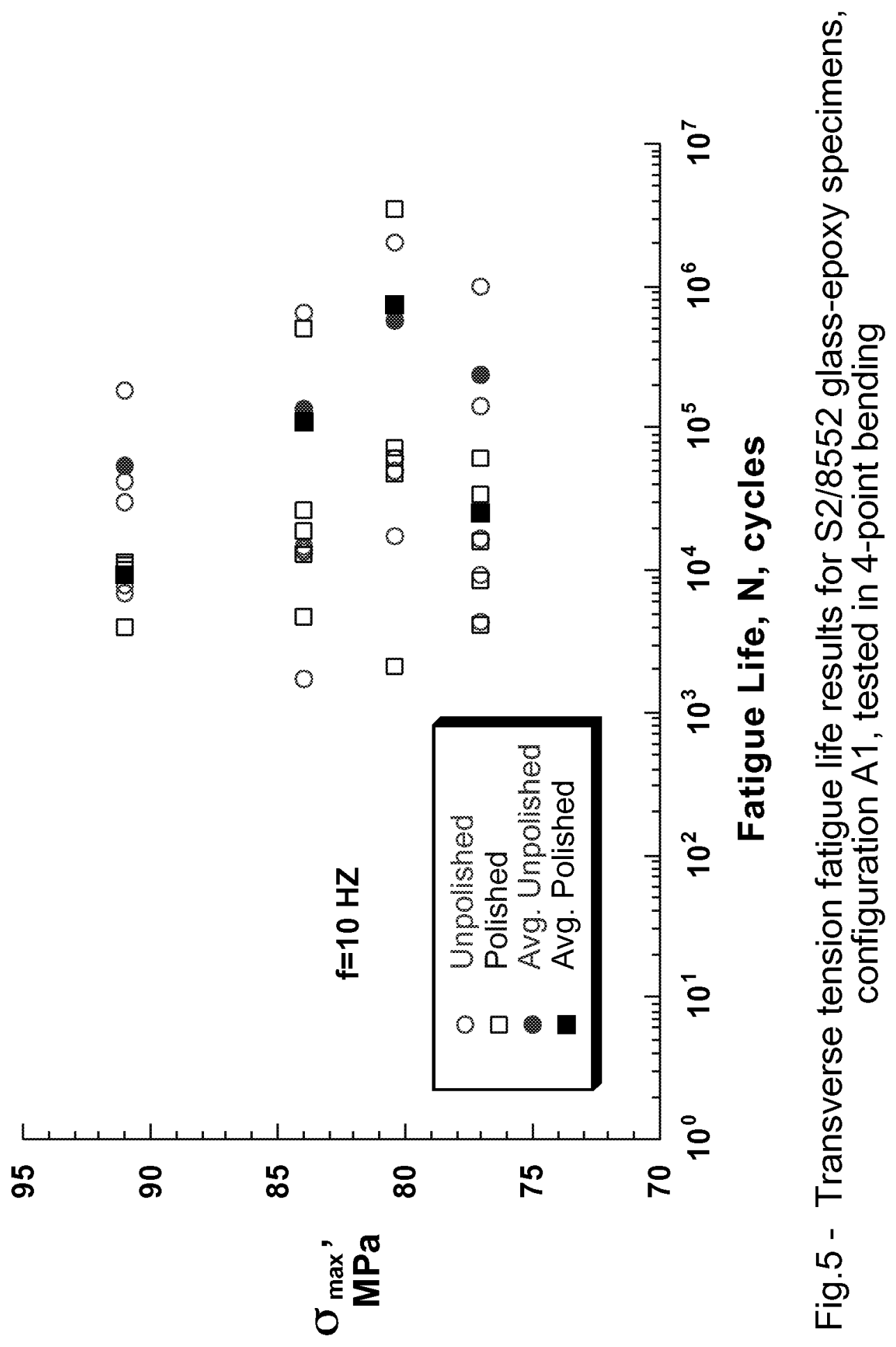




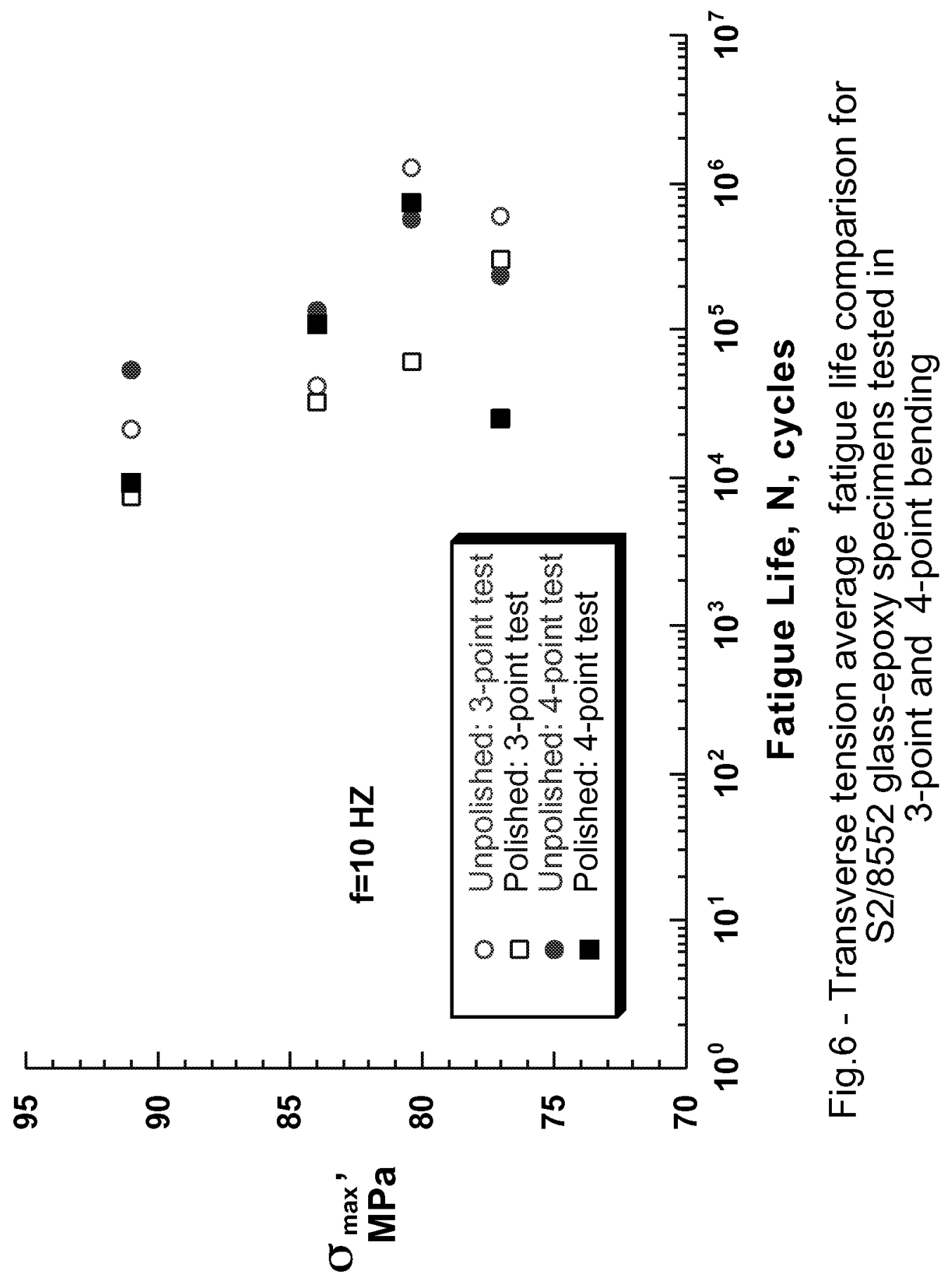




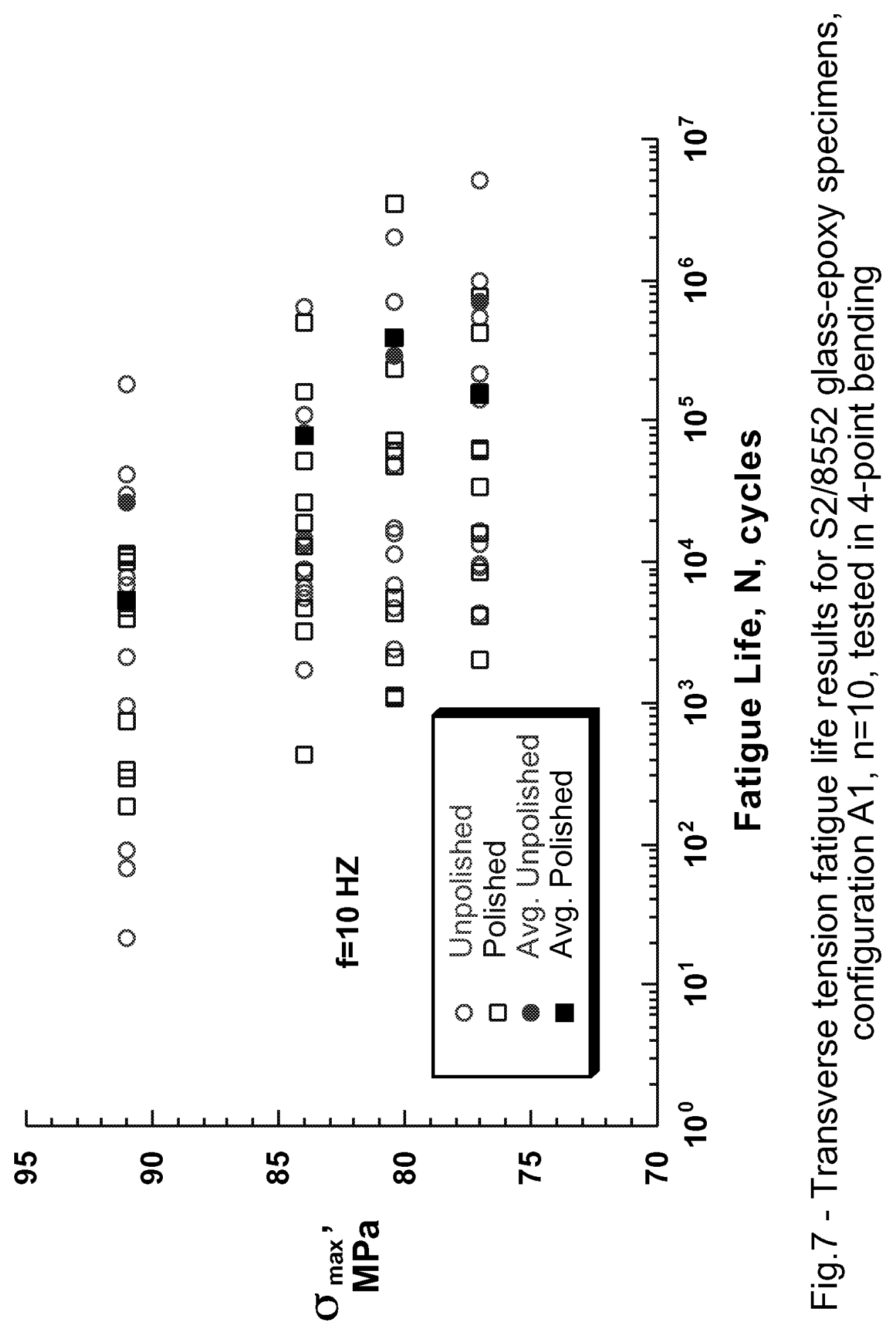




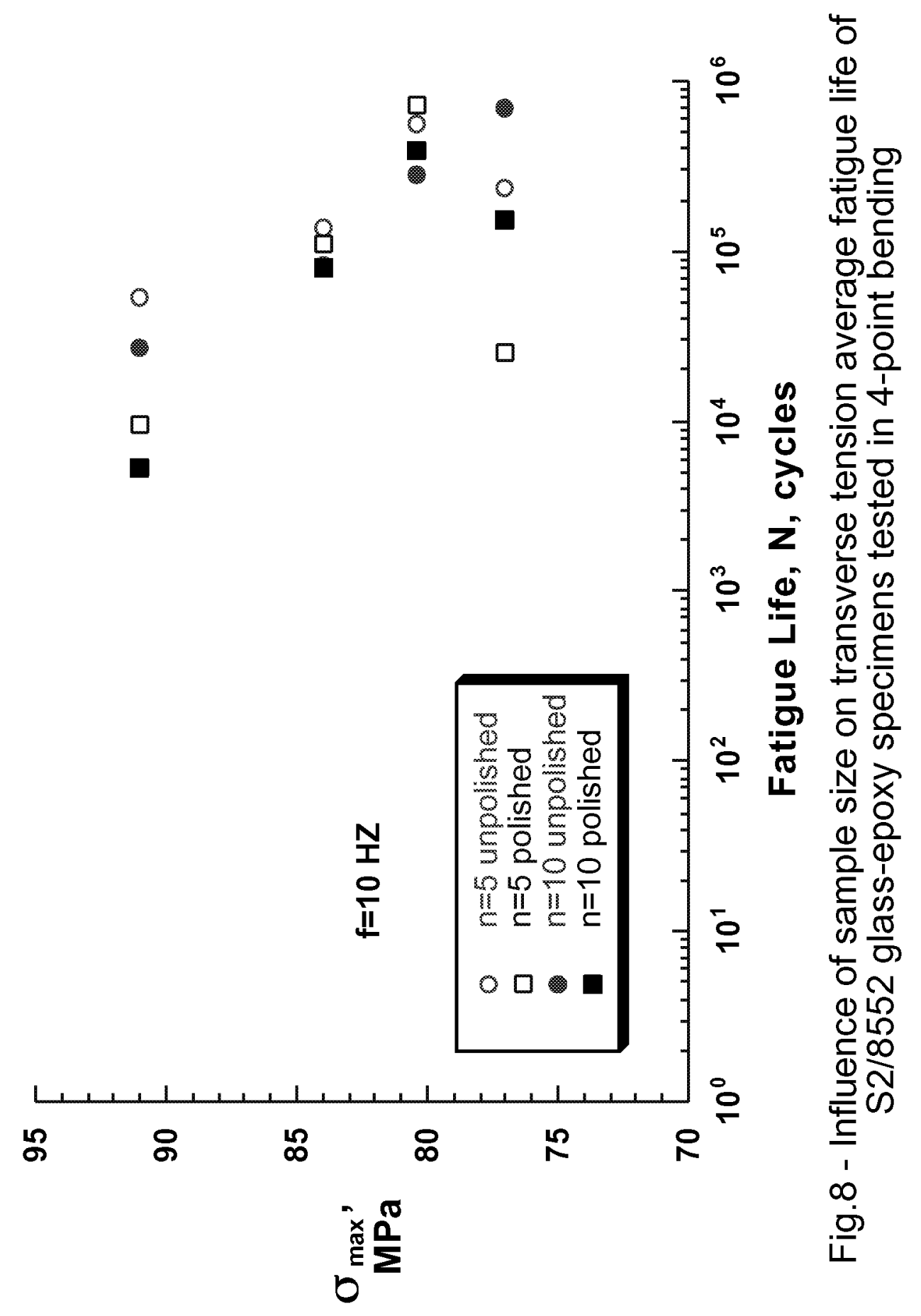




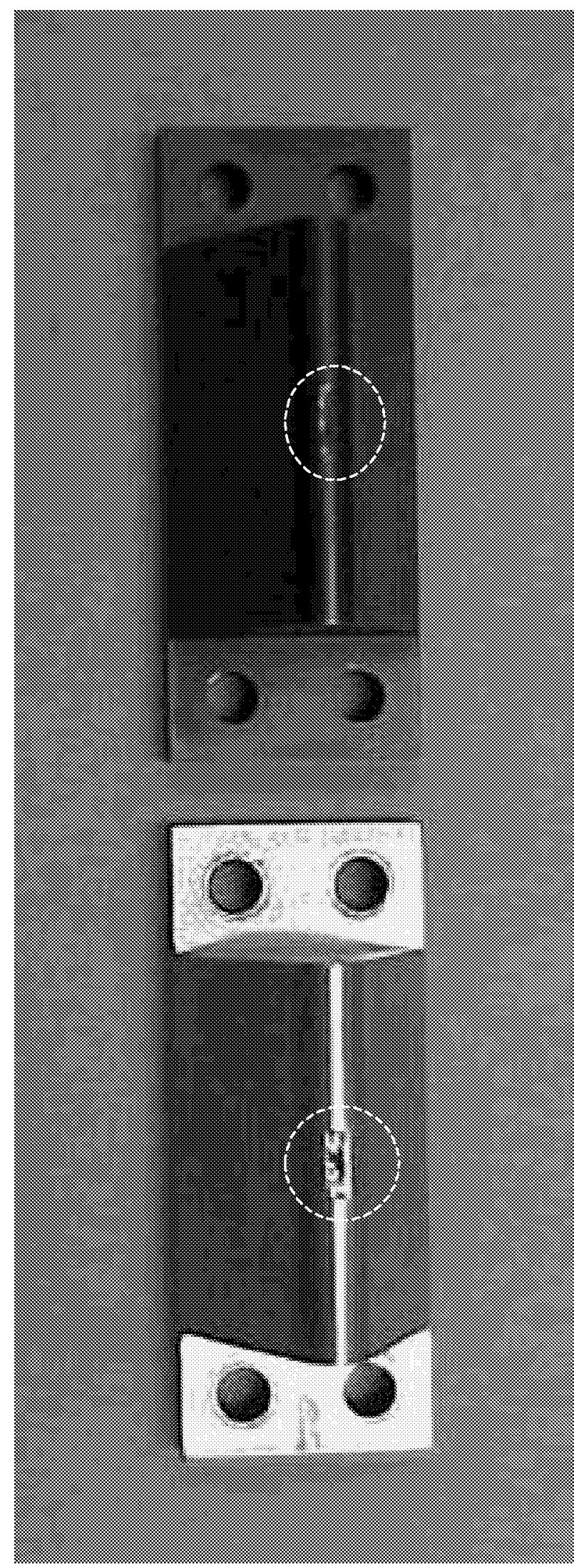

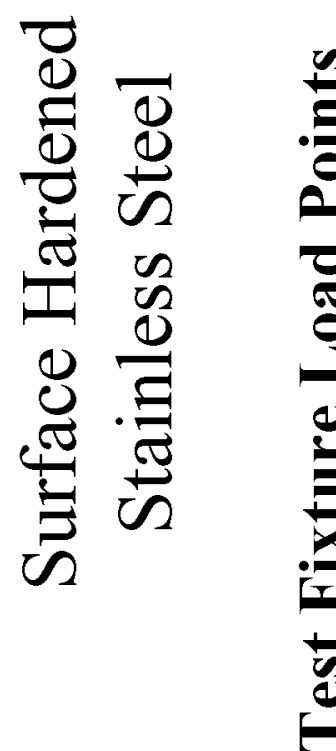

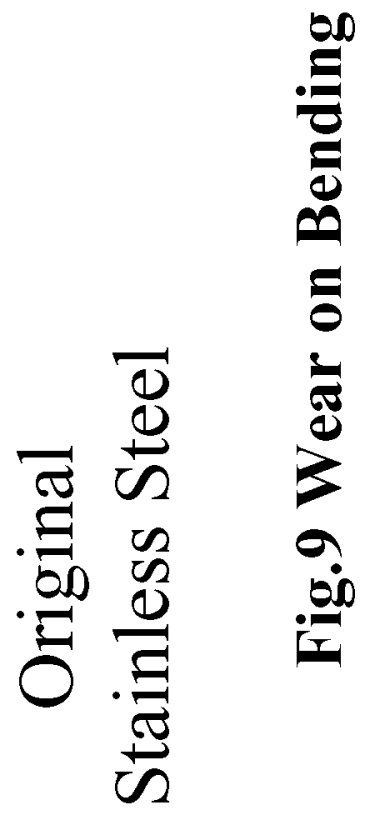




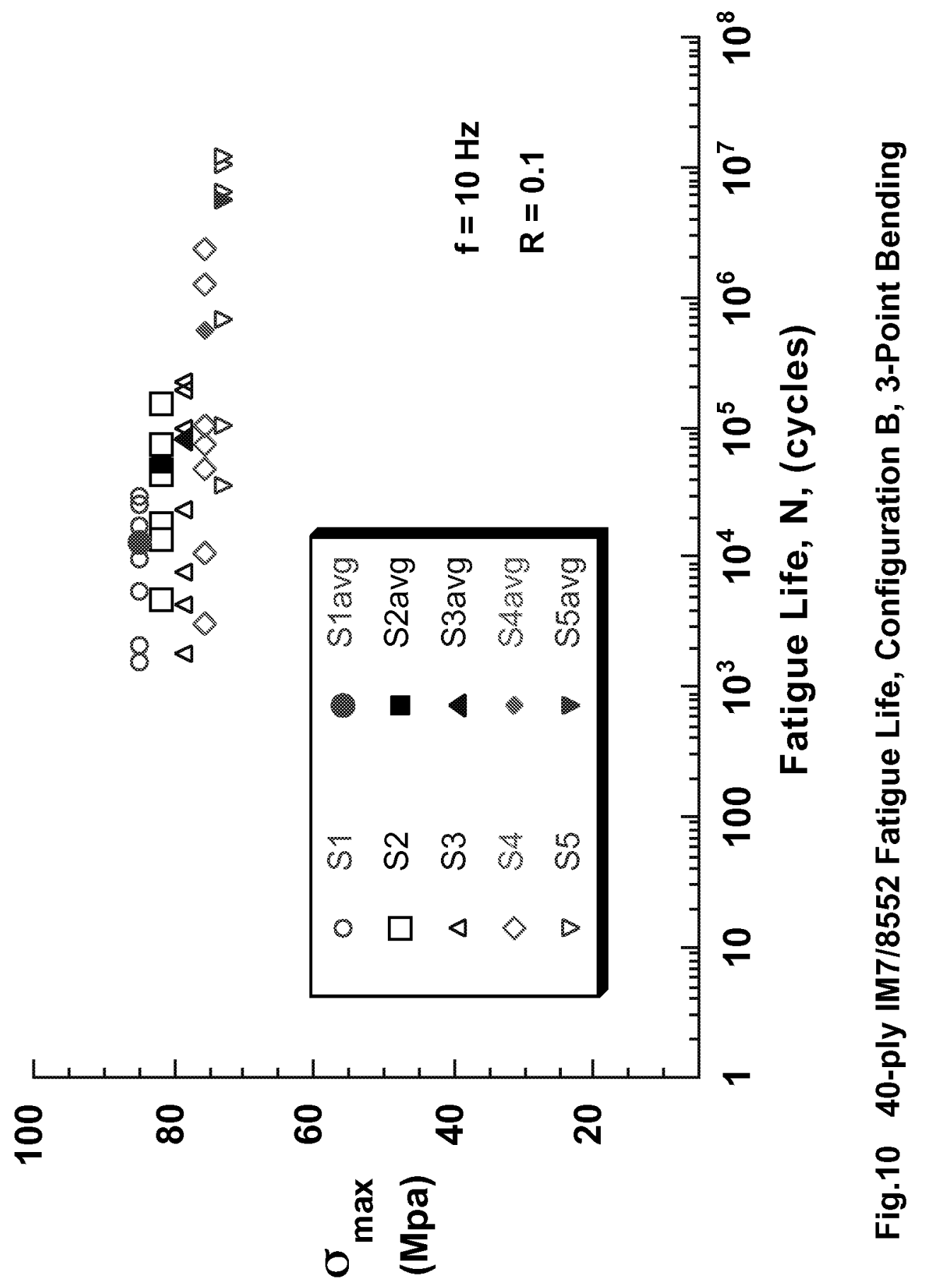




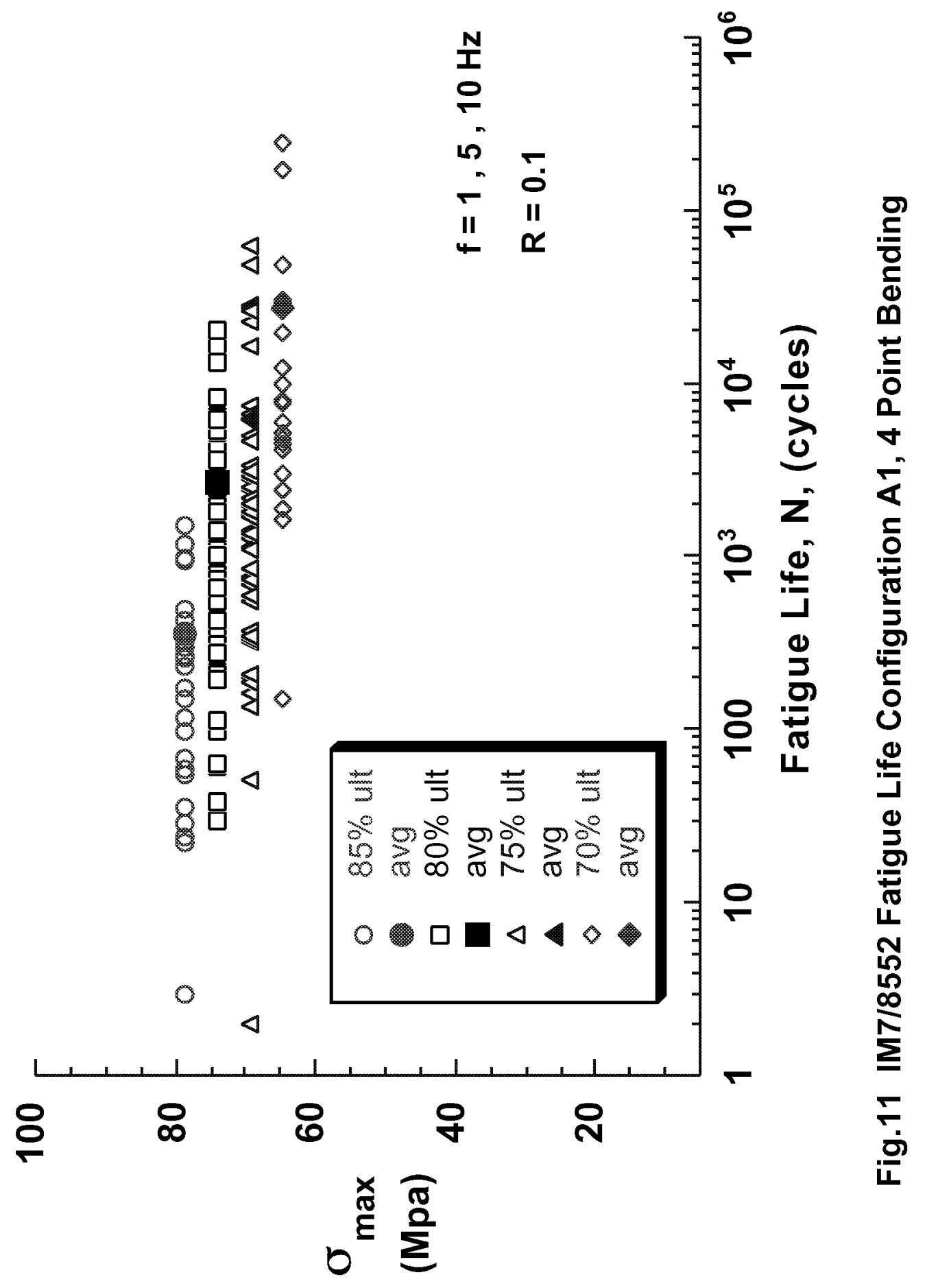




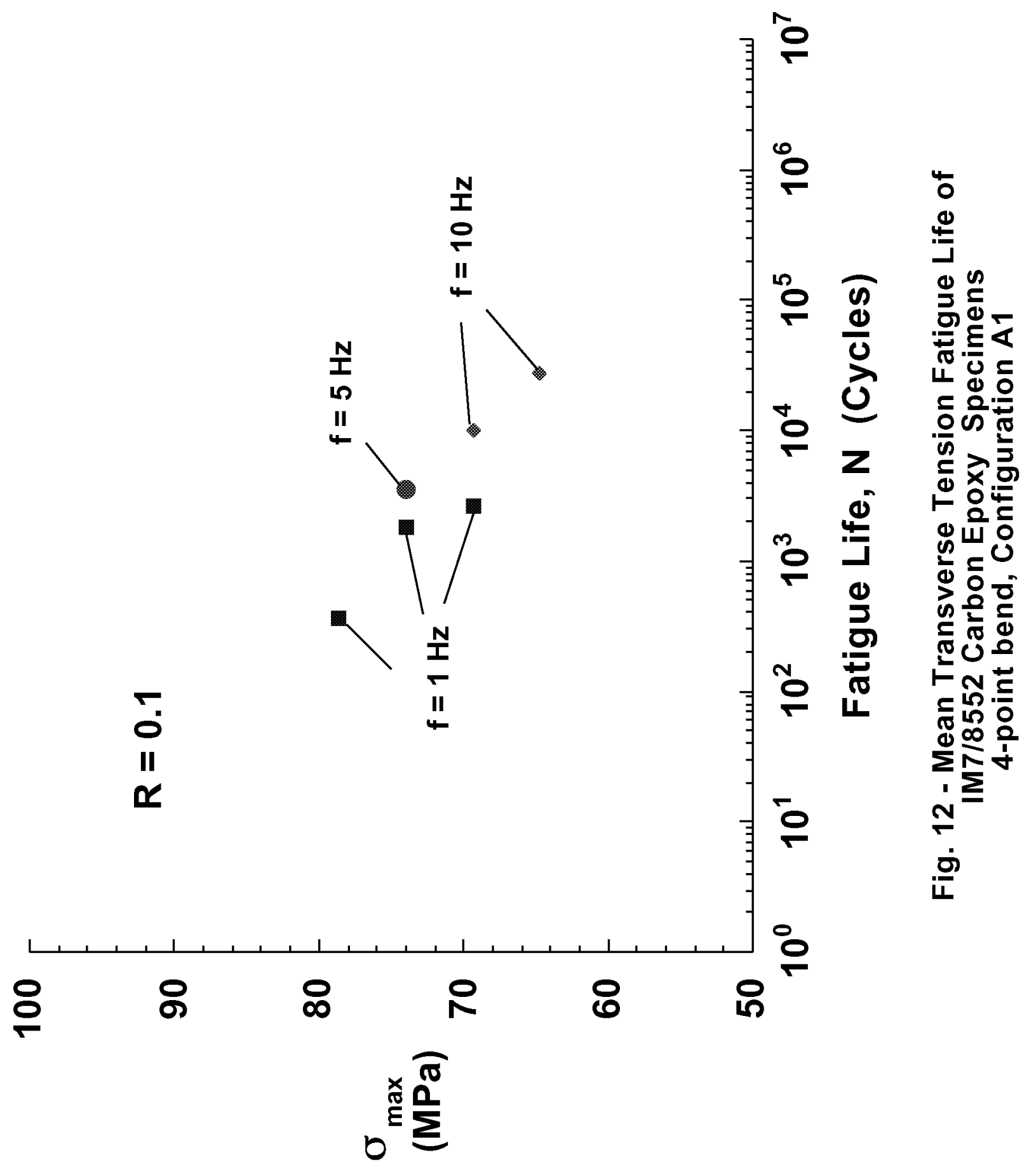




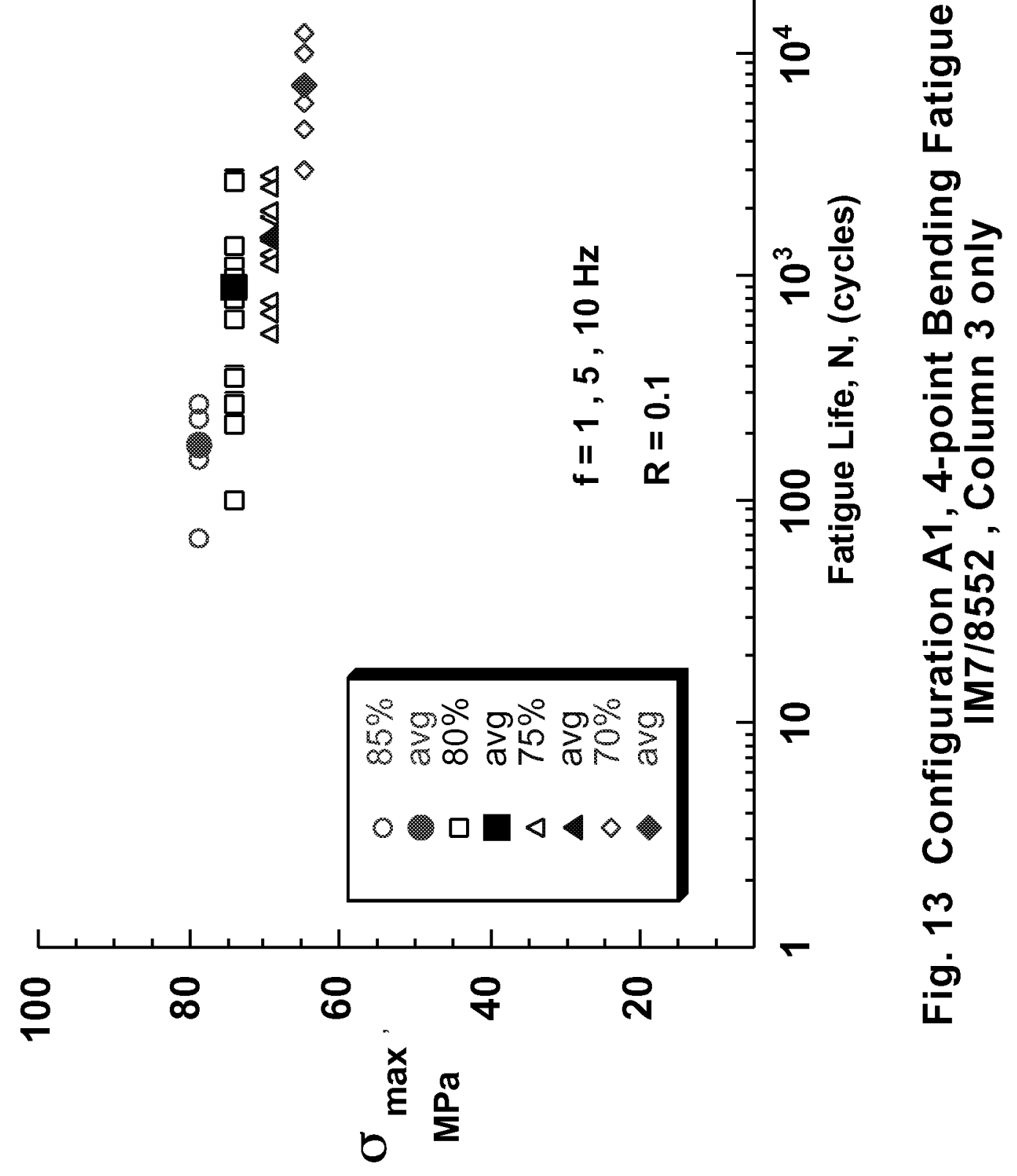




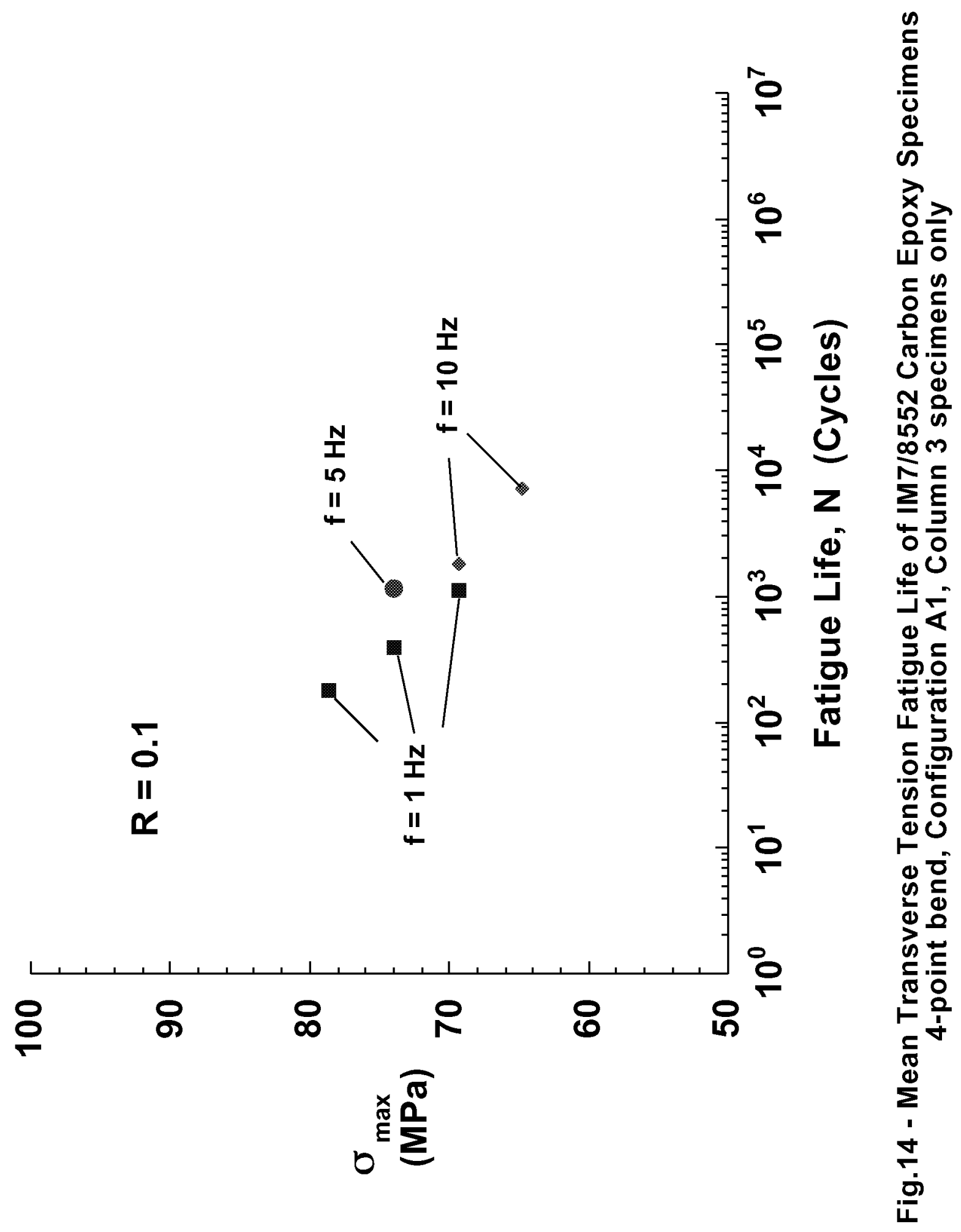




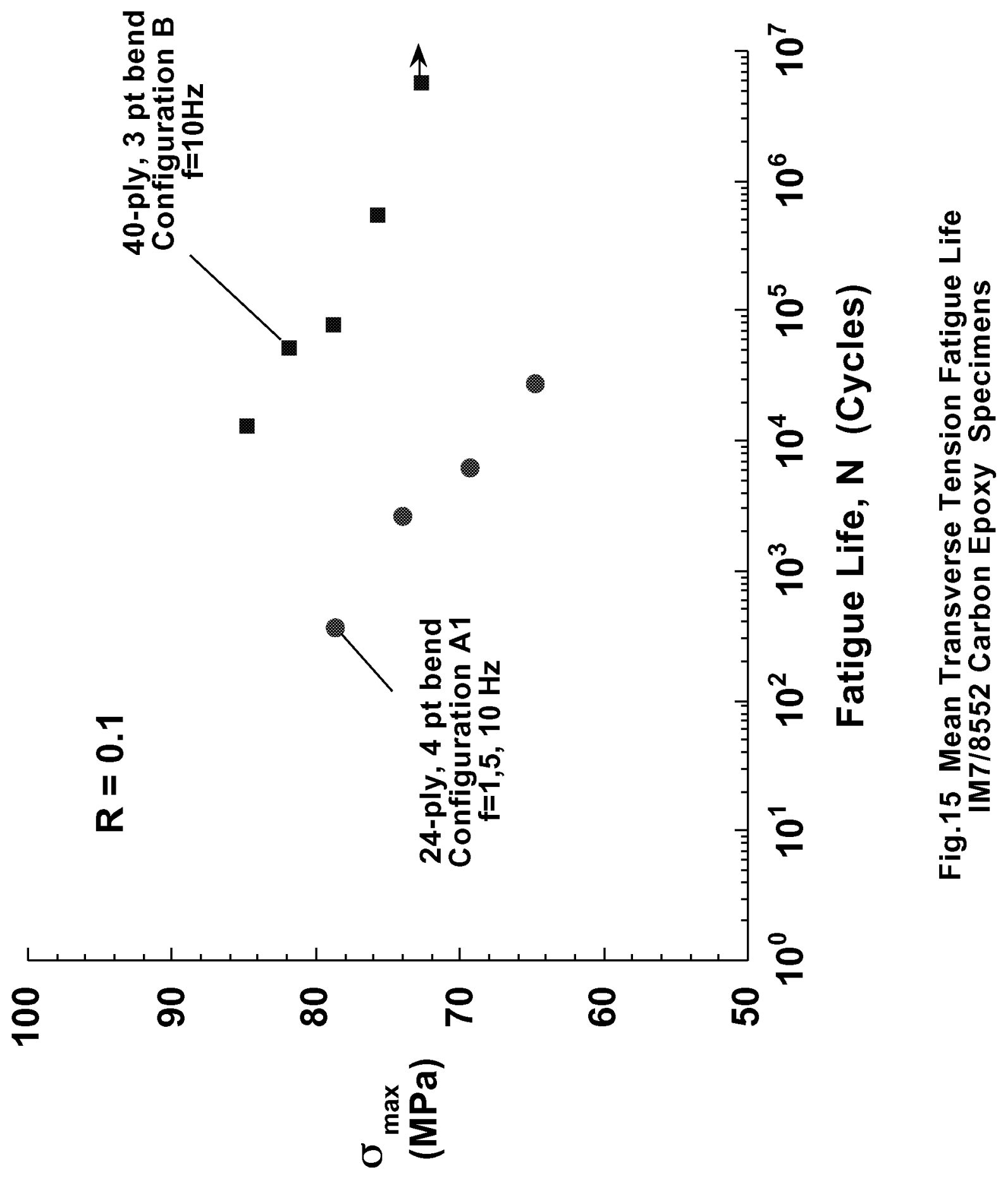




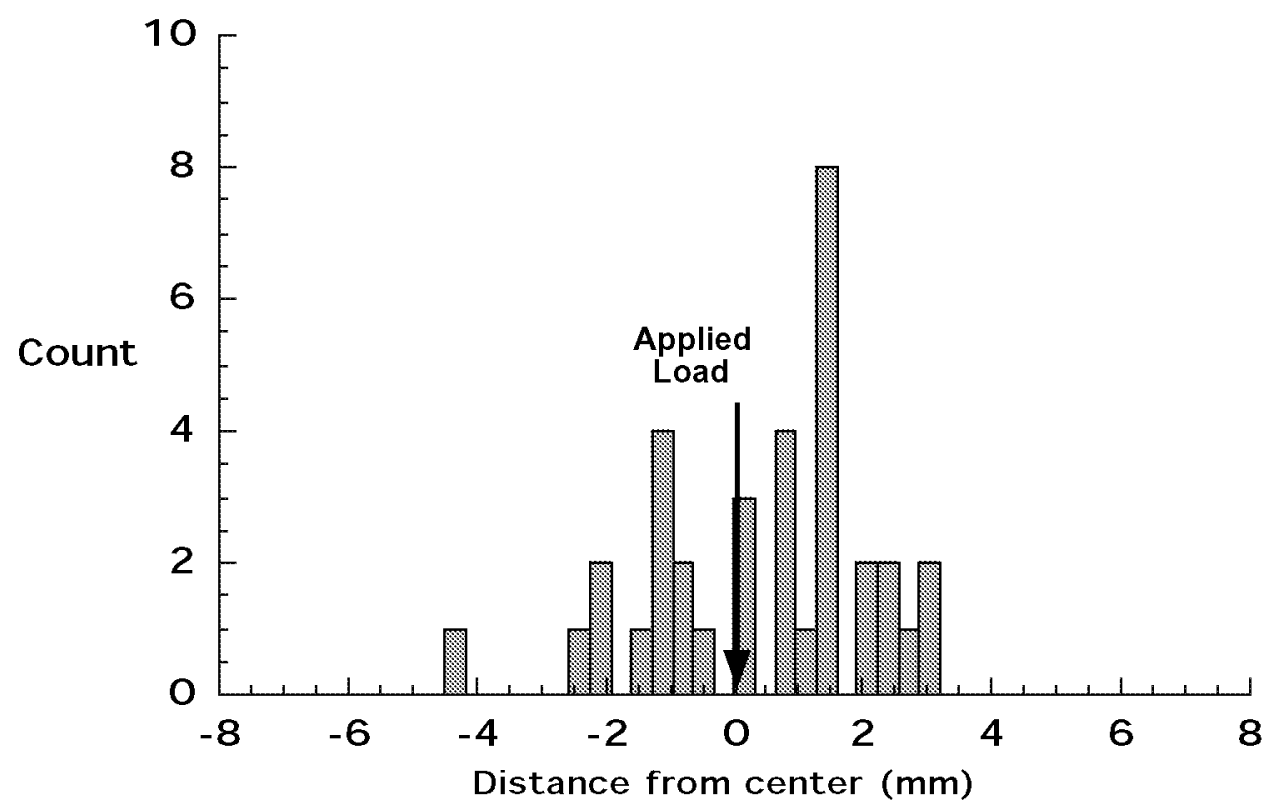

Fig.16a Failure Location S2/8552 Glass Epoxy Polished 3-Point bend, Configuration B, Fatigue

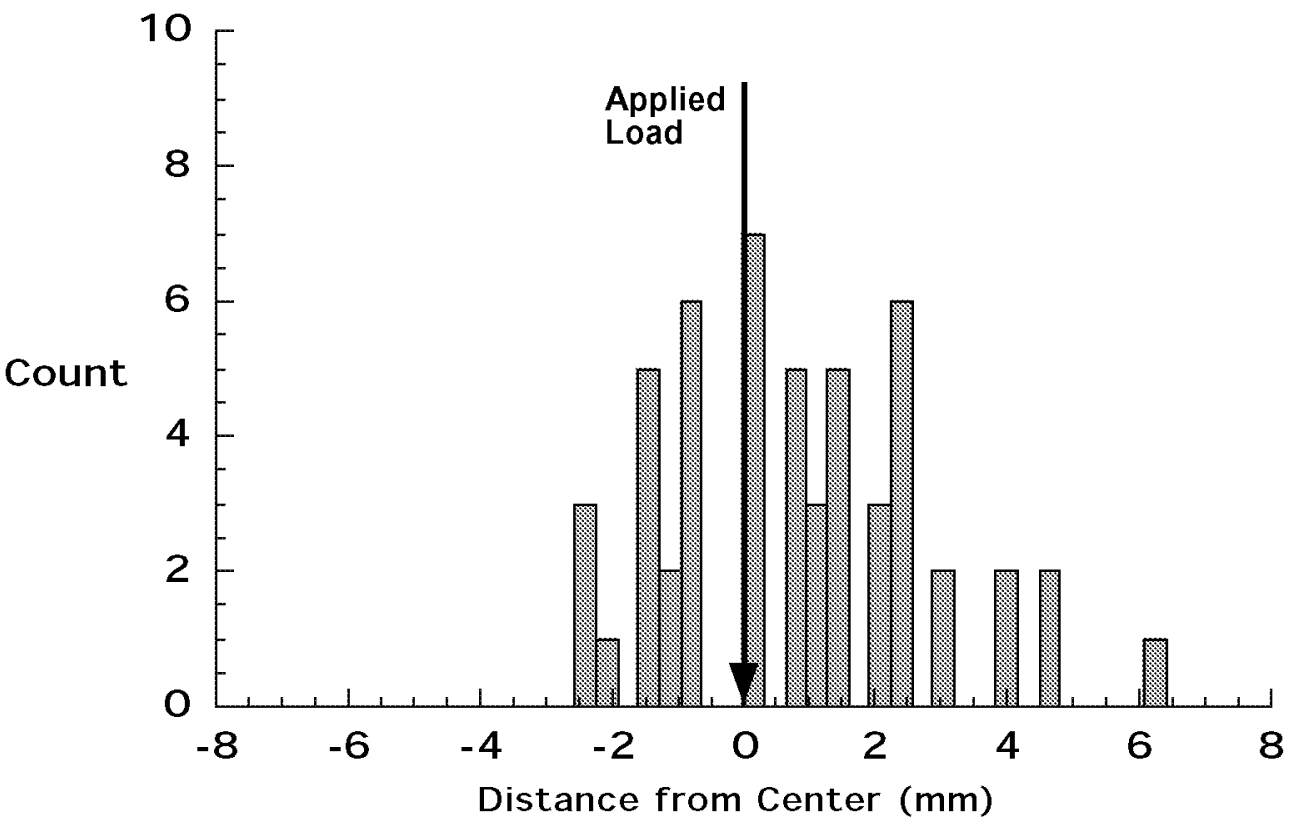

Fig.16b Failure Location S2/8552 Glass Epoxy Unpolished 3-point bend, Configuration B, Fatigue 


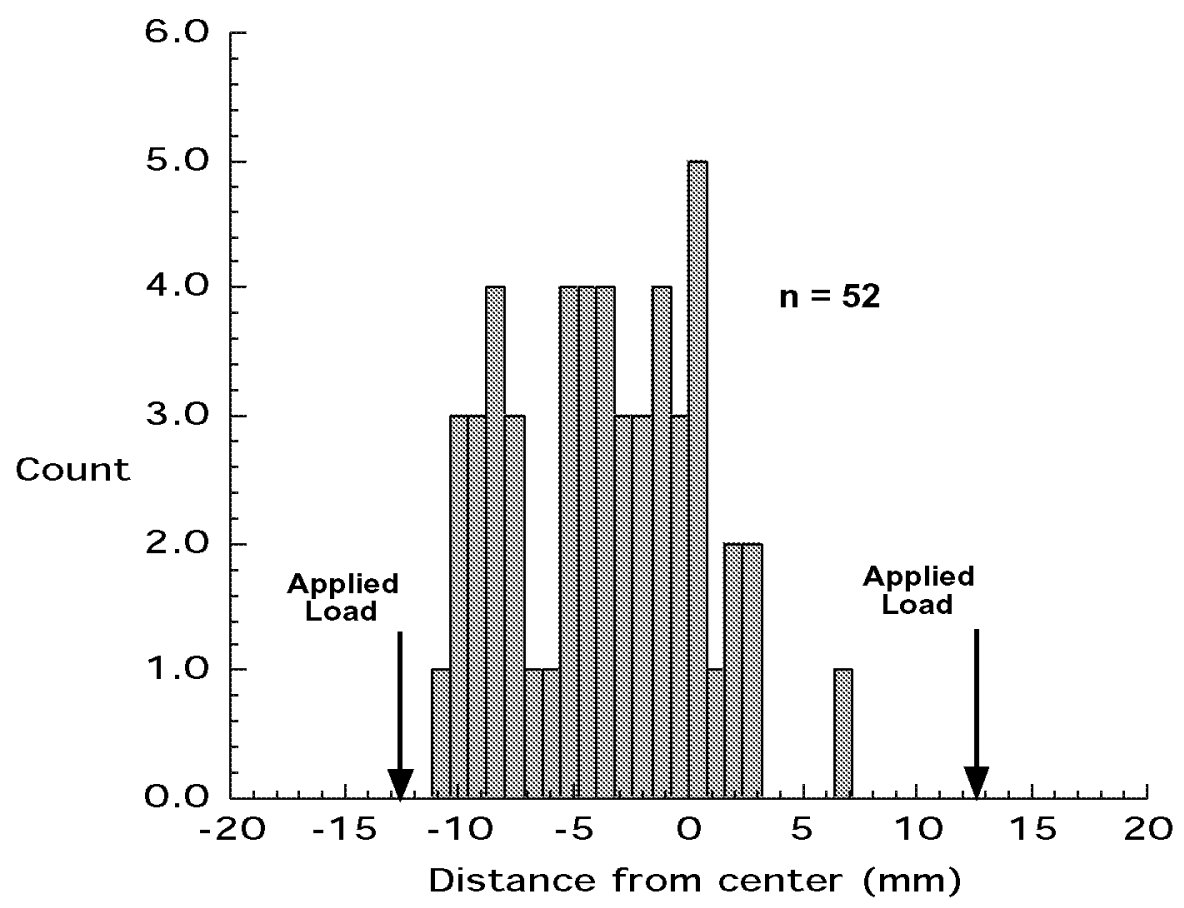

Fig.17a Failure Location $\$ 2 / 8552$ Glass Epoxy Unpolished 4-point bend, Configuration A1, Static

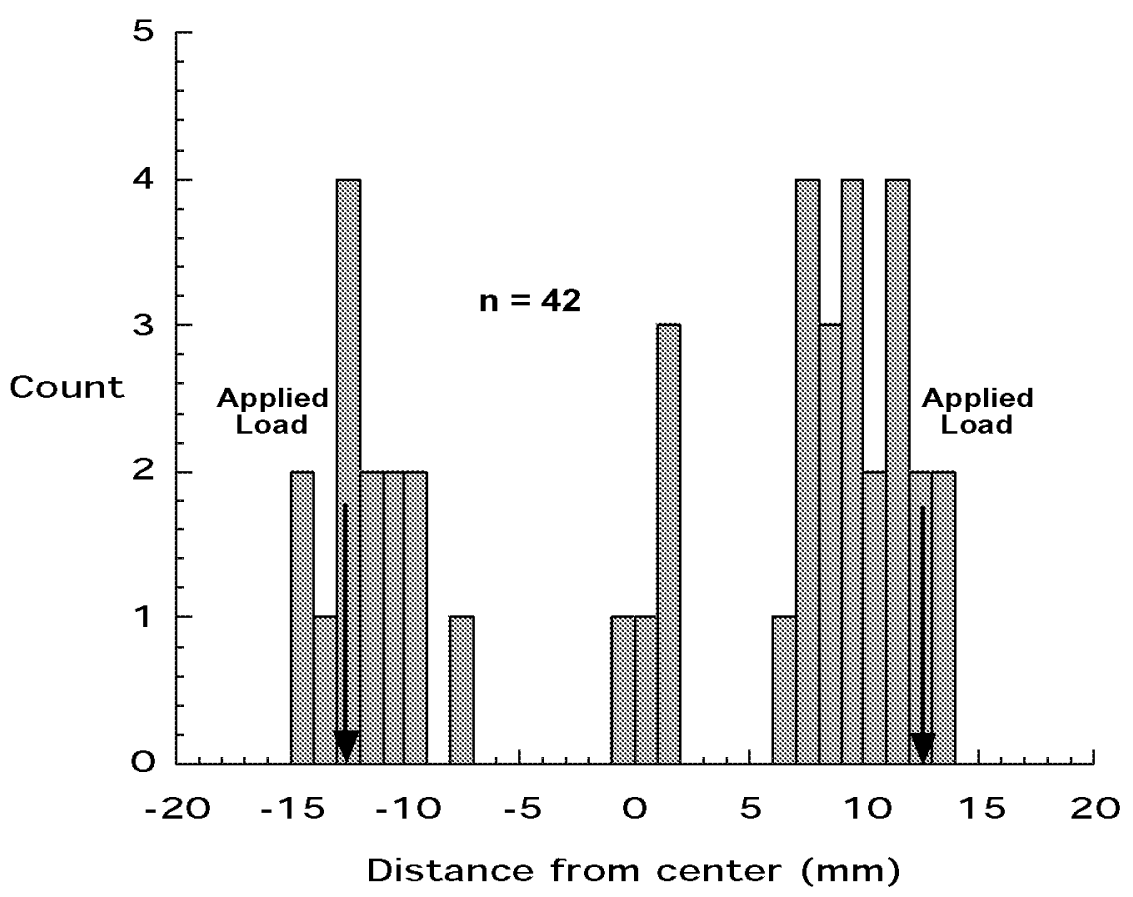

Fig.17b Failure Location S2/8552 Glass Epoxy Unpolished 4-point bend, Configuration A1, Fatigue 


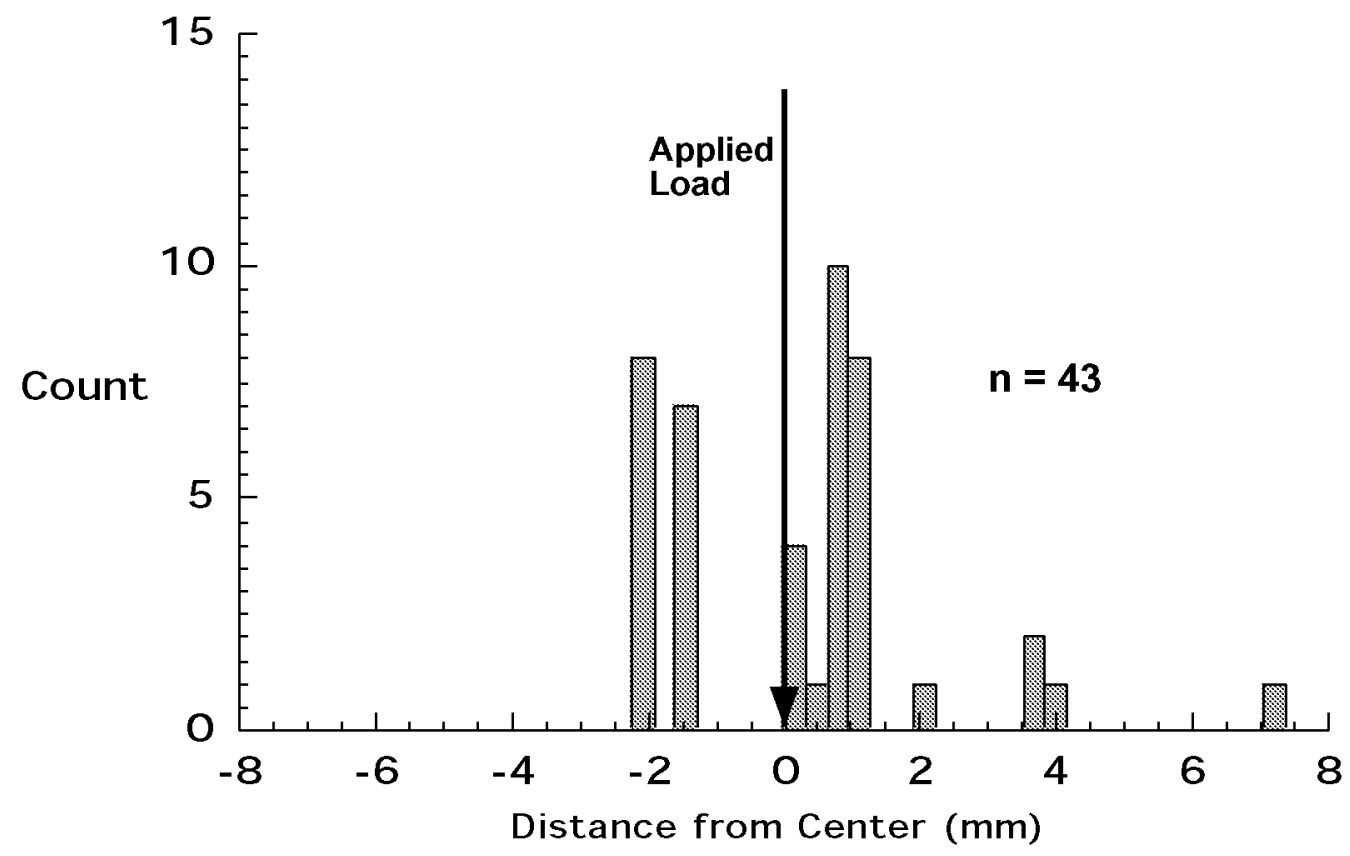

Fig. 18a Failure Location, IM7/8552 Carbon Epoxy 3-point bending, Configuration B, Static

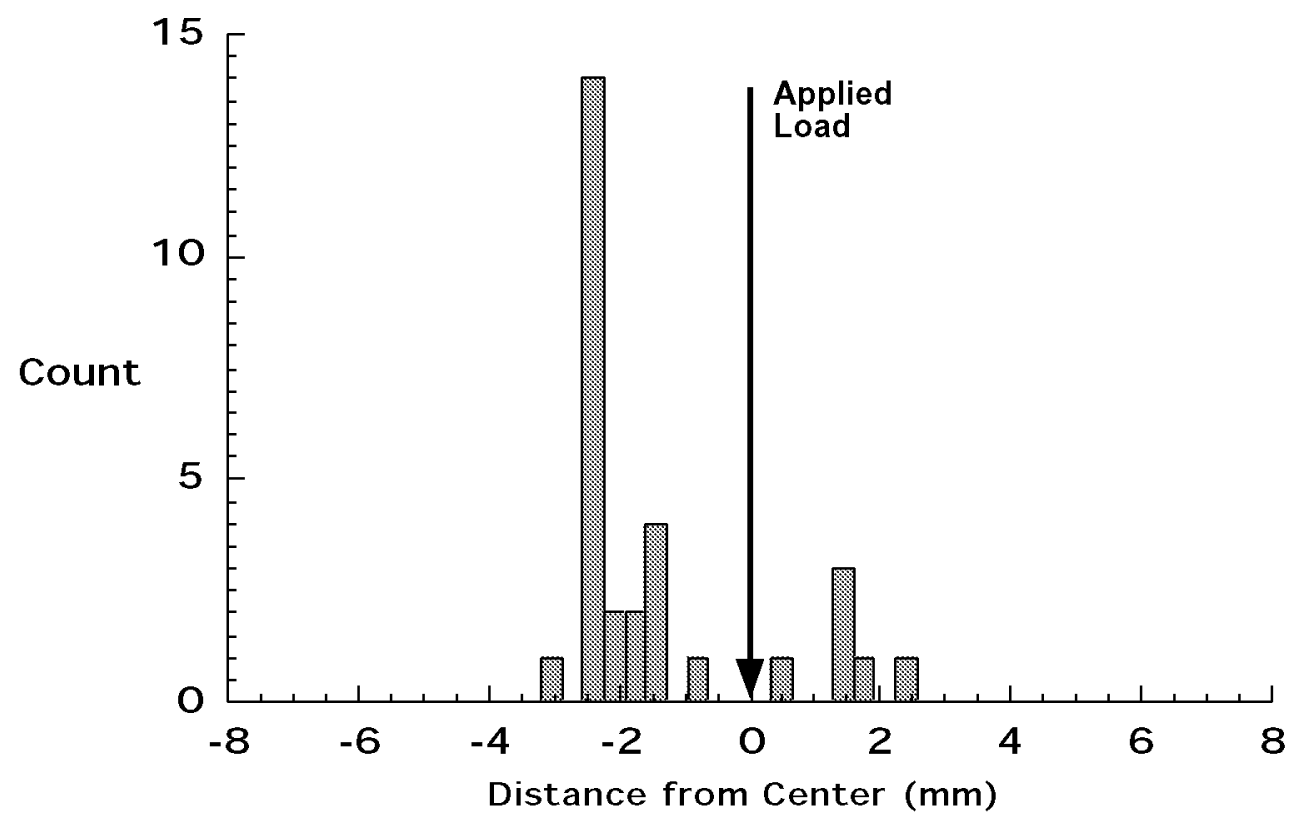

Fig.18b Failure Location IM7/8552 Carbon Epoxy 3-point bending, Configuration B, Fatigue 


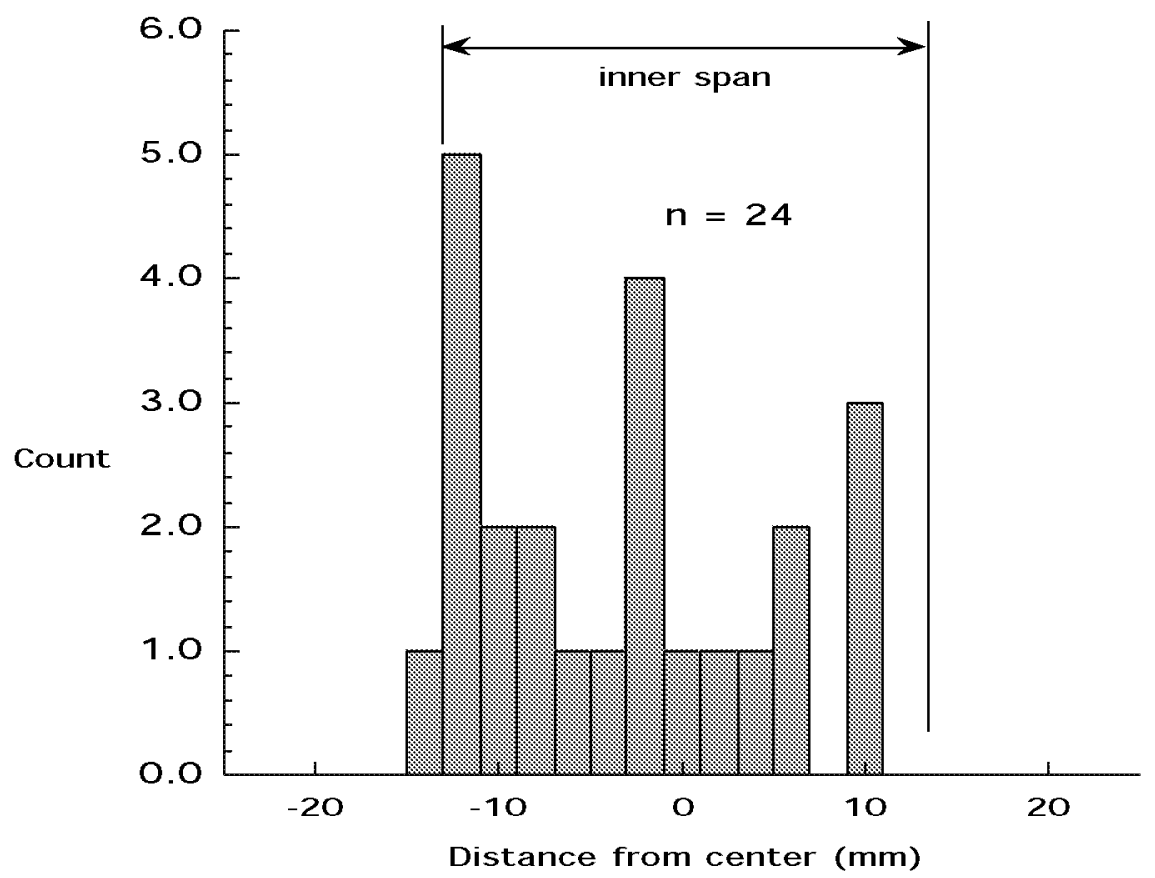

Fig. 19a Histogram of failure locations, 24-ply IM7/8552 4 -point bending configuration $A 1$, Static

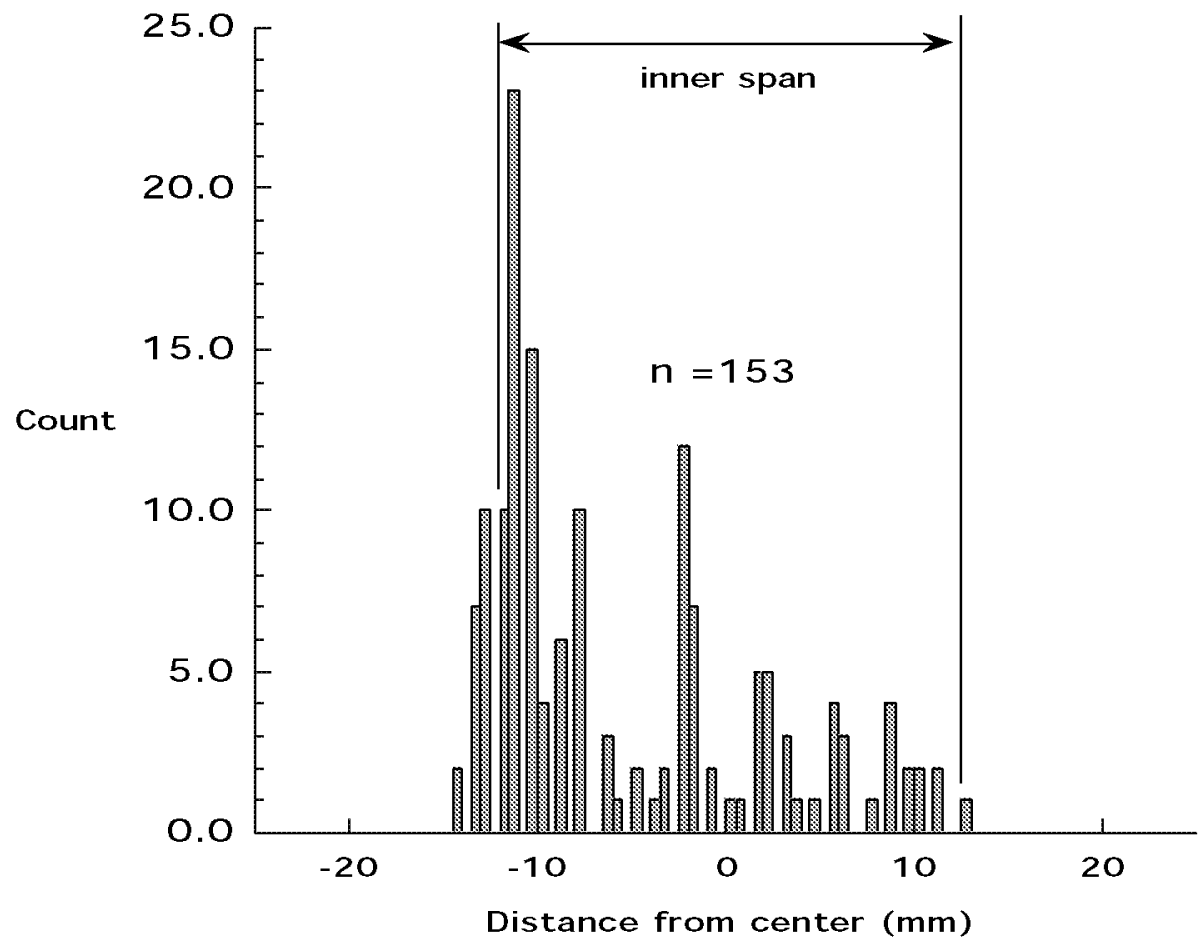

Fig. 19b Histogram of failure locations, 24-ply IM7/8552 4-point bending configuration A1, Fatigue 

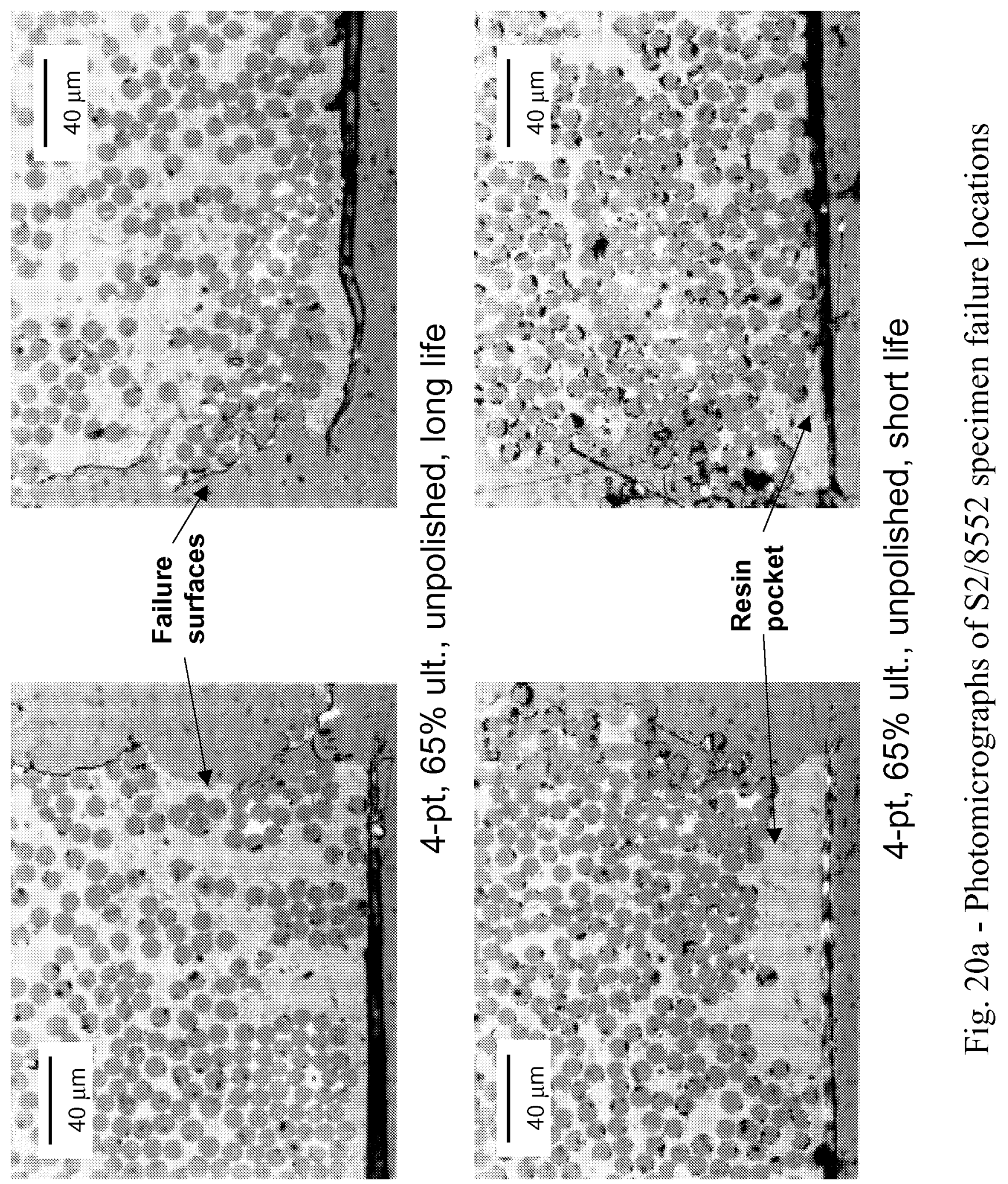

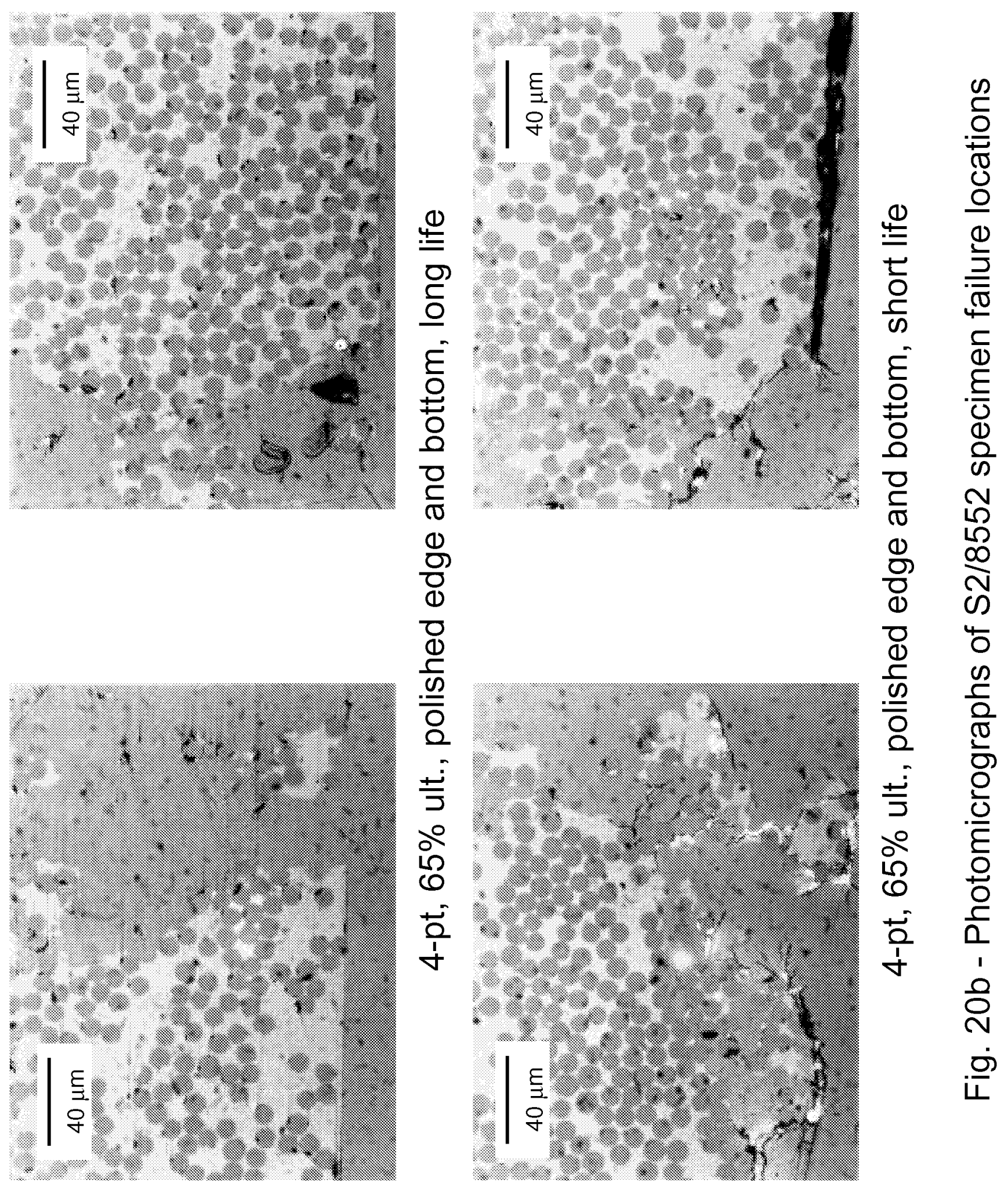

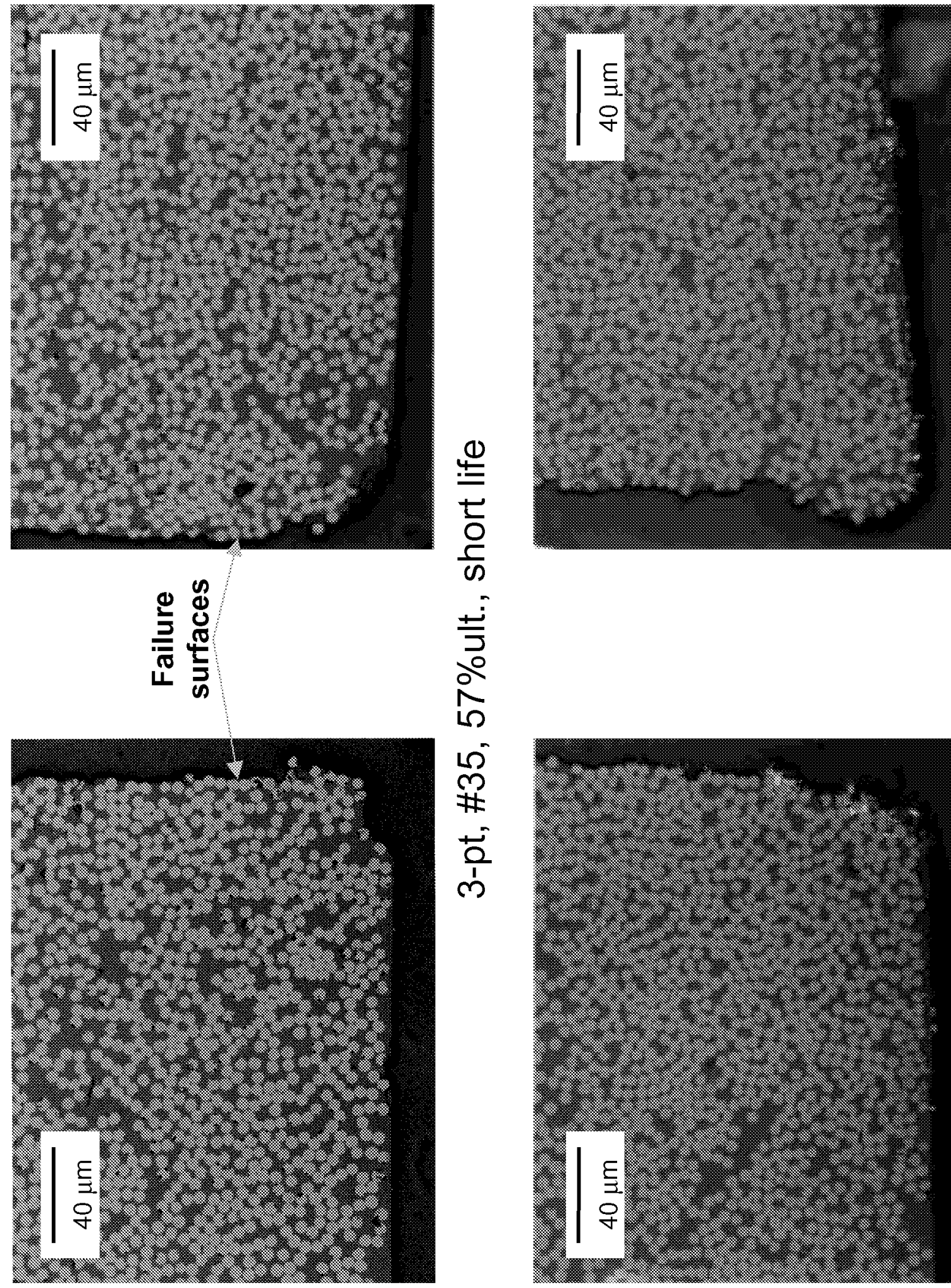

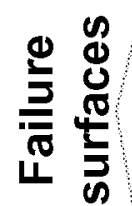

n̊
\#
लํำ

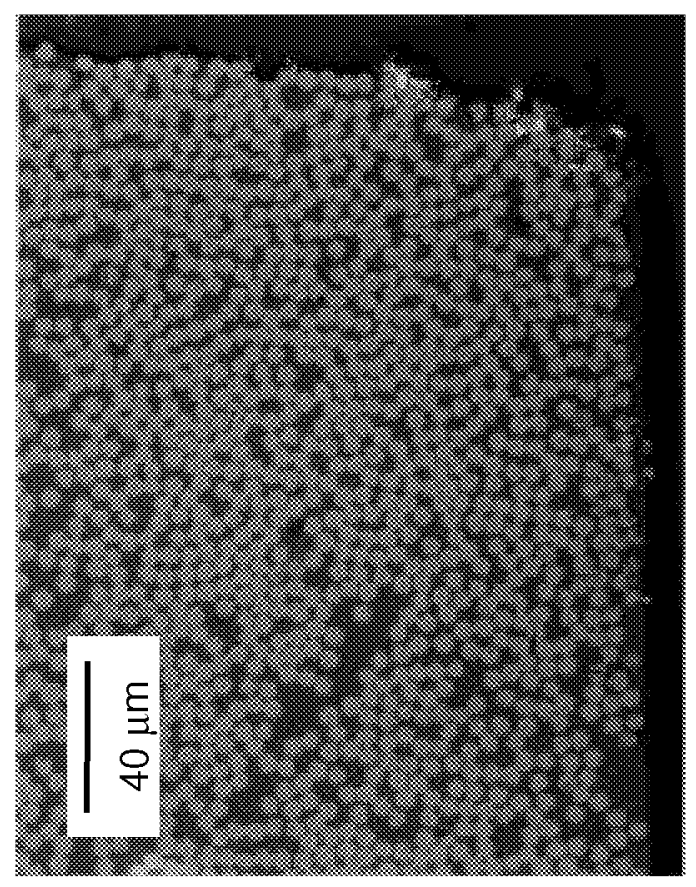

49 

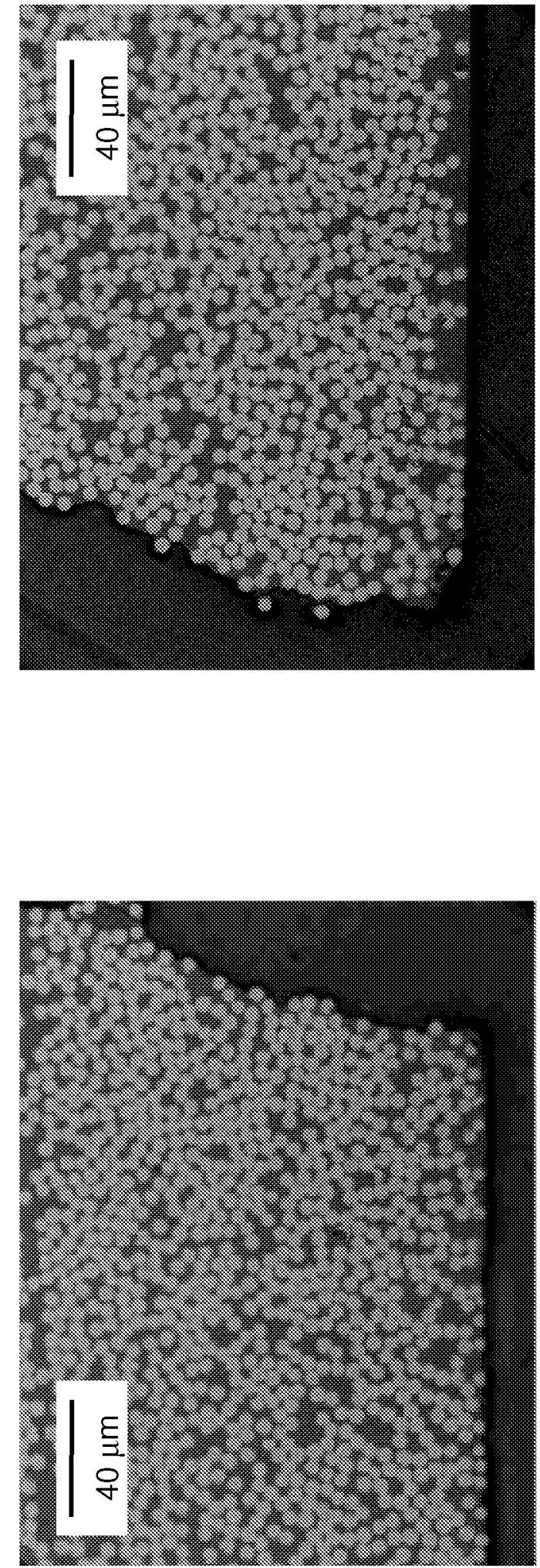

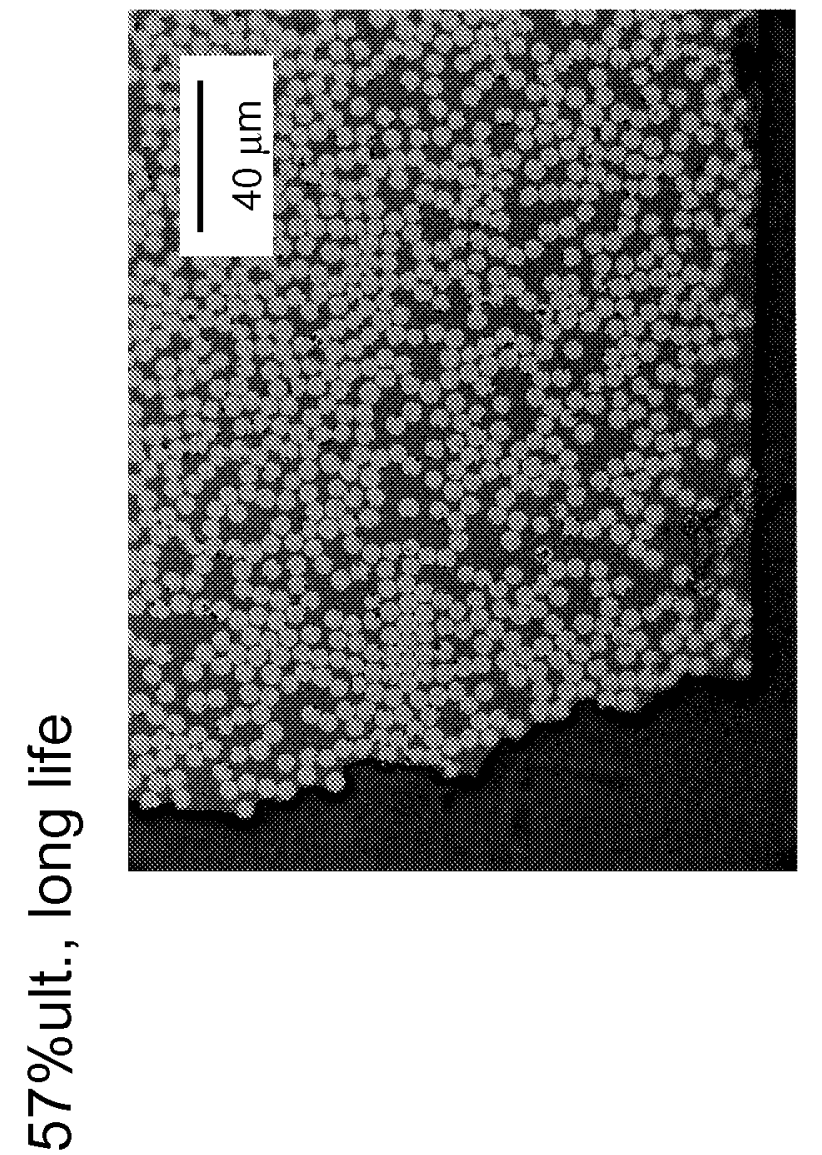

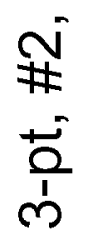

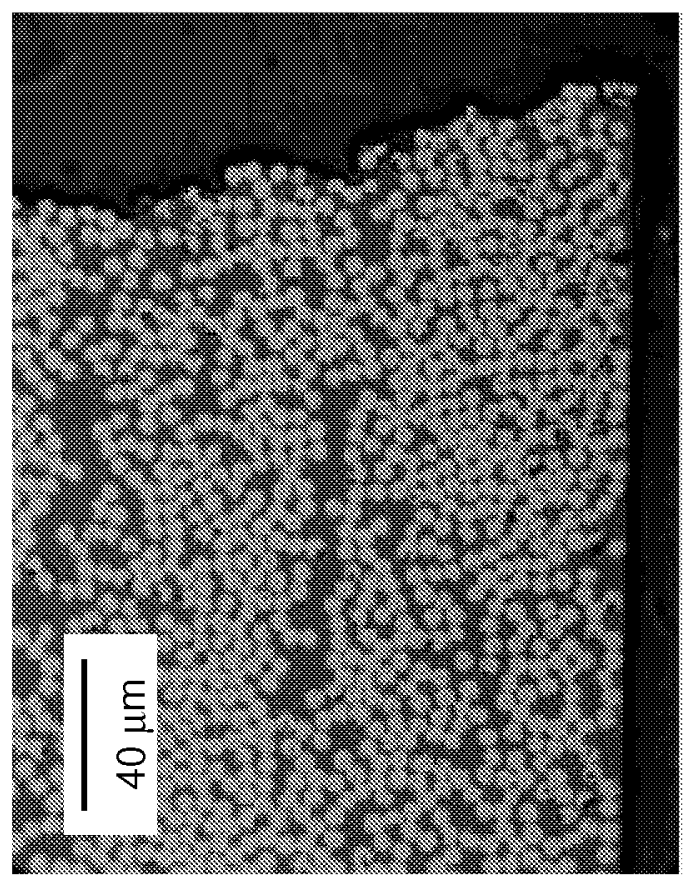

\begin{tabular}{l} 
동 \\
음 \\
뜽 \\
\hline
\end{tabular}

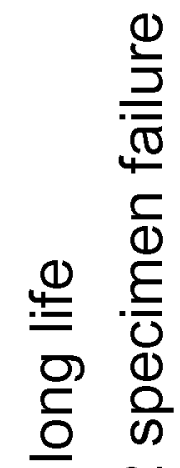

م

స

$i_{0}^{\circ} N$

$0 \leqq$

F

\#

लํํㅇ

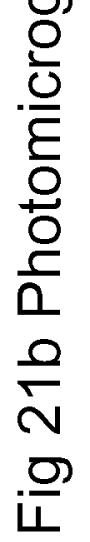




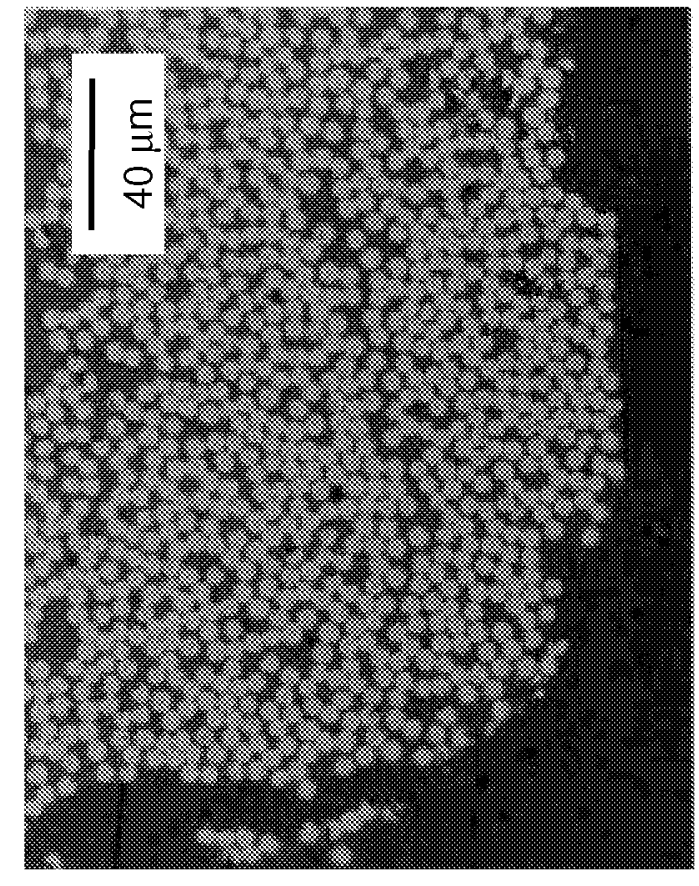

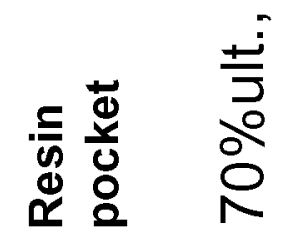

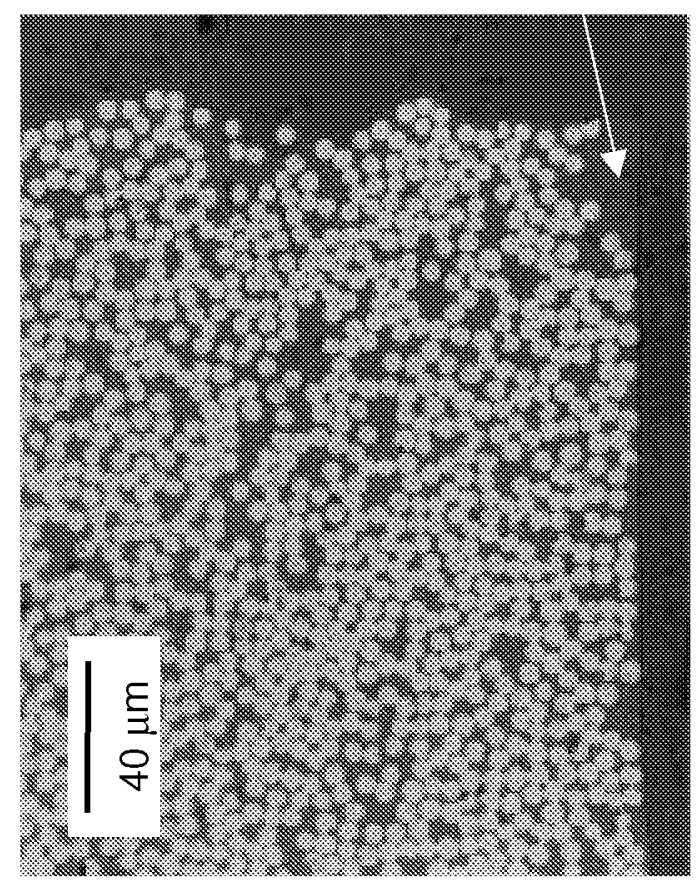

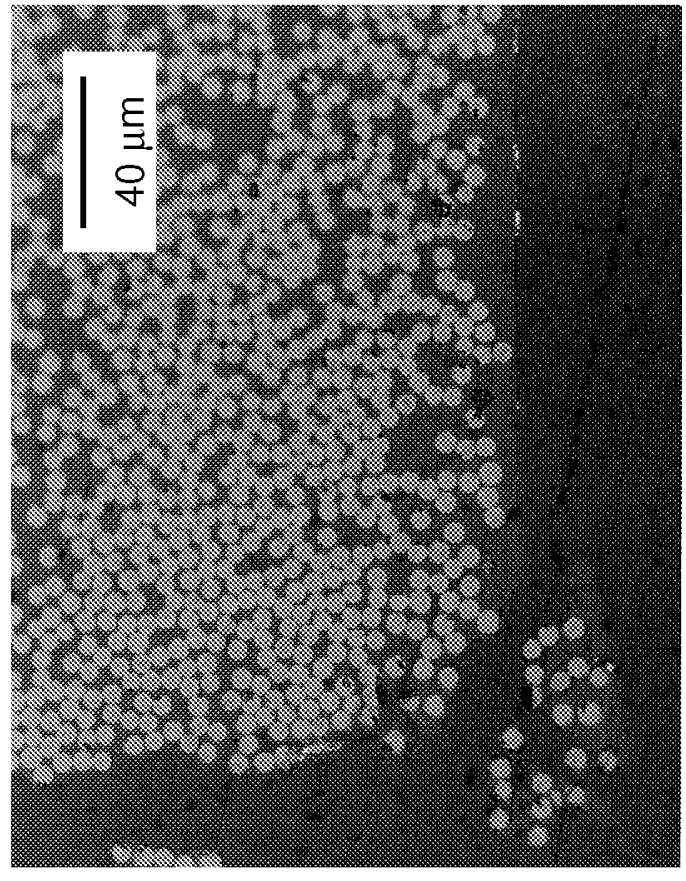

동

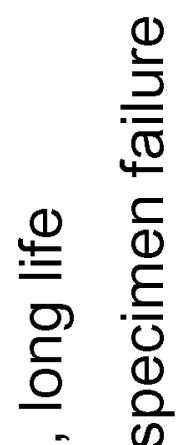

స

ㅇํ 1

L

$\infty \sum$

造

( )

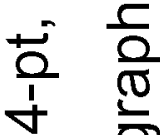

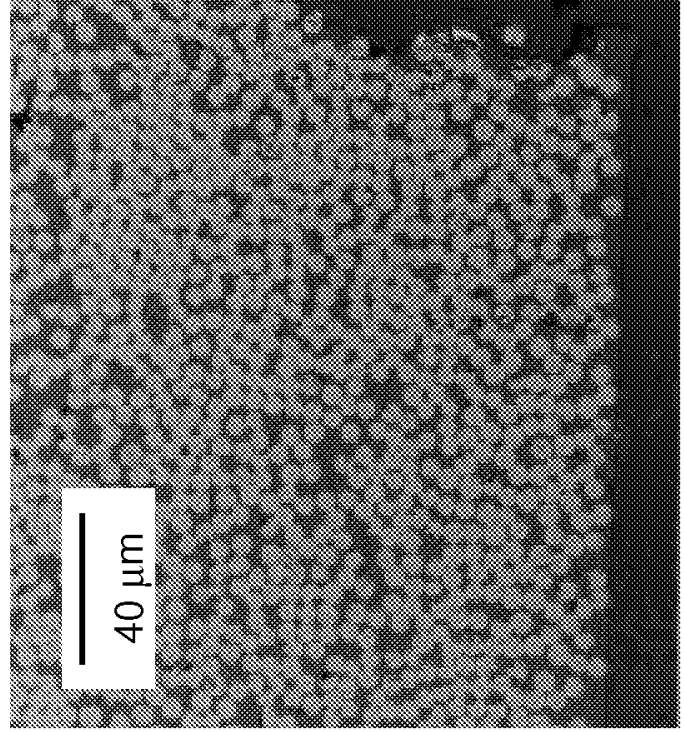

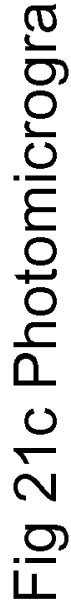




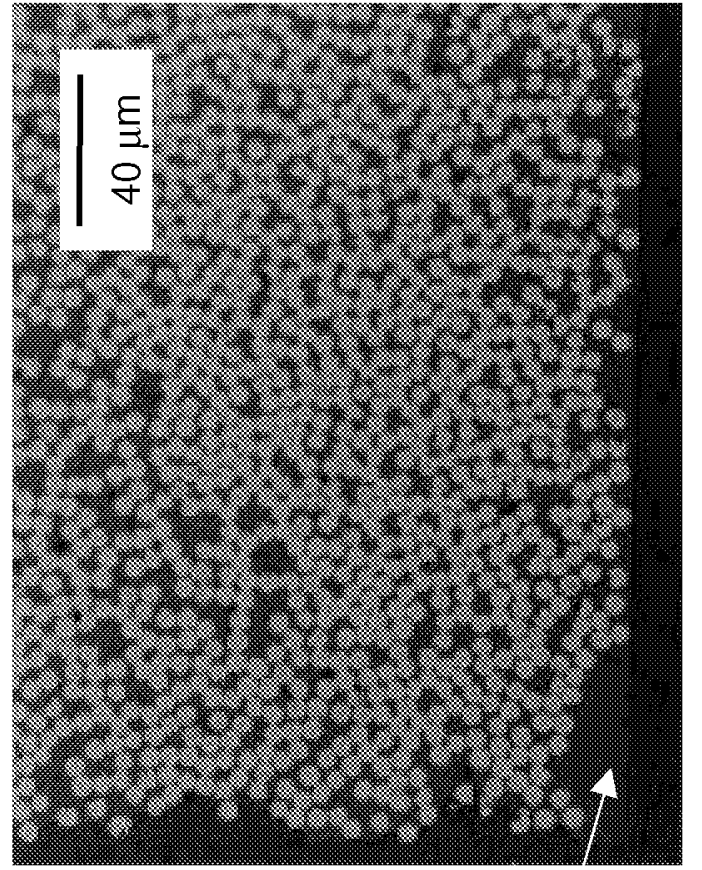

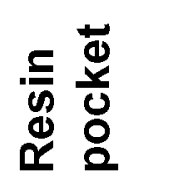

200

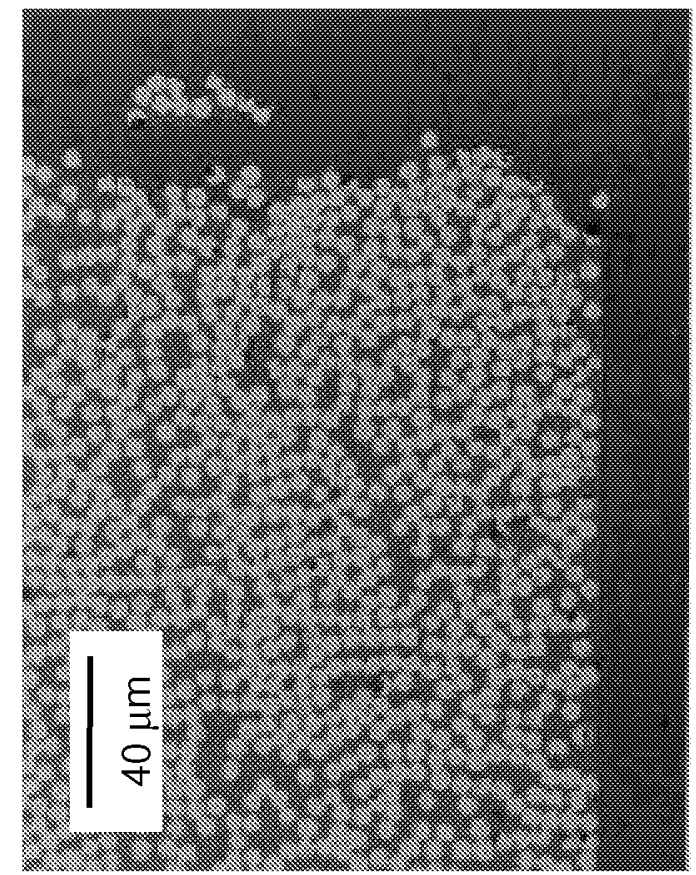

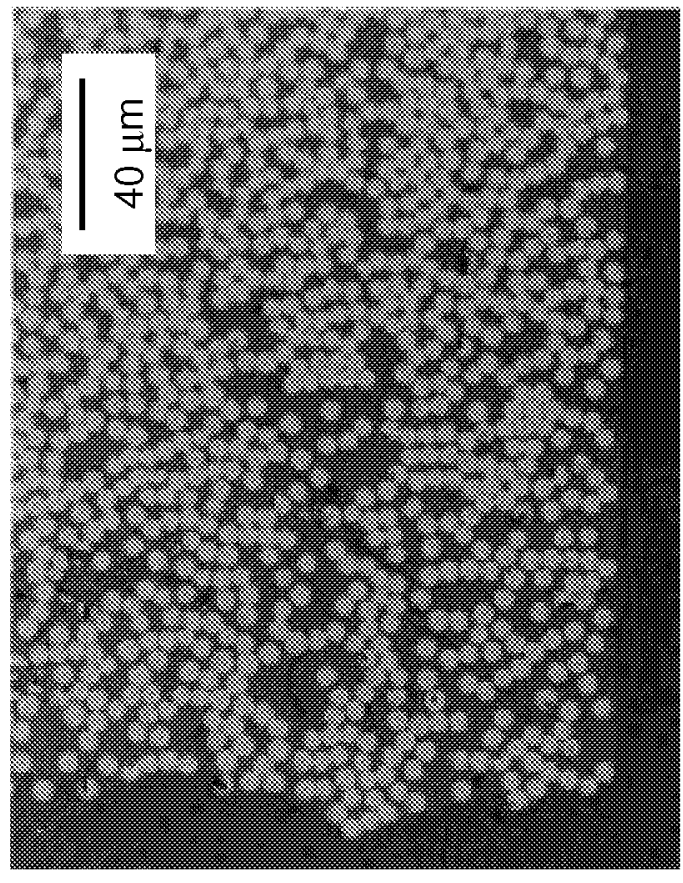

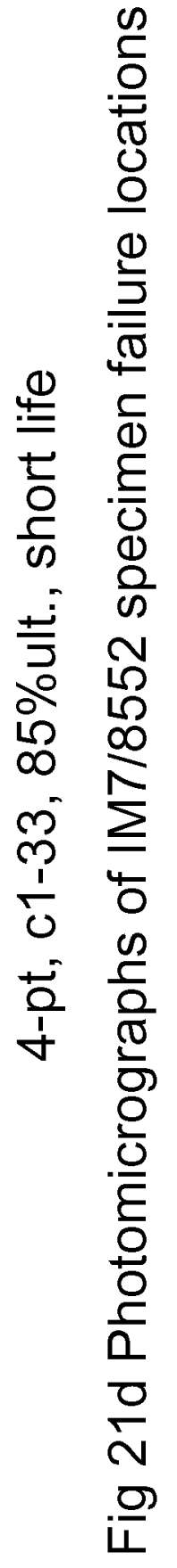




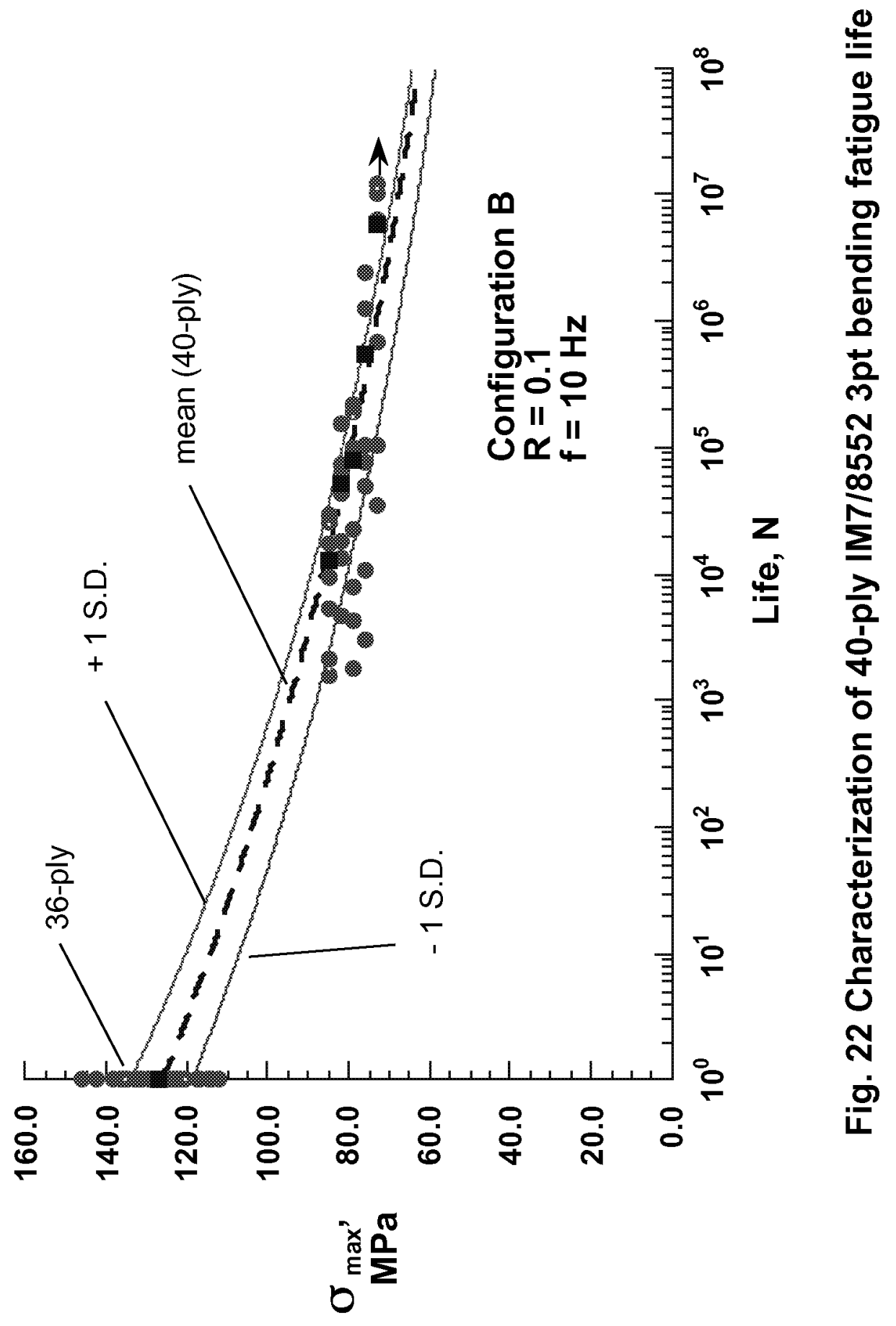




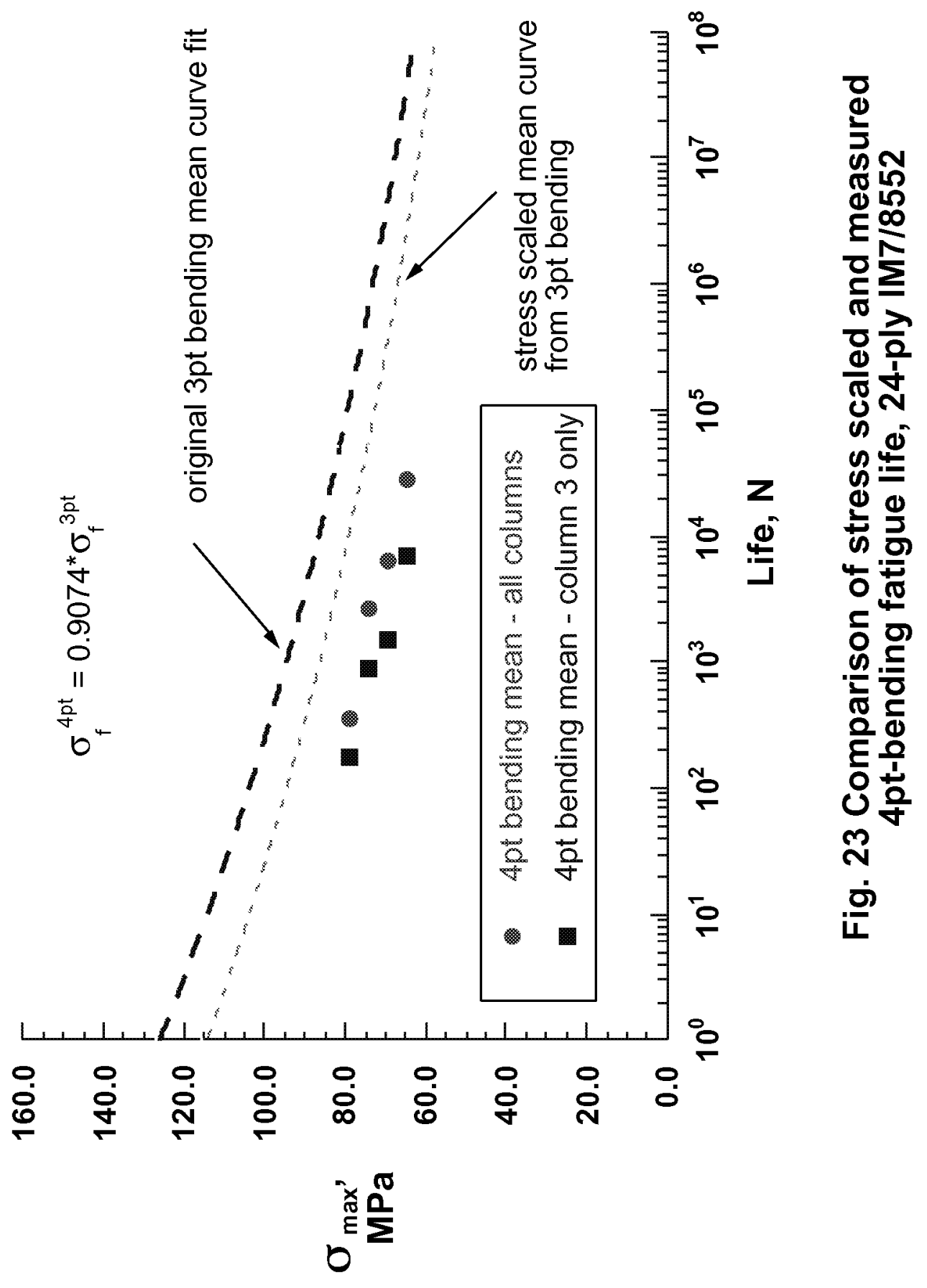




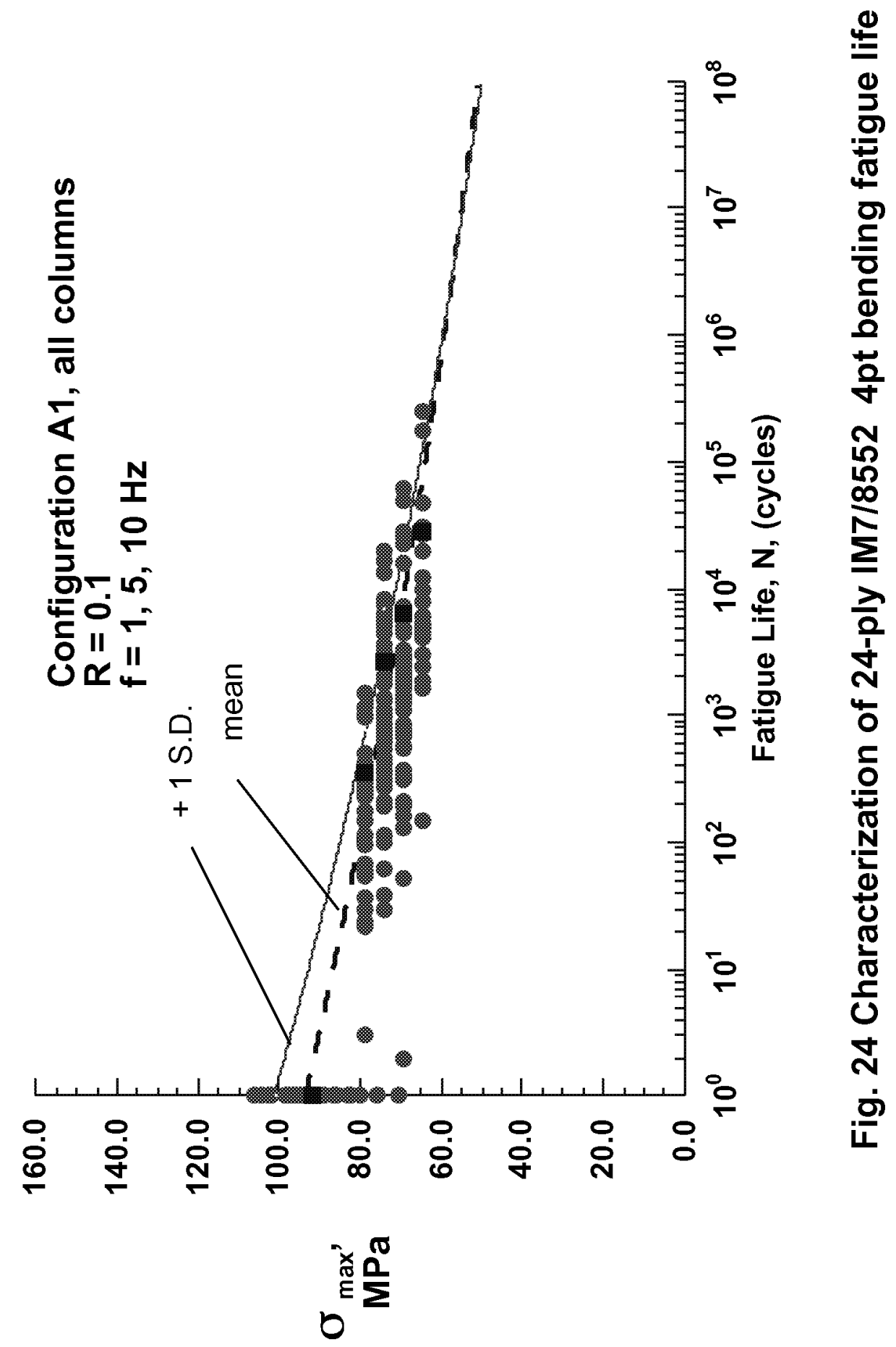




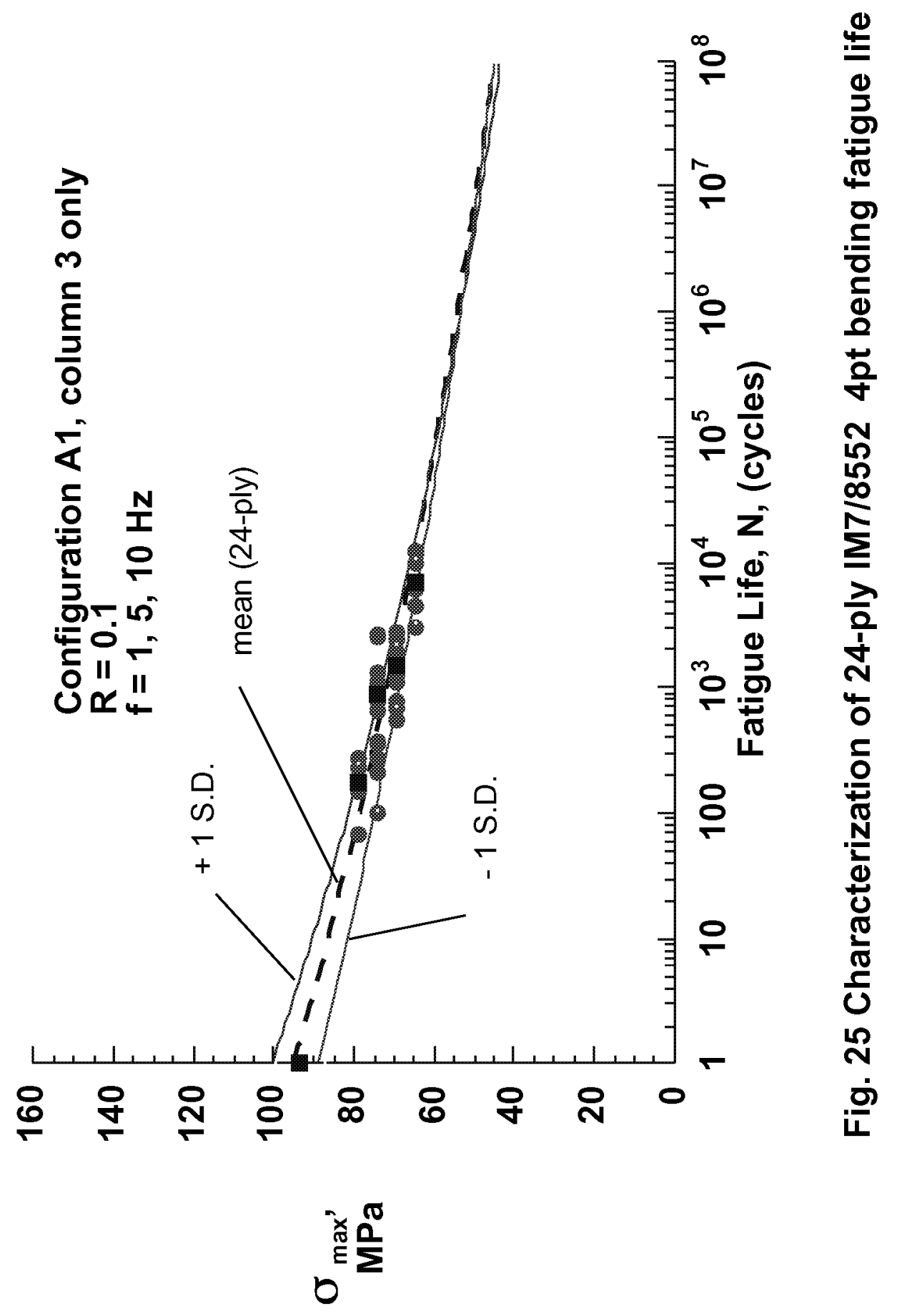




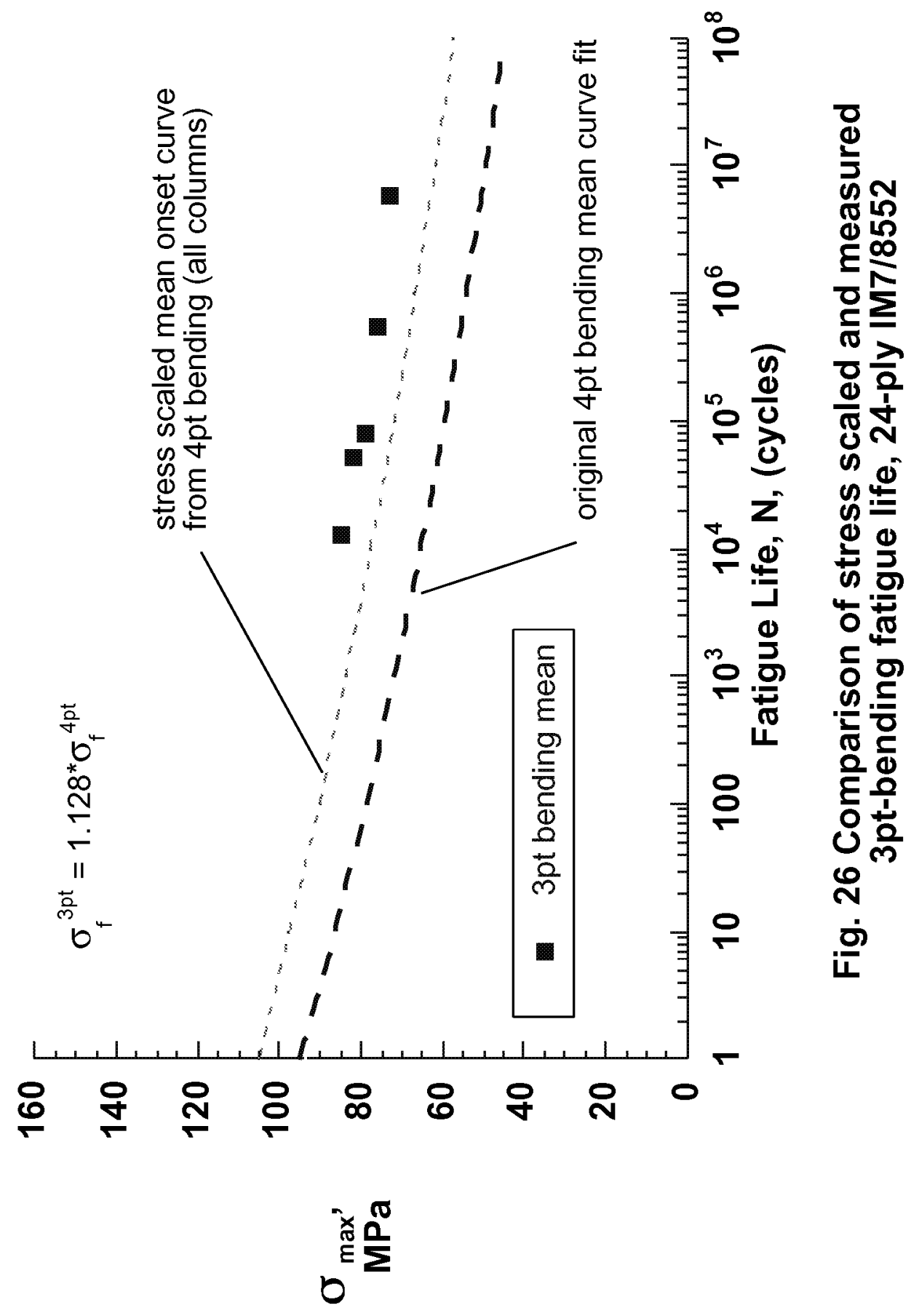




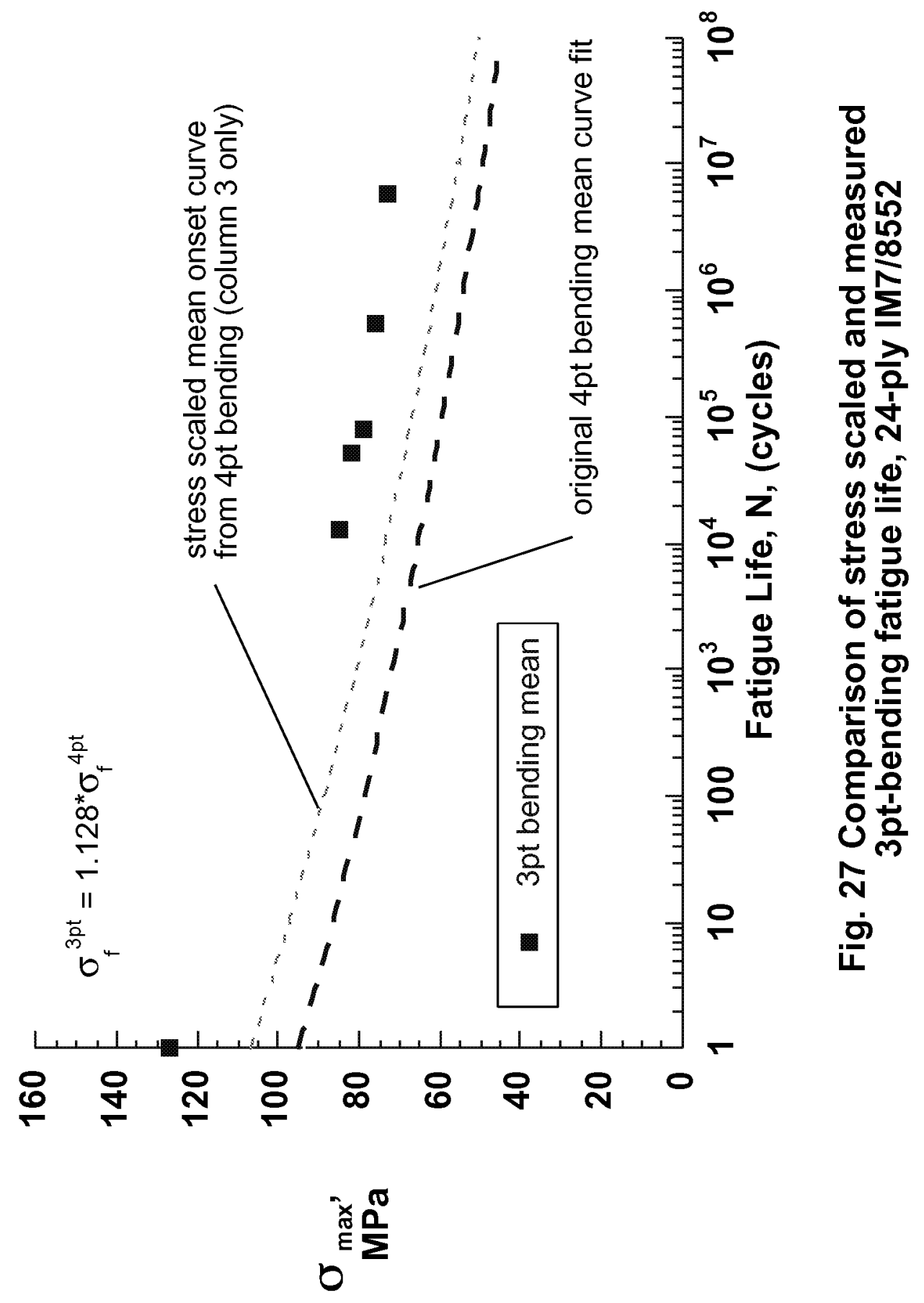




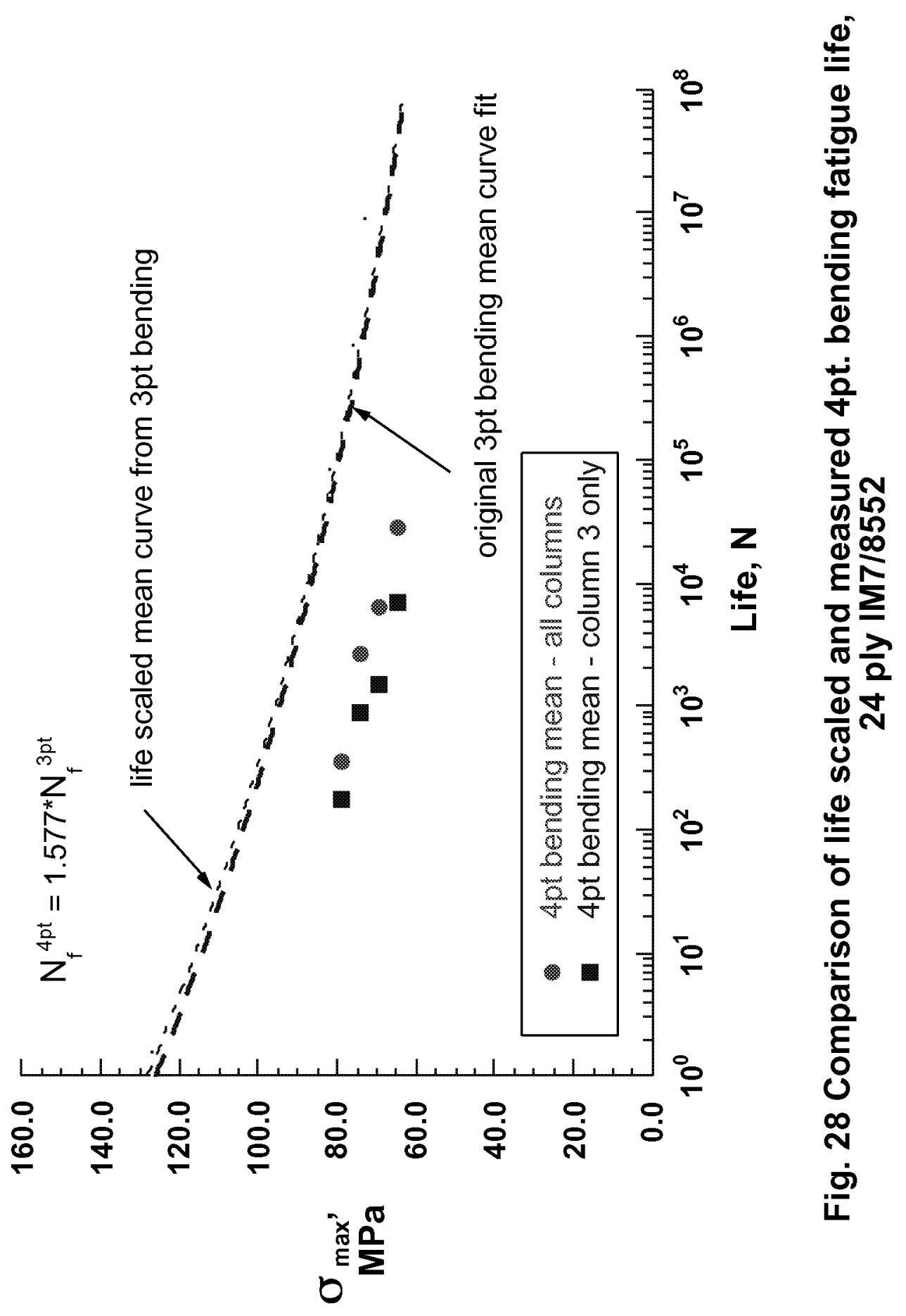




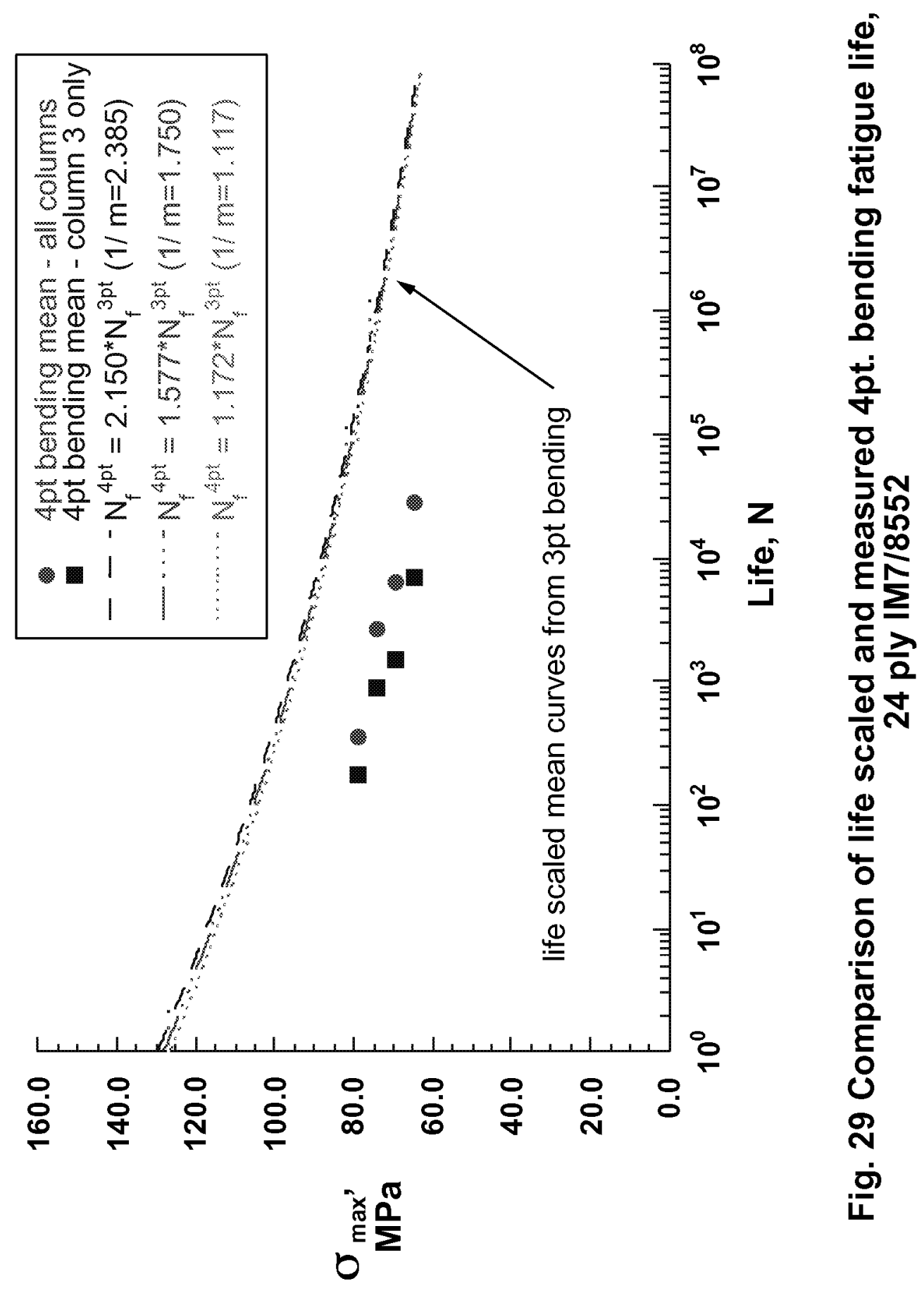




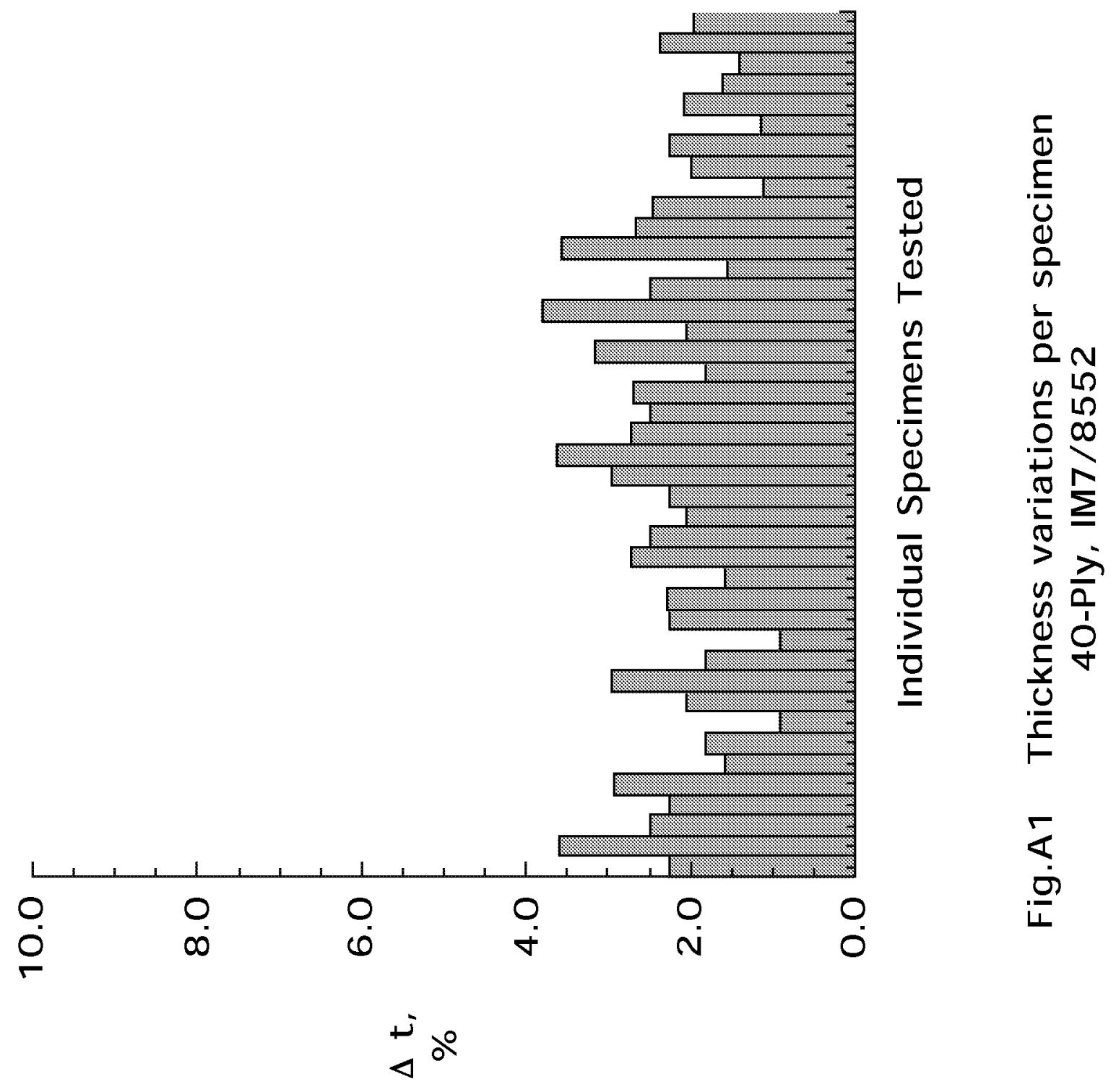



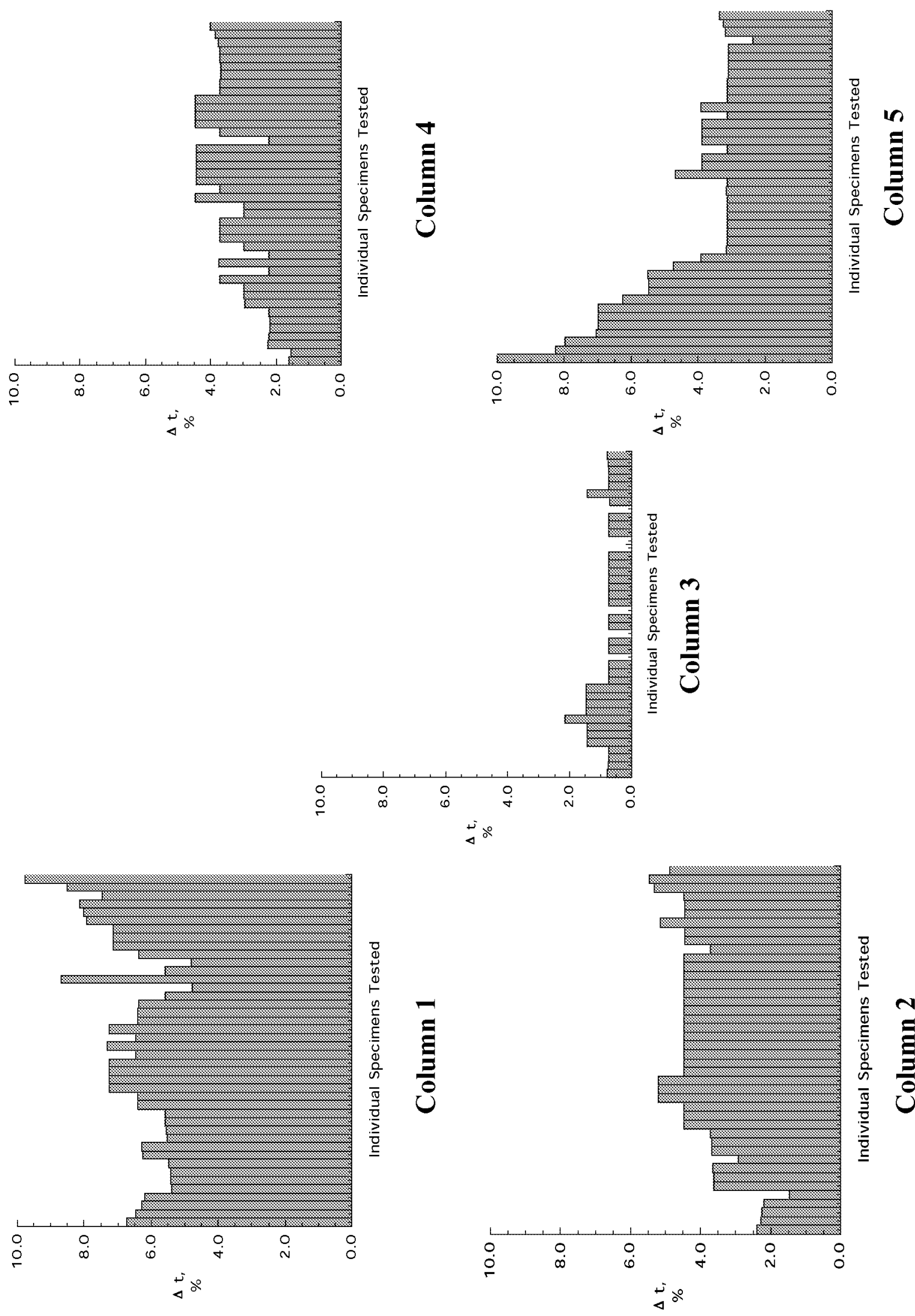

$\frac{n}{n}$ 


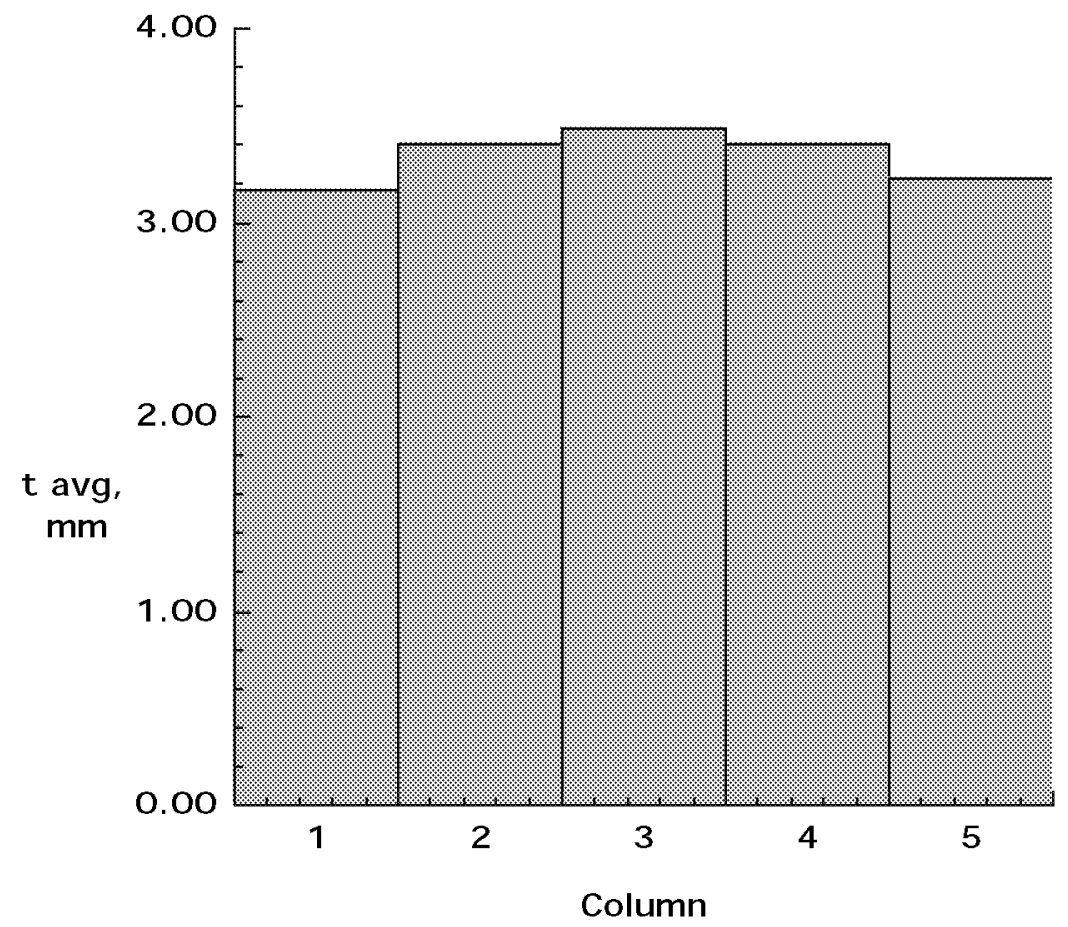

Fig.A3 Average Thickness ordered by Panel Column 24-ply IM7/8552

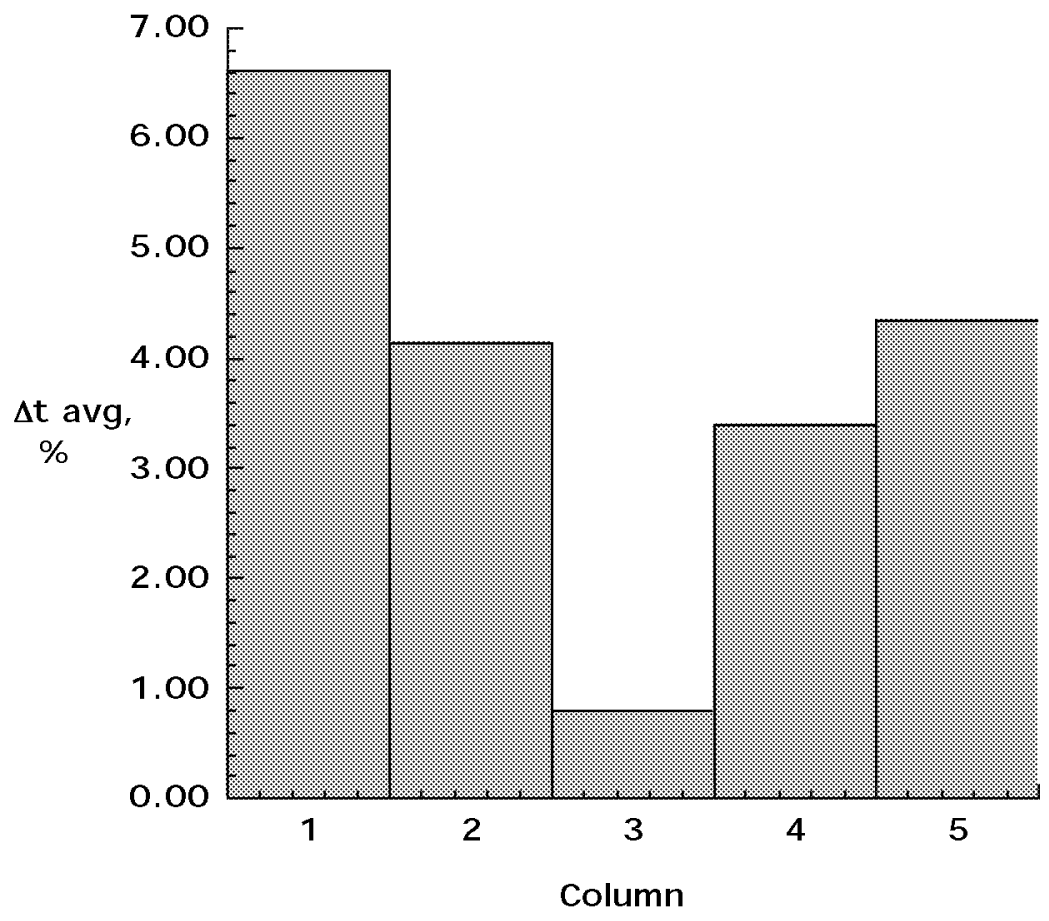

Fig. A4 Average Thickness Variation ordered by Panel Column 24-ply IM7/8552 


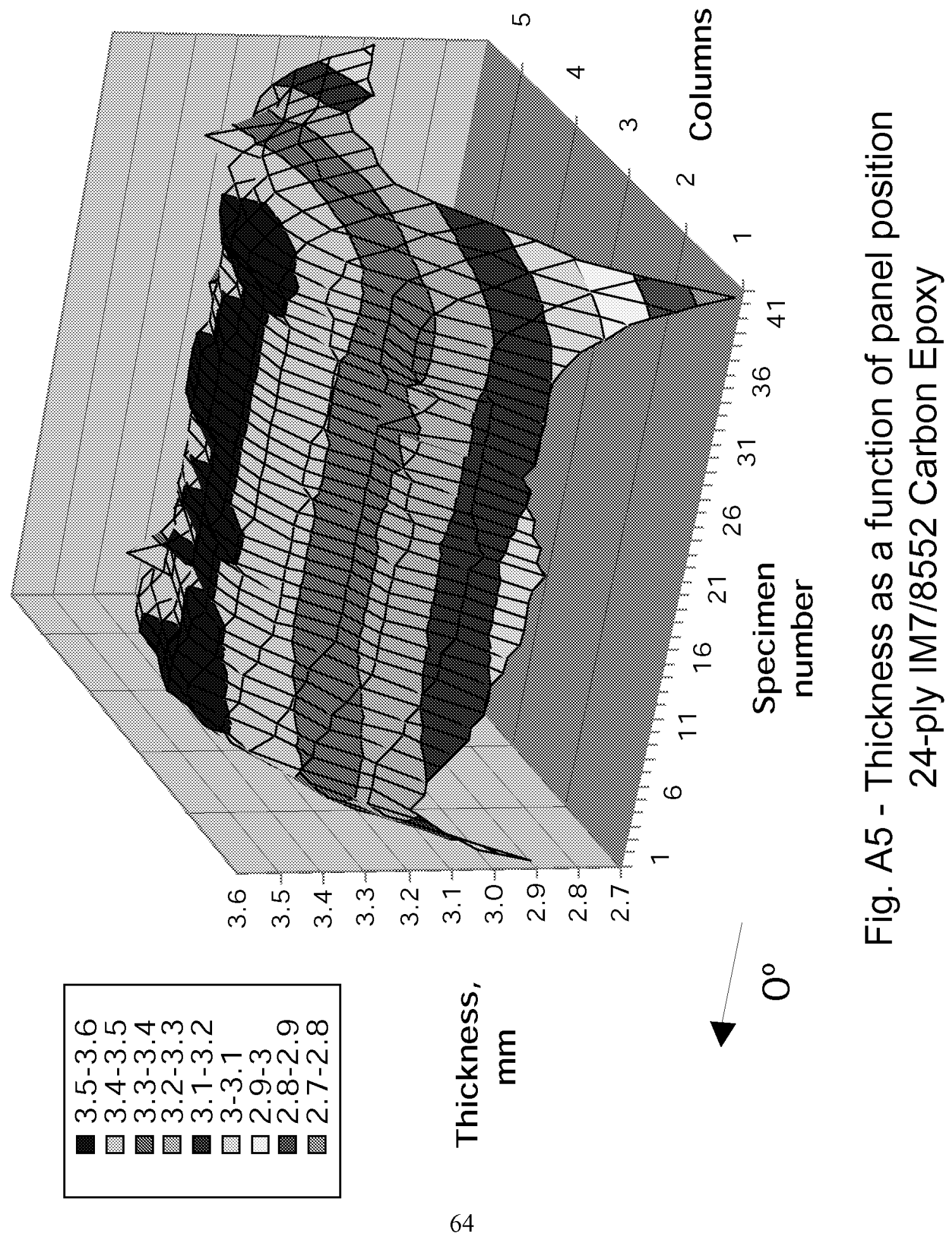



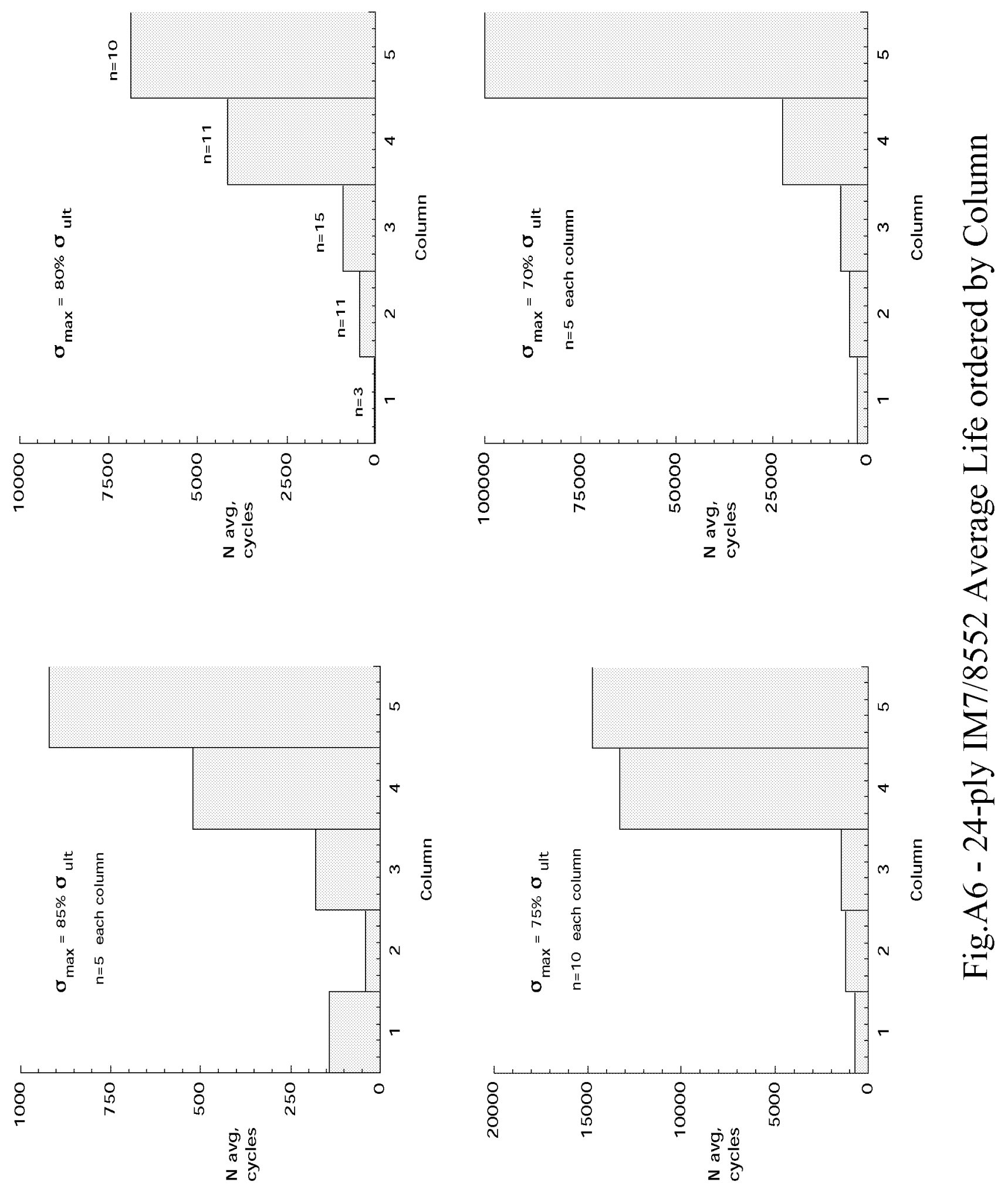


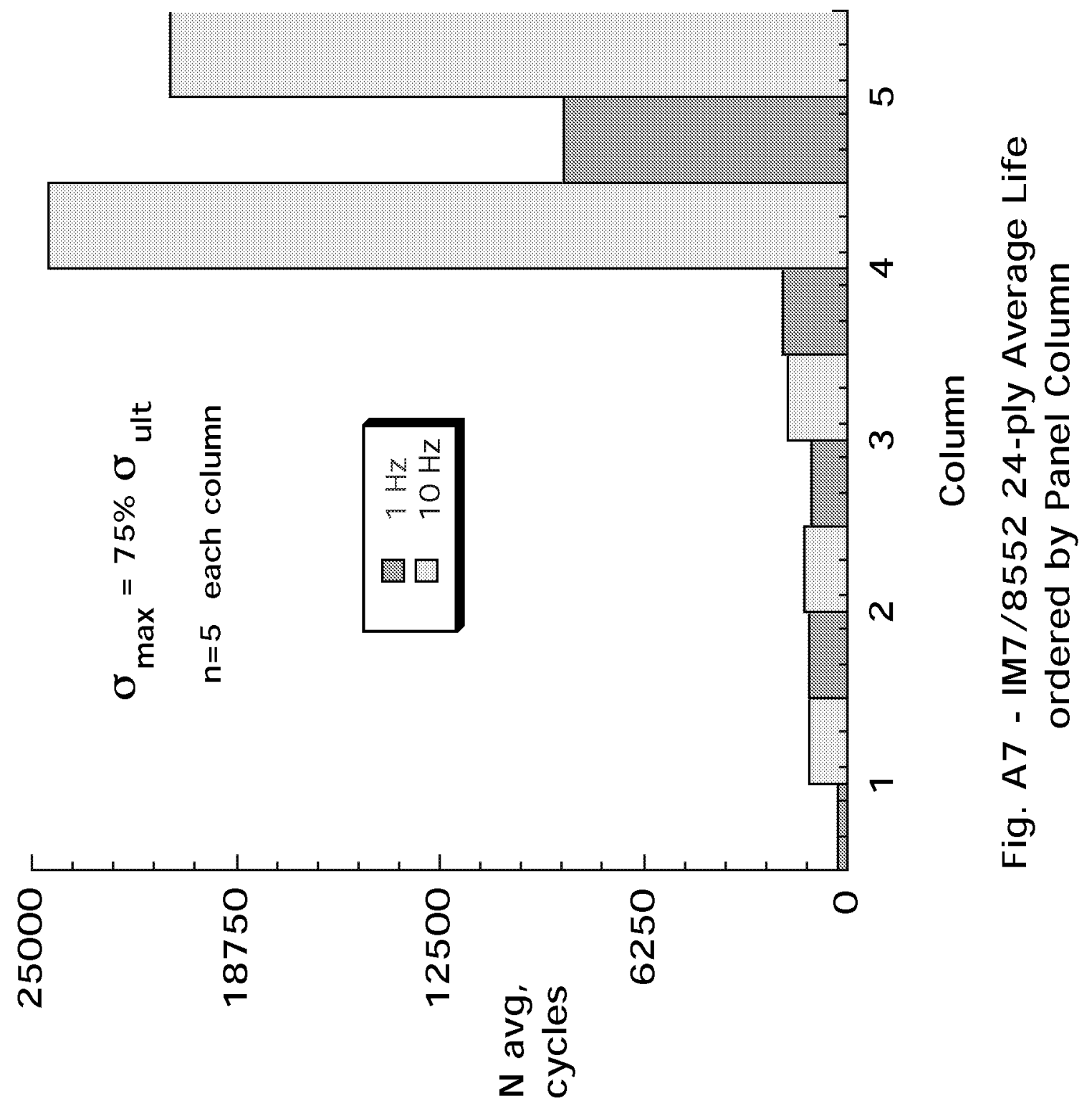



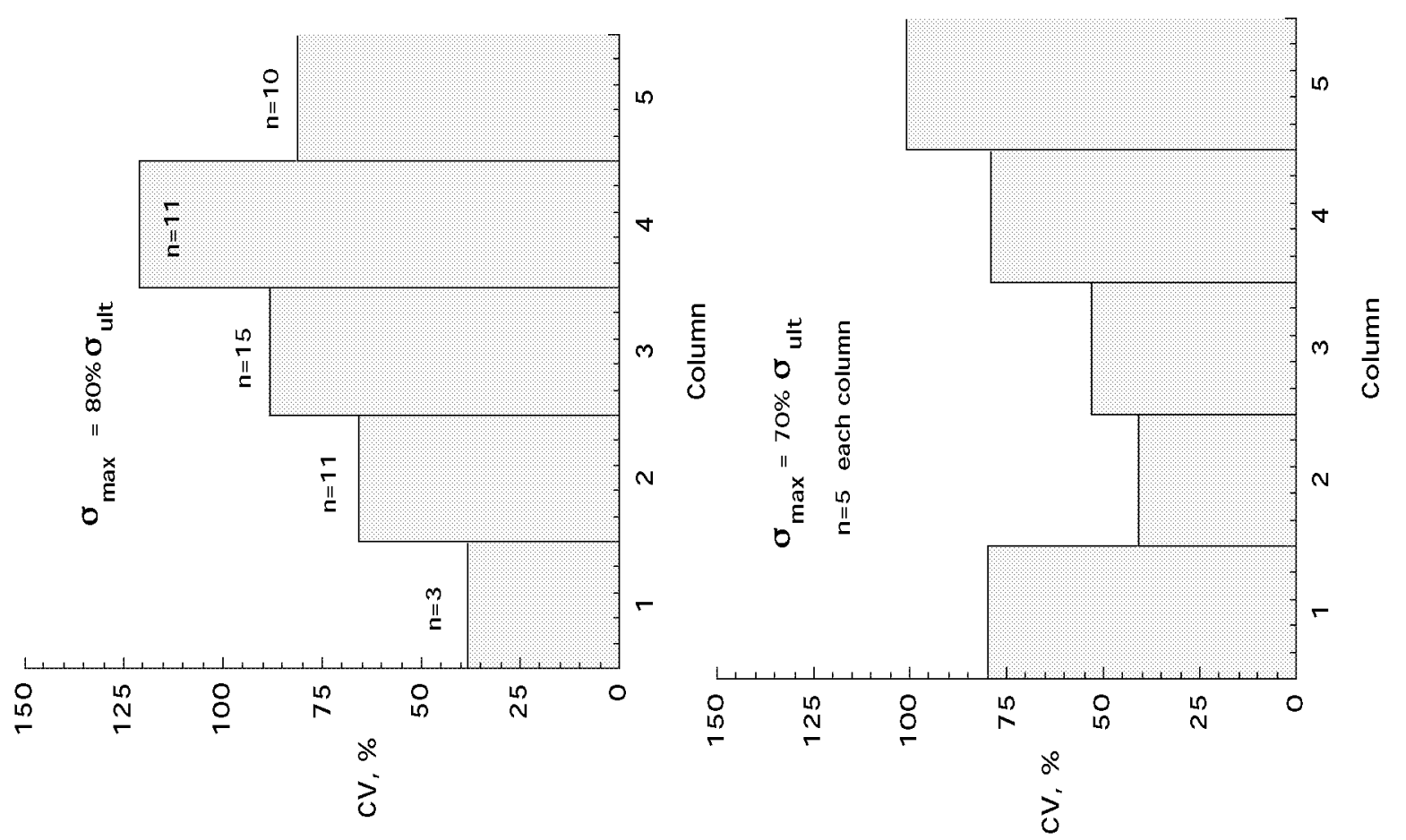

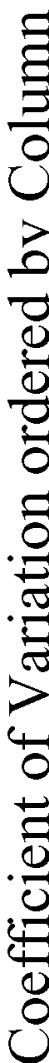
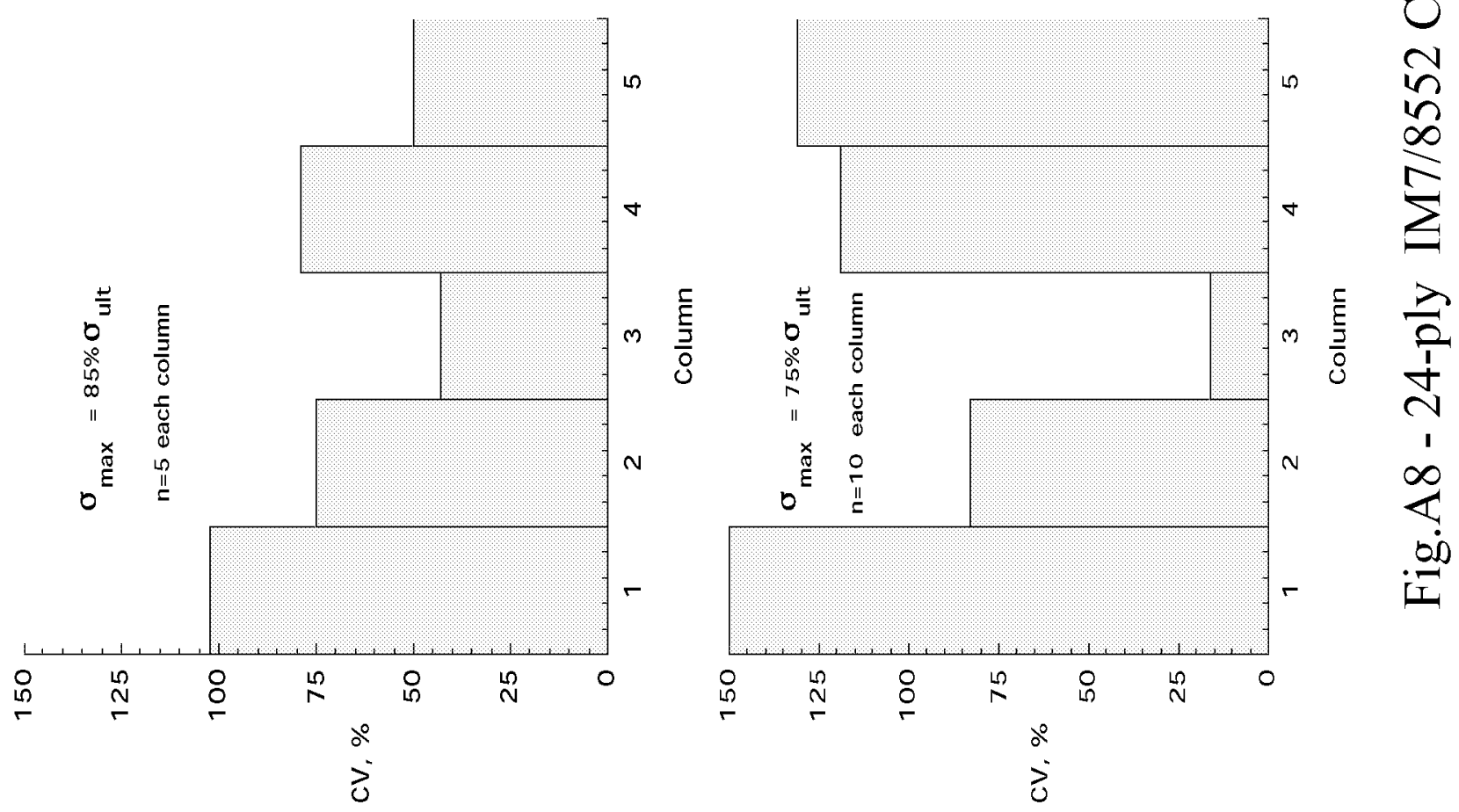


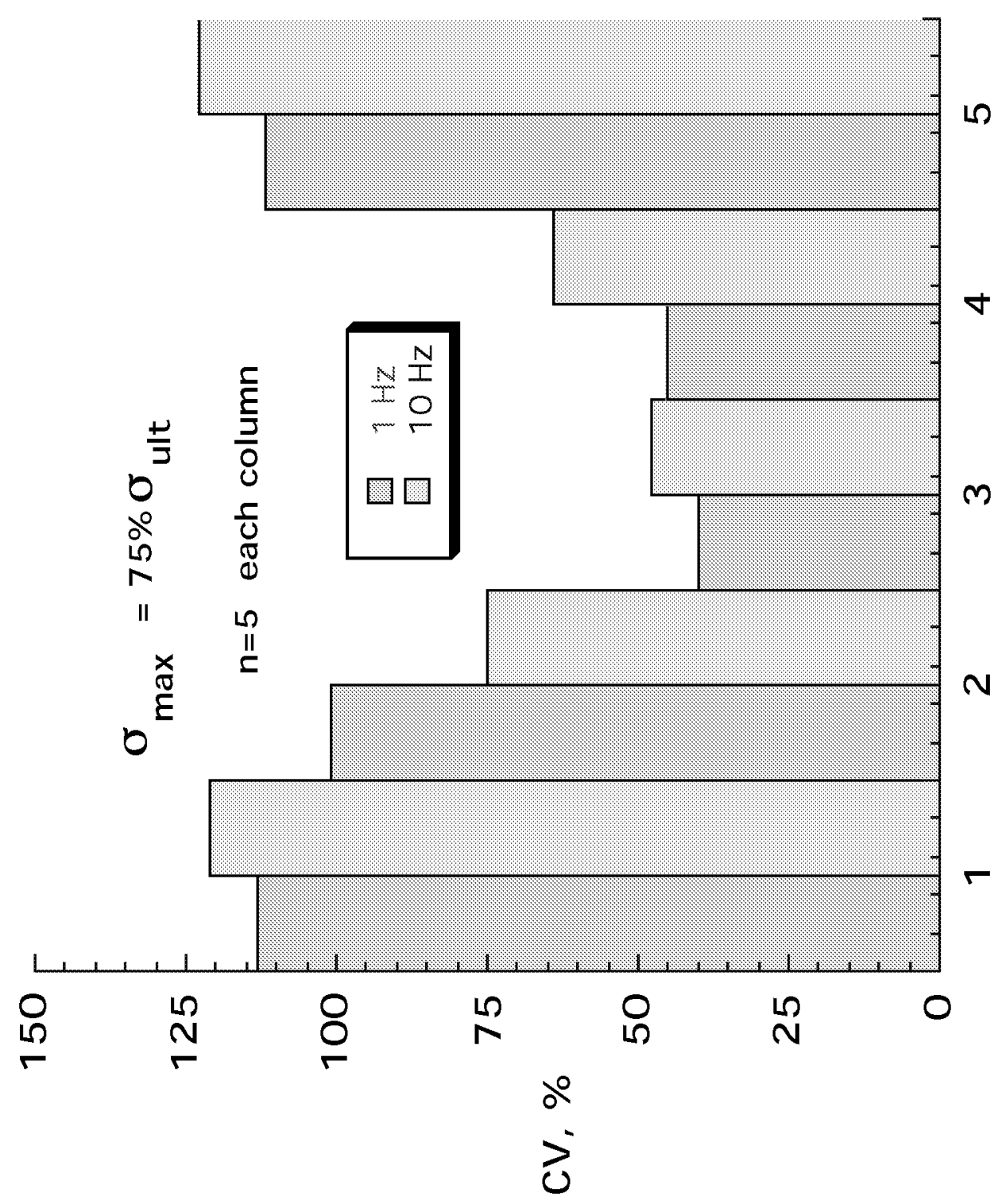

$\frac{\frac{5}{5}}{\frac{5}{0}}$

రृ

(1) N

$\frac{E}{\varrho}$

믄

$0 \infty$

인

完 $\frac{\pi}{2}$

$>\frac{1}{4}$

论

$\frac{\pi}{\frac{1}{0}}$

$\stackrel{9}{<}$

훈 


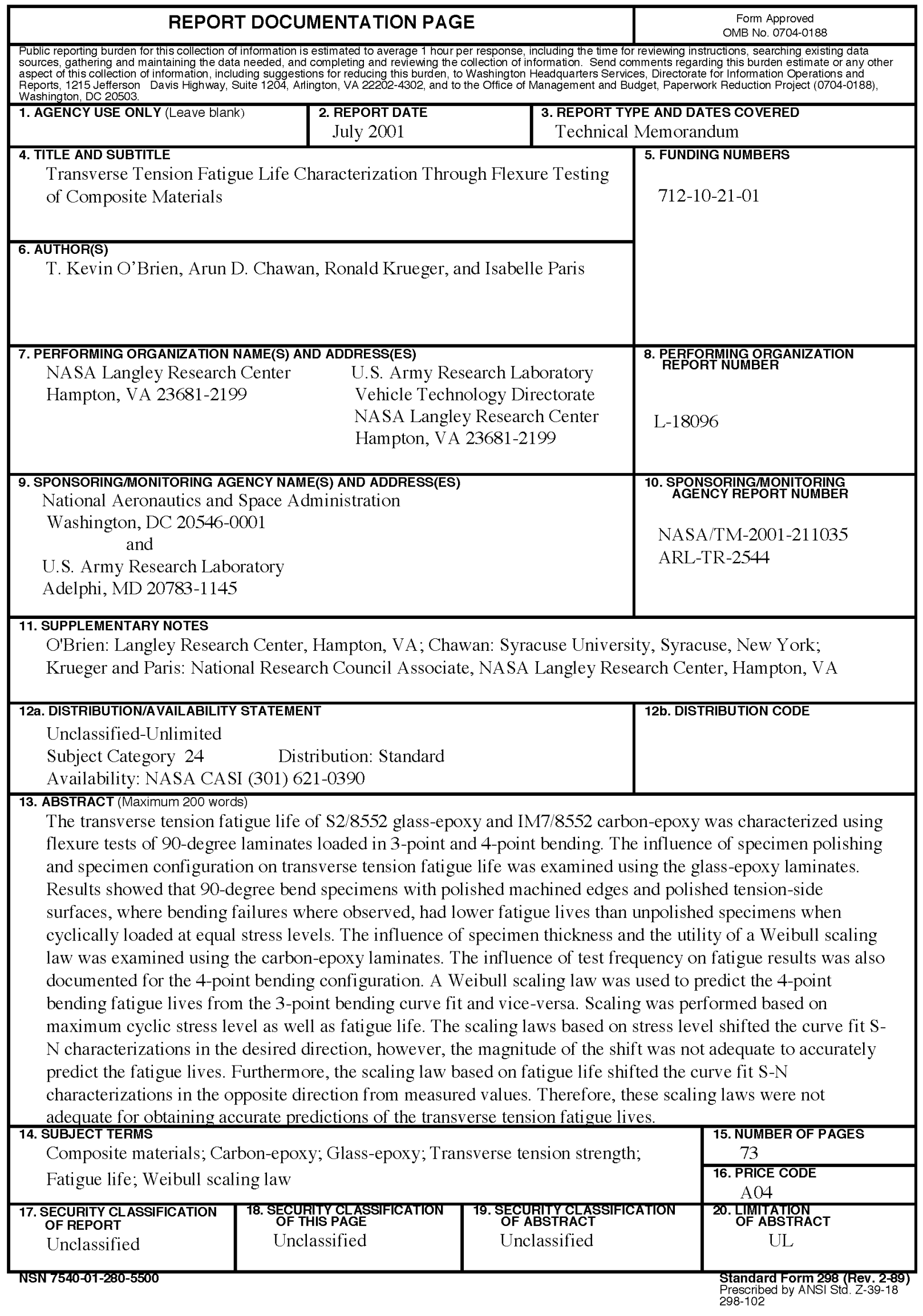

